\title{
Toward ICT-enabled Co-production for Effective Crisis and Emergency Response
}

\author{
Elina Ramsell
}

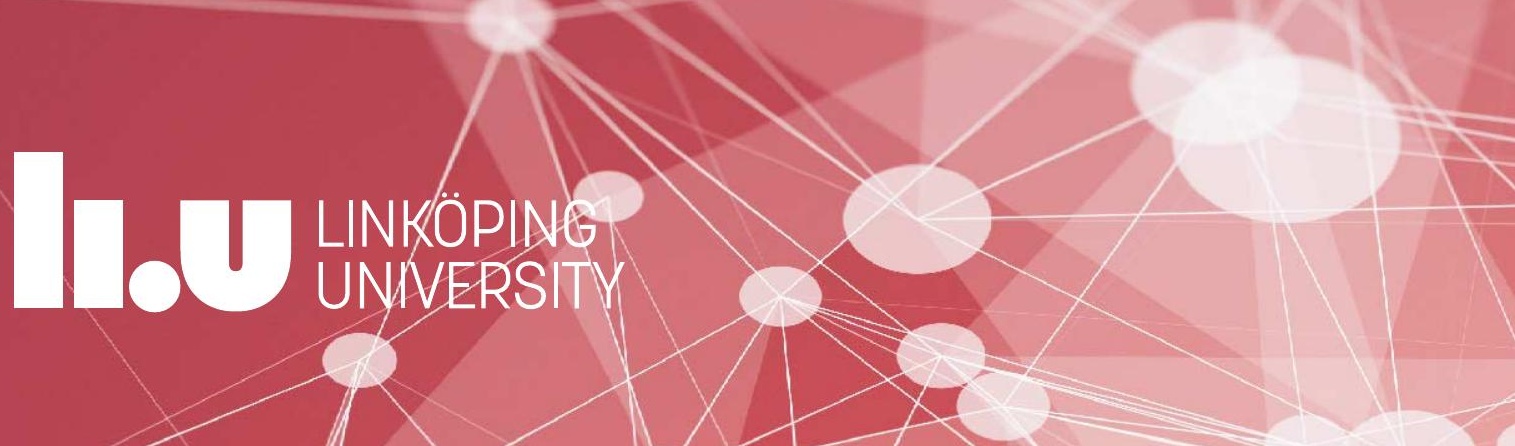





\title{
Toward ICT-enabled Co-production for Effective Crisis and Emergency Response
}

\author{
Elina Ramsell
}

Department of Management and Engineering, Information Systems and Digitalization

Linköping University, SE-581 83 Linköping, Sweden

Linköping 2021 
Linkoping Studies in Arts and Sciences No. 799

Distributed by:

Department of Management and Engineering

Linköping University

58183 Linköping

Sweden

Elina Ramsell

Toward ICT-enabled Co-production for

Effective Crisis and Emergency Response

(CElina Ramsell, 2021

Printed in Sweden by LiU-tryck, 2021

Edition 1:1

ISSN: 0282-9800

ISBN: 978-91-7929-729-9

(c))EY-No This work is licensed under a Creative Commons AttributionNonCommercial 4.0 International License.

https://creativecommons.org/licenses/by-nc/4.0/ 


\section{Abstract}

In contemporary society, public services struggle to maintain a high quality of service if the authority responsible for the service delivery experiences resource deficit and increased uncertainties and vulnerabilities. This thesis explores how information and communication technology (ICT) can enable new types of network collaborations - co-production - between government (municipalities) and citizens, for a more effective crisis and emergency response. This is explored in the light of digitalization and taking an enduser perspective.

The thesis's first objective is to describe the transformation toward ICT-enabled co-production. The second objective is to identify opportunities and challenges involved in ICT-enabled co-production. The thesis's method includes two case studies supported by various theories and approaches: network collaboration (including co-production), sociotechnical systems, and end-user involvement. The data collection is conducted using semi-structured interviews, focus groups, user participation techniques, and document reviews. The intended audience is practitioners (local government and national agencies) and researchers within crisis and emergency response, information systems (IS), and public administration research disciplines and domains (e.g. co-production).

The description of the transformation toward ICT-enabled coproduction in crisis and emergency response is a result in its own right. Here, the citizen volunteers become involved in the actual delivery of the response, despite non-specific competence and non-organizational affiliation. In relation to the transformation toward co-production, the thesis concludes that digitalization facilitates end-user involvement in the ICT development process and increases their influence. If open systems as mobile technologies are used, end-users can adapt the technology on their own and add technologies, without the support of the formal developer or local government. The thesis also identifies opportunities and challenges of ICT-enabled co-production. Examples of opportunities include citizen volunteers having a high degree of engagement, being an effective complement to professional responders, and increasing perceived safety in the community. This informal structure of co-production enabled by ICT minimizes the need for local governments to spend resources on managing collaboration. Examples of challenges include the lack of organizational affiliation of volunteers (e.g. integration of citizen volunteers, i.e. end-users with non-organizational affiliation in the technology of the ICT system) and aspects of formal and social control (regulation, and moral and privacy issues). 
The thesis's contributions include enriched knowledge of essential aspects to consider when developing ICT-enabled co-production with an end-user perspective, and an understanding of the transformation of the application domain over time and the implications of ICT-enabled coproduction. This makes it easier to comprehend and develop contemporary and future co-productions.

The thesis is perceived to have high originality and value since it studies time periods in which local government, technology, and crisis and emergency response have undergone dramatic changes, and explores one of the first Swedish empirical initiatives involving citizen volunteers as responders. 


\section{Foreword}

Information Systems (IS) is a research discipline within the Faculty of Arts and Sciences at Linköping University (LiU), Linköping Sweden. IS is a discipline studying human work with developing and changing different kinds of IT systems in organizational and societal settings. The research discipline includes theories, strategies and policies, models, methods, coworking principles and artefacts related to information systems development. Different development and change situations can be studied as planning, analysis, specification, design, implementation, maintenance, evaluation and redesign of information systems. Focus is also on the interplay with other forms of organizational development, processes of digitalization and innovation. The discipline also includes the study of prerequisites for and results from information systems development, as e.g. institutional settings, studies of usage and consequences of information systems on individual, group, organizational and societal levels.

The IS research at LiU is conducted in collaboration with private and public organizations. Collaboration also includes national and international research partners in the information systems research field. The research has a clear ambition to give distinct theoretical contributions within the information systems research field and relevant focus areas. Simultaneously, the research aims to contribute with practically needed and useful knowledge.

This work, Toward ICT-enabled Co-production for Effective Crisis and Emergency Response, is written by Elina Ramsell, Linköping University. She presents this work as her PhD thesis in Information Systems Development, Division of Information Systems and Digitalization, Center for Advanced Research in Emergency Response (CARER), Department of Management and Engineering, Linköping University, Sweden.

Linköping, December 2020

Karin Axelsson Professor
Ulf Melin

Professor
Sofie Pilemalm Professor 



\section{Doctoral dissertations in information systems ${ }^{1}$}

1. Karin Axelsson (1998) Metodisk systemstrukturering - att skapa samstämmighet mellan informationssystemarkitektur och verksamhet

2. Stefan Cronholm (1998) Metodverktyg och användbarhet - en studie av datorstödd metodbaserad systemutveckling

3. Anders Avdic (1999) Användare och utvecklare - om anveckling med kalkylprogram

4. Owen Eriksson (2000) Kommunikationskvalitet hos informationssystem och affärsprocesser

5. Mikael Lind (2001) Från system till process - kriterier för processbestämning vid verksamhetsanalys

6. Ulf Melin (2002) Koordination och informationssystem i företag och nätverk

7. Pär J. Ågerfalk (2003) Information Systems Actability: Understanding Information Technology as a Tool for Business Action and Communication

8. Ulf Seigerroth (2003) Att förstå och förändra systemutvecklingsverksamheter - en taxonomi för metautveckling

9. Karin Hedström (2004) Spår av datoriseringens värden - effekter av IT i äldreomsorg

10. Ewa Braf (2004) Knowledge Demanded for Action - Studies of Knowledge Mediation in Organisations

11. Fredrik Karlsson (2005) Method Configuration - method and computerized tool support

12. Malin Nordström (2005) Styrbar systemförvaltning - Att organisera systemförvaltningsverksamhet med hjälp av effektiva förvaltningsobjekt

13. Stefan Holgersson (2005) Yrke: Polis - yrkeskunskaper, motivation, IT-system och andra förutsättningar för polisarbete

14. Marie-Therese Christiansson \& Benneth Christiansson (2006) Mötet mellan process och komponent - mot ett ramverk för en

${ }^{1}$ The label was changed (to Information Systems) from Information Systems Development in May 2019. 
verksamhetsnära kravspecifikation vid anskaffning av komponentbaserade informationssystem

15. Britt-Marie Johansson (2007) Kundkommunikation vid distanshandel. En studie om kommunikationsmediers möjligheter och hinder

16. Göran Hultgren (2007) eTjänster som social interaktion via användning av IT-system - en praktisk teori

17. Björn Johansson (2007) Deciding on Sourcing Option for Hosting of Software Applications in Organisations

18. Per Oscarson (2007) Actual and perceived information systems security

19. Hanna Broberg (2009) DEVIS: Design av verksamhetsstödjande ITsystem

- En designteori och metod

20. Anders Hjalmarsson (2009) Behovet av struktur och frihet - en avhandling om situationsanpassad facilitering vid samarbetsinriktad modellering

21. Jenny Lagsten (2009) Utvärdera informationssystem - Pragmatiskt perspektiv och metod

22. Ida Lindgren (2013) Public e-Service Stakeholders - On who matters for public e-service development and implementation

23. Malin Granath (2016) The Smart City - how smart can 'IT' be? Discourses on digitalisation in policy and planning of urban development

24. Fredrik Söderström (2016) Introducing public sector eIDs - the power of actors' translations and institutional barriers

25. Sten-Erik Öhlund (2017) Interoperability. Capability to interoperate in a shared work practice using information infrastructures - studies in ePrescribing

26. Yousefi Mojir, Kayvan (2018) Information Systems Development for Emerging Public Sector Cross-sector Collaborations: The Case of Swedish Emergency Response

27. Petersson, Johan (2019) Elektroniska marknadsplatser - IT-stöd för små- och medelstora leverantörer

28. Ramsell, Elina (2021) Toward ICT-enabled Co-production for Effective Crisis and Emergency Response 


\section{Licentiate theses in information systems development}

1. Owen Eriksson (1994) Informationssystem med verksamhetskvalitet - utvärdering baserat på ett verksamhetsinriktat och samskapande synsätt

2. Karin Pettersson (1994) Informationssystemstrukturering, ansvarsfördelning och användarinflytande - en komparativ studie med utgångspunkt i två informationssystemstrategier

3. Stefan Cronholm (1994) Varför CASE-verktyg i systemutveckling? En motiv- och konsekvensstudie avseende arbetssätt och arbetsformer

4. Anders Avdic (1995) Arbetsintegrerad systemutveckling med kalkylprogram

5. Dan Fristedt (1995) Metoder i användning - mot förbättring av systemutveckling genom situationell metodkunskap och metodanalys

6. Malin Bergvall (1995) Systemförvaltning i praktiken - en kvalitativ studie avseende centrala begrepp, aktiviteter och ansvarsroller

7. Mikael Lind (1996) Affärsprocessinriktad förändringsanalys utveckling och tillämpning av synsätt och metod

8. Carita Åbom (1997) Videomötesteknik i olika affärssituationer möjligheter och hinder

9. Tommy Wedlund (1997) Att skapa en företagsanpassad systemutvecklingsmodell - genom rekonstruktion, värdering och vidareutveckling i $\mathrm{T}_{50} \mathrm{O}$-bolag inom $\mathrm{ABB}$

10. Boris Karlsson (1997) Metodanalys för förståelse och utveckling av system-utvecklingsverksamhet - analys och värdering av systemutvecklingsmodeller och dess användning

11. Ulf Melin (1998) Informationssystem vid ökad affärs- och processorientering - egenskaper, strategier och utveckling

12. Marie-Therese Christiansson (1998) Inter-organisatorisk verksamhetsutveckling - metoder som stöd vid utveckling av partnerskap och informationssystem

13. Fredrik Öberg (1998) Object-oriented frameworks - a new strategy for CASE tool development

14. Ulf Seigerroth (1998) Integration av förändringsmetoder - en modell för välgrundad metodintegration 
15. Bengt EW Andersson (1999) Samverkande informationssystem mellan aktörer i offentliga åtaganden - en teori om aktörsarenor i samverkan om utbyte av information

16. Pär J. Ågerfalk (1999) Pragmatization of information systems - a theoretical and methodological outline

17. Karin Hedström (2000) Kunskapsanvändning och kunskapsutveckling hos verksamhetskonsulter - erfarenheter från ett FoU-samarbete

18. Göran Hultgren (2000) Nätverksinriktad förändringsanalys perspektiv och metoder som stöd för förståelse och utveckling av affärsrelationer och informationssystem

19. Ewa Braf (2000) Organisationers kunskapsverksamheter - en kritisk studie av "knowledge management"

20. Henrik Lindberg (2000) Webbaserade affärsprocesser - möjligheter och begränsningar

21. Benneth Christiansson (2000) Att komponentbasera informationssystem - Vad säger teori och praktik?

22. Per-Arne Segerkvist (2001) Webbaserade imaginära organisationers samverkansformer - Informationssystemarkitektur och aktörssamverkan som förutsättningar för affärsprocesser

23. Stefan Holgersson (2001) IT-system och filtrering av verksamhetskunskap - kvalitetsproblem vid analyser och beslutsfattande som bygger på uppgifter hämtade från polisens ITsystem

24. Per Oscarson (2001) Informationssäkerhet i verksamheter - begrepp och modeller som stöd för förståelse av informationssäkerhet och dess hantering i verksamheter

25. Johan Petersson (2002) Lokala elektroniska marknadsplatser informationssystem för platsbundna affärer

26. Fredrik Karlsson (2002) Meta-method for Method Configuration - A Rational Unified Process Case

27. Lennart Ljung (2003) Utveckling av en projektivitetsmodell - om organisationers förmåga att tillämpa projektarbetsformen

28. Britt-Marie Johansson (2003) Kundkommunikation på distans - en studie om kommunikationsmediets betydelse i affärstransaktioner

29. Fredrik Ericsson (2003) Information Technology for Learning and Acquiring Work Knowledge among Production Workers

30. Emma Eliason (2003) Effektanalys av IT-systems handlingsutrymme 
31. Anders Hjalmarsson (2004) Att etablera och vidmakthålla förbättringsverksamhet. Behovet av koordination och interaktion vid förändring av systemutvecklingsverksamheter

32. Björn Johansson (2004) Deciding on Using Application Service Provision in SMEs

33. Ulf Larsson (2004) Designarbete i dialog - karaktärisering av interaktionen mellan användare och utvecklare $\mathrm{i}$ en systemutvecklingsprocess

34. Anders Forsman (2005) Standardisering som grund för informationssamverkan och IT-tjänster - En fallstudie baserad på trafikinformationstjänsten RDS-TMC

35. Jenny Lagsten (2005) Verksamhetsutvecklande utvärdering i informationssystemprojekt

36. Jan Olausson (2005) Att modellera uppdrag - grunder för förståelse av processinriktade informationssystem i transaktionsintensiva verksamheter

37. Amra Halilovic (2006) Ett praktikperspektiv på hantering av mjukvarukomponenter

38. Hanna Broberg (2006) Verksamhetsanpassade IT-stöd - designteori och metod

39. Sandra Haraldson (2008) Designprinciper för handlingskvalitet i samverkan - ett multiorganisatoriskt perspektiv på tredjepartslogistik

40. Jonas Sjöström (2008) Making Sense of the IT artefact - A sociopragmatic inquiry into IS use qualities

41. Anders Persson (2009) Förutsättningar för sammanhållen kommunal eFörvaltning

42. Ann-Margreth Hammar (2011) Från projektorganisation till förvaltnings-organisation - en studie av överlämningsarenan

43. Eva Karlsson (2012) Systemutveckling för riskbaserad tillsyn - Hur verksamhetsanalys på praktikteoretisk grund kan användas för kravfångst

44. Hannes Göbel (2014) IT Service Management - Designprinciper för informationssystemsartefakter

45. Kayvan Yousefi Mojir (2016) New Forms of Collaboration in Emergency Response Systems: A framework for participatory design of information systems 
46. Siri Wassrin (2018) Why is it difficult to design innovative IT? An agential realist study of designing IT for healthcare innovation

47. Jonathan Crusoe (2019) Why is it so difficult to cultivate open government data? Understanding impediments from an ecosystem perspective 


\section{Acknowledgements}

There are many people who have made my $\mathrm{PhD}$ studies possible, and I would like to thank them here even though my thanks cannot repay the support I have been given.

My main supervisor, Sofie Pilemalm, who saw the opportunity for me to continue my research within a new research discipline, and believed in my idea of cross-fertilizing both research disciplines and application domains. Thank you for your constant support, encouragement and never-ending coaching. Without you, it would not have been achievable.

My supervisor, Ida Lindgren, who has guided me in the IS discipline throughout my PhD studies and given me many thoughtful comments. My supervisor, Elin Wihlborg, for introducing me to academia and having been with me ever since, and for all your enthusiasm.

Tobias Andersson Granberg, whom I have had the great privilege of working with, for giving me insightful knowledge of the emergency response field.

All the participants in my two case studies who have shared their thoughts and experiences with me, with enthusiasm and trust.

All my colleagues at the Division of Information Systems and Digitalization for your warm welcome, and for giving me a steep learning curve and constructive feedback. It has been a pleasure to be a part of this inspiring environment, with its in-depth, cutting-edge knowledge in the field. Especially thank you Göran, Ulf, Karin, Kayvan, Malin, Johanna, Fredrik, Siri, Truls, Jonathan, Daniel, Maria, who have provided valuable input through research seminars, and to Anki and Madde, who have provided excellent administrative support.

My opponent Eva Söderström at the final thesis seminar for all your useful comments and the rewarding, fruitful discussion. Thanks also to my colleagues Ulf, Johanna, Malin, Truls, Siri, and Daniel for your comments.

The Center for Advanced Research in Emergency Response (CARER), which has been an important forum for presenting my research and for sharing experiences with other researchers and practitioners.

The Swedish Contingency Agency (MSB), which funded both the research projects on which my thesis is based.

My other employer, Combitech, who has given me the opportunity to combine my work as a consultant and my research, with great flexibility, support, and understanding.

My family and friends. Johan, for reminding me of the importance of having fun, and that there is more to life than work, and for encouraging me 
when I have questioned my decision to write a thesis. Edvard and Ivar, who succeeded in directing my thoughts to other things than my thesis, with laughter and tremendous energy. My parents, siblings, and dear friends who have been a great support and who are still with me despite the fact that I have had no time outside work.

And to all those who have been a part of my journey - including the ones who have not been mentioned above - an immense thank you!

Elina Ramsell

Stockholm, December 2020 


\section{List of papers}

\section{Paper I}

Palm, J., \& Ramsell, E. (2007) Developing Local Emergency Management by Co-ordination Between Municipalities in Policy Networks: Experiences from Sweden, Journal of Contingencies and Crisis Management, 15(4), 173182, December.

\section{Paper II}

Ramsell, E., \& Wihlborg, E. (2012) Governing Technical Information Systems in Local Crisis Management, Public Works Management \& Policy, 17(3), 303-318.

\section{Paper III}

Ramsell, E., Pilemalm, S., \& Andersson Granberg, T. (2017) Using Volunteers for Emergency Response in Rural Areas - Network Collaboration Factors and IT Support in the Case of Enhanced Neighbors, Proceedings of the 14th International Conference of Information Systems for Crisis Response and Management (ISCRAM) - Albi, France, May.

\section{Paper IV}

Pilemalm, S., Lindgren, I., \& Ramsell, E. (2016) Emerging Forms of Interorganizational and Cross-sector Collaborations in e-Government Initiatives: Implications for Participative Development of Information Systems, Transforming Government: People, Process and Policy, 10(4), 605-636.

\section{Paper V}

Ramsell, E., Andersson Granberg, T., \& Pilemalm, S. (2019) Identifying Functions for Smartphone Based Applications in Volunteer Emergency Response, Proceedings of the 16th International Conference of Information Systems for Crisis Response and Management (ISCRAM)- València, Spain, May.

The author's role in each paper is described in chapter 2 Method. 


\section{Related work}

\section{Licentiate thesis}

Ramsell, E. (2010) Local Crisis Management: Development through Collaboration and Information Systems, Linköping: Liu-Tryck, Linköping University Electronic Press, ISBN 978-91-7393-263-0, ISSN 1401-4637; 99. The original title in Swedish is: Kommunal krisberedskap - utveckling genom samverkan och tekniska informationssystem. 


\section{Contents}

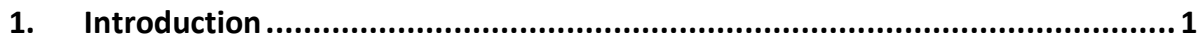

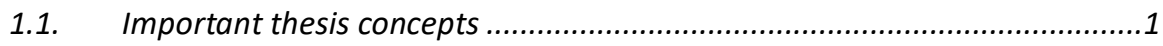

1.2. Transforming crisis and emergency response with ICT-enabled co-production..........................................................................................

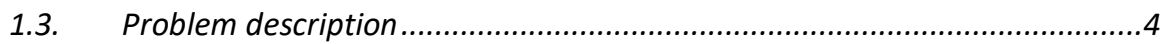

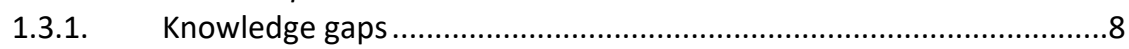

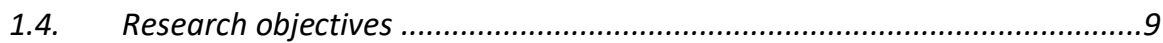

1.5. Research design to answer the research objectives ................................9

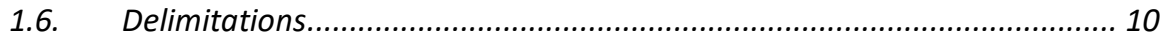

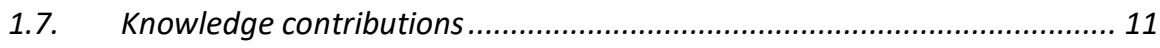

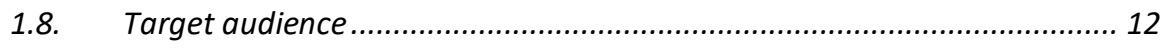

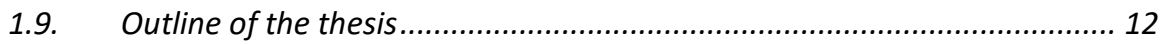

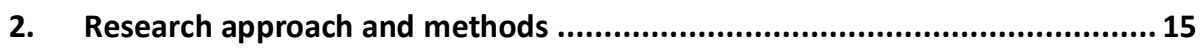

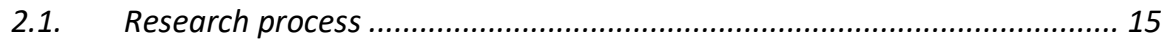

2.1.1. The author's background ................................................................ 15

2.1.2. The overall focus of the included papers and the connection to the research process.................................................................... 16

2.1.3. The papers' contributions to the thesis objectives ........................... 19

2.1.4. The author's role in each paper.................................................... 21

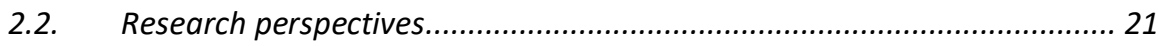

2.3. Building a theoretical foundation and an analytical framework .............. 22

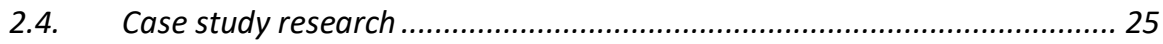

2.4.1. The case of inter-municipal network collaboration

_ "Extended VÖKBYT" (the first case study) ..................................... 26

2.4.2. The case study of ICT-enabled co-production

- "Enhanced Neighbors" (the second case study) ............................ 27

2.4.3. Differences and similarities between the two case studies ............. 28

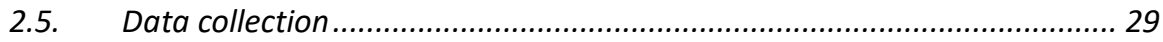


2.5.1. Methods used in the data collection .................................................... 29

2.5.2. Selection of case studies and respondents ........................................ 30

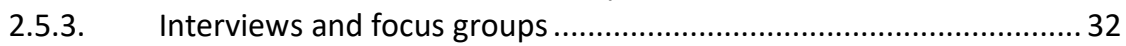

2.5.4. Future workshop - a participatory design technique ....................... 33

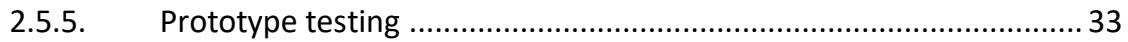

2.5.6. Literature and document reviews................................................... 34

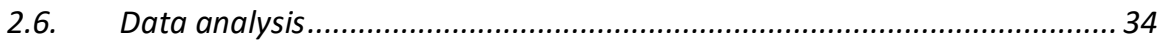

2.6.1. Hermeneutic understanding as a basis for narrative analysis with the support of an analytical framework.................................. 35

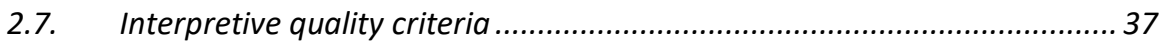

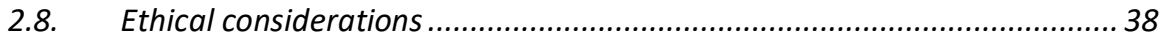

3. Theoretical foundation and analytical framework building....................... 41

3.1. Digitalization in crisis and emergency response .................................... 41

3.2. An ICT approach when studying collaboration to transform crisis and emergency response ........................................................... 43

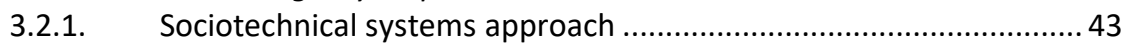

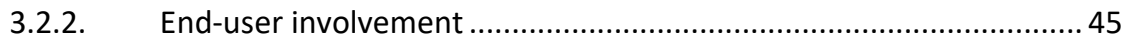

3.3. Network collaboration - one solution to meet public service challenges .. 46

3.3.1. The sociotechnical systems approach to ICT in network

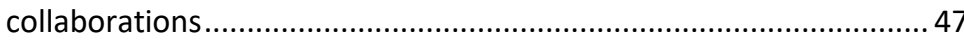

3.4. Co-production - one type of network collaboration .................................. 48

3.4.1. Definition of co-production............................................................... 48

3.4.2. ICT-enabled co-production in transforming public service ...............50

3.4.3. Various roles and degrees of involvement for citizens in

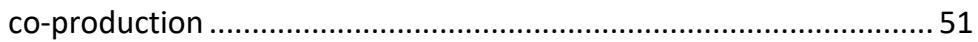

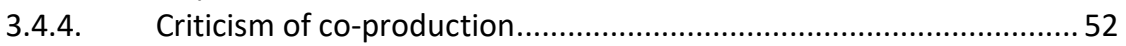

3.5. Developing ICT-enabled co-production - analytical framework building.. 53

3.5.1. Previous research used for the analytical framework ........................ 53

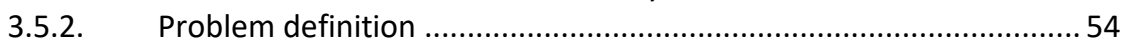

3.5.3. Physical and organizational environment ......................................... 55

3.5.4. Generalized belief and common ground .................................... 55

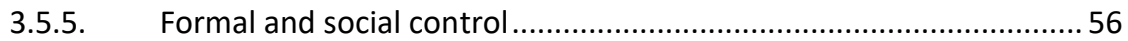

3.5.6. Complexity of technology and technology knowledge......................56

3.5.7. Technology divisibility (incremental project management) ..............57

3.5.8. Technology championing (key actor) .......................................... 58

3.5.9. Summary of the analytical framework for essential aspects when developing ICT-enabled co-production ........................................... 58

3.6. Application domain: crisis and emergency response ................................ 61 
3.6.1. The interlinked concepts of crises and emergencies........................ 61

3.6.2. Definition of citizen volunteers within crisis and emergency response.

3.6.3. ICT-enabled network collaborations including co-production in crisis and emergency response.

3.6.4. Swedish crisis and emergency response as the setting.....................64 64

3.7. Summary and reflections of the thesis theoretical foundation .................. 66

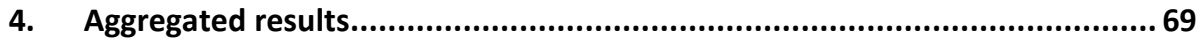

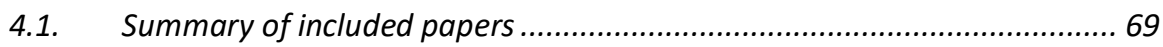

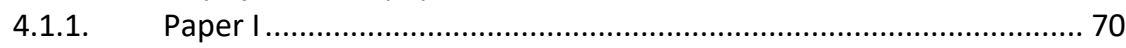

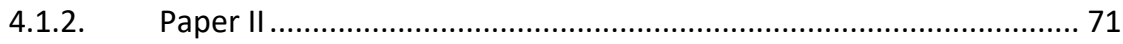

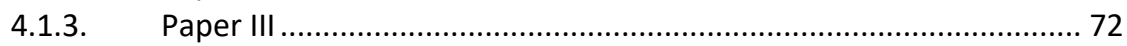

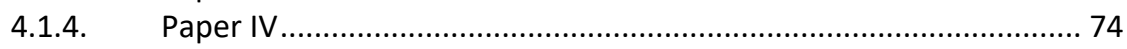

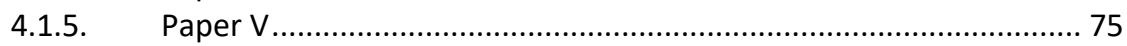

4.2. Aggregated results from the first case study: ICT-enabled

inter-municipal network collaboration ........................................................ 76

4.2.1. Reasons for developing ICT-enabled inter-municipal network

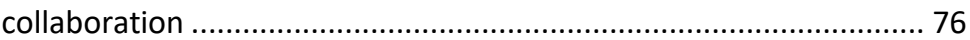

4.2.2. Developing ICT-enabled inter-municipal network collaboration ...... 77

4.2.3. End-user involvement in ICT development ...................................... 79

4.2.4. ICT functions for municipal professionals in crisis response ............. 80

4.3. Aggregated results from the second case study: ICT-enabled network collaboration between municipalities and citizen volunteers,

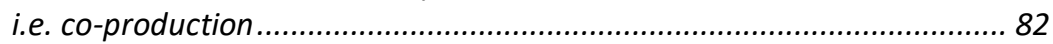

4.3.1. Reasons for developing ICT-enabled co-production ....................... 82

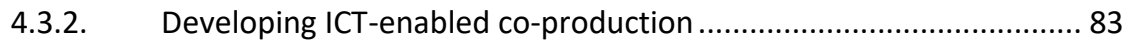

4.3.3. End-user involvement in ICT development .................................... 86

4.3.4. ICT functions for citizen volunteers in emergency response ............87 87

4.4. Cross-comparison between the aggregated analysis of the two case studies - moving toward co-production ......................................... 89

4.4.1. Similarities and differences between ICT-enabled inter-municipal network collaboration and ICT-enabled co-production ................... 89

4.4.2. The influence of end-user involvement........................................... 93

4.4.3. Common ICT functions for municipal professionals and citizen

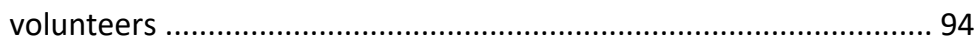

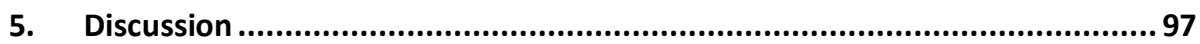

5.1. Transformation of the crisis and emergency response........................... 97

5.1.1. Toward ICT-enabled co-production .............................................. 97 
5.1.2. Digitalization and understanding of the ICT as an enabler for the response.....

5.1.3. New possibilities of end-user involvement through digitalization .. 101

5.2. Developing ICT-enabled co-production............................................... 102

5.2.1. Understanding a new phenomenon - the lack of a coherent concept definition

5.2.2. Changed perception of citizen volunteers in crisis and emergency response

5.2.3. ICT-enabled co-production - an increase in complexity .................. 106

5.3. The opportunities and challenges of ICT-enabled co-production .............. 108

5.3.1. Using citizen volunteers as responders: the impact on public service delivery

5.3.2. Mobile app technology for citizen volunteers as responders .......... 109

5.3.3. The need for end-user involvement in order for ICT to truly enhance co-production

5.3.4. Non-organizational affiliation of the citizen volunteers - both a challenge and an opportunity .....

5.3.5. Ethical and privacy considerations when engaging citizen volunteers as responders - a lack of formal and social control

5.3.6. High engagement from citizen volunteers and high personal democratic values.

6. Conclusions and future research

6.1. Summary of conclusions.

6.1.1. Transformation of the crisis and emergency response domain toward ICT-enabled co-production

6.1.2. Implications of ICT-enabled co-production

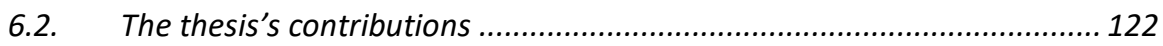

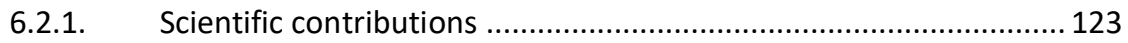

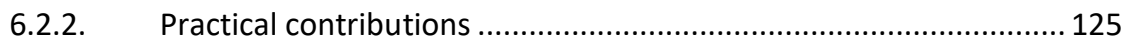

6.3. Reflections on the thesis's limitations and transferability ....................... 127

6.3.1. The conceptual framework - theoretical quality and application

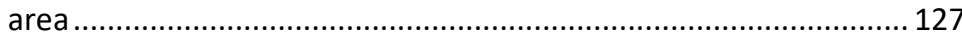

6.3.2. The concept of co-production - connection with other concepts and network collaborations ...................................................... 128

6.3.3. Sweden as the setting for the case studies...................................... 129

6.3.4. Using two case studies from different time periods...................... 129

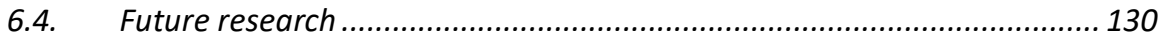

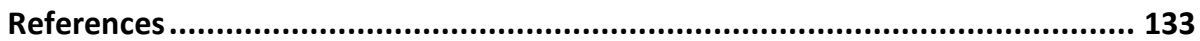




\section{Chapter 1}

\section{Introduction}

This is a compilation thesis in the research discipline of information systems (IS), but with connections to the discipline of public administration. The thesis is a result of a ten-year research process, during which both the domain and the disciplines have changed substantially. Digitalization has opened up new ways for governments to deliver crisis and emergency response service together with other actors, not least with citizen volunteers. In the thesis, this is described as co-production of crisis and emergency response. The thesis provides knowledge about this transformation of responses toward ICT-enabled co-production, i.e. collaboration between local government (municipalities) and citizen volunteers. In addition, the thesis details implications - opportunities and challenges - of the acquired knowledge, which can be used by practitioners and other researchers to test and learn for future co-productions, for example to accomplish a more effective crisis and emergency response despite resource deficits.

This chapter introduces the thesis by defining the important concepts used, the background, the problem description, and the objectives, as well as the overall research design. Delimitations, expected knowledge contributions, and the target audience for the thesis are also described. The final section provides the thesis's outline.

\subsection{Important thesis concepts}

Crisis and emergency response is the thesis's application domain. Within the context of the thesis, this is seen as a policy area where municipalities deliver public service. The application domain includes both frequent emergencies of a smaller size (e.g. traffic accidents, fires, and cardiopulmonary resuscitation) that are dealt with by the emergency services and professional response organizations (e.g. firefighters, police, and ambulance), and serious crises (e.g. major forest fires, power cuts, and terrorist incidents) affecting society's ability to function. The response phase is the phase when responders are alerted and act operationally in response to a crisis or an emergency. The concept of crisis and emergency response is thus seen as a specific phase within crisis and emergency management. How 
these emergencies and crises are initially managed is referred to as a "response" in the thesis, regardless of whether it is an emergency or a crisis.

In the context of this thesis, transformation is used to describe the change in how collaboration is conducted or performed in crisis and emergency response, i.e., who collaborates with whom and how, largely due to public service challenges such as budget deficits, increased quality demands, and uncertainties from a time perspective.

Information communication technology (ICT) is used in the thesis to describe how municipalities and citizen volunteers communicate and share information within the application domain. The concept of ICT is generally used on an overall level in the thesis.

A sociotechnical systems approach is applied in the thesis. Thus, the ICT systems used in the response are seen as containing both social and technical components. With this approach, an ICT system includes not only technology (device, tools, and techniques) but also interactions with human actors and how these human actors are organized.

Digitalization is used in the thesis to refer to the increasing use of various ICT, or digital technologies, both in contemporary society and on an individual level. This includes how technology affects and changes individuals, organizations, and governments. Thus, in the thesis's context, digitalization is perceived as a broader concept than ICT.

End-users are defined in the thesis as the users who actually use the ICT system, including the technology, in their assignments. In this thesis, the end-users are mainly municipalities (professional responders) and citizen volunteers (non-professional responders).

End-user involvement occurs if the end-users are actively involved in the development of the ICT system, i.e., when the needs of end-users are identified in cooperation with them, including both material needs and technology needs, such as the ICT functions being end-user based.

In the thesis, municipalities - i.e. local government - mostly refers to the municipalities' rescue services. However, in crisis response the professional responders are also organizationally located in other areas within the municipal organization. Thus, the concept of municipalities is used in the thesis and the concept of rescue service is sometimes used, but not widely.

Citizen volunteers are citizens who are involved in the response in collaboration with local government, in this thesis' municipalities. These citizen volunteers have no specific competence of relevance for the response. This phenomenon can also be referred to using concepts such as "civic volunteer" or "lay responder/volunteer/individual". They can also be 
referred to as a "civil responder" [civil insatsperson, CIP] by Swedish practitioners within the emergency response.

Network collaboration is defined in the thesis as a phenomenon whereby different actors come together to resolve public service challenges. The different actors are united by the common interest of providing more effective and flexible public service. Two examples of network collaboration are co-production and inter-municipality network collaboration.

Co-production is understood as one type of network collaboration whereby citizen volunteers co-produce with municipalities (professional responders). These citizen volunteers are involved in the delivery of the response, and thus become first responders.

ICT-enabled co-production refers to co-production enabled by ICT, i.e. the citizen responders are alerted by ICT. Co-production without ICT also exists, but is not the focus of this thesis.

\subsection{Transforming crisis and emergency response with ICT-enabled co-production}

From a worldwide perspective, society faces intensified uncertainties, threats, and vulnerabilities - for instance natural disasters, financial crises, aging populations, cyberthreats, and security policy instability (Bason, 2018; Fleishman, 2009; Gazley, 2008; Haddow and Bullock, 2013; Thomson and Perry, 2006). The ability of governments to respond to these crises and emergencies is vital for citizens' safety and the functionality of society as a whole. Thus, an effective response to crises and emergencies becomes increasingly important to limit their consequences -from both individual and societal perspectives (Chen et al., 2008). An effective response includes both the planning and organization (preparation) and the execution of the response - the ability to prevent or limit casualties and material damage (Chen et al., 2008; Salasznyk and Lee, 2006).

One example of a response is forest firefighting. A forest fire can have major consequences, lives can be at stake, and the fire can result in interruptions to critical societal functions (e.g. power supply, electronic communications, food deliveries, and transportation). Another example is managing a virus pandemic, where both individuals and society as a whole are affected. Thus, crisis and emergency response includes responding to both major crises and frequent, smaller emergencies (emergency service alerts, for instance traffic accidents, fires, drownings, and heart failure).

In order to maintain high quality and adequate service levels in crisis and emergency response despite uncertainties, decreased budgets, and demands for increased service (Wankhade and Murphy, 2012), one solution is to 
develop new forms of collaboration between local government and citizen volunteers (Ostrom, 1996; Alford and O'Flynn, 2012; Bekkers and Homburg, 2007; Linders, 2012). This emerging collaboration can be described as co-production of crisis and emergency response, where governments and citizens come together to deliver the response (Alford, 2014; Ostrom, 1996). Co-production is understood in this thesis as:

\section{"[...] the process through which inputs used to produce a good or service are contributed by individuals who are not 'in' the same organization." (Ostrom 1996: 1073)}

Co-production is one type of network collaboration. There are other network collaboration types which consist of other involved actors, for instance inter-municipality network collaboration. The common denominator for network collaborations is that they enable societal challenges, such as resource deficits and complex interdependencies, to be managed and effective solutions to be reached (e.g. Agranoff, 2007; O'Leary \& Bingham, 2009; Wankhade and Murphy, 2012). The different actors are united by the common interest of providing more effective and flexible public service (Kickert et al., 1997; Börzel, 1998; Carlsson, 2000). In network collaborations, the actors involved exchange resources in an informal structure in which social interactions are essential. Actors engaged in network collaboration can have several roles and engage in different network collaborations (Goldsmith and Eggers, 2004; Agranoff, 2007).

Co-production and other types of network collaboration can be enabled using information communication technology (ICT). The use of ICT is rapidly growing to become a natural and interconnected part of public service delivery. Here, both the social components of the ICT system and humans and organizations interact with the technological components of the ICT system, according to a sociotechnical systems approach. Thus, ICT changes and influences the possibilities to support co-production. In crisis and emergency response where volunteers are involved, mobile technologies with applications containing functionalities are widely used, as are online platforms.

\subsection{Problem description}

At the beginning of the 21st century, there was a growing understanding within public service of how technology could be applied for "electronic" or "online" use, often referred to as e-government (Layne and Lee, 2001; Archer, 2005). The latter became a common concept. Initially, this use of 
technology mainly focused on authorities' own administration, for instance ways in which ICT could reduce paperwork and structure information workload. It was then expanded to include more interactive processes and technologies to encourage citizens to participate through ICT (Sæbø et al., 2008; Asgarkhani, 2005; Layne and Lee, 2001).

As a growing understanding of how ICT can enable public service delivery evolved (i.e. at the beginning of the 21 century), several crises occurred, such as the 2004 tsunami in southern Asia, followed in 2005 by Hurricane Katrina in southern USA, a terror attack in London, and the devastating Storm Gudrun in Sweden (e.g. Kaiser et al., 2004; Parker et al., 2009; SOU 2005:104; SEMA, 2005a). These crises led to an increased focus on crisis response, and governments began to invest more resources to improve their response. Sweden was no exception, and one solution for improving response was to pay greater attention to collaboration between the actors involved, for instance inter-municipality collaboration (SFS 2006:544; Government bill 2007/08:92). The concept of 'collaboration' became a buzzword, and one common way to define it was through different network collaboration approaches to describe and understand the development of authorities coming together to improve response (e.g. Ödlund, 2008; Parker et al., 2009).

This increased attention on collaboration and ICT as a way to achieve a more effective response has continued. ICT now plays a more vital role within public service. With the digitalization, i.e. "applying digitizing techniques to broader social and institutional contexts that render digital technologies infrastructural" (Tilson et al., 2010: 749), ICT is used on a different scale than before. It is a part of the response, and is used by responders (e.g. de Lanerolle, 2010; Schmidt et al., 2018). Intermunicipality network collaboration plays an obvious role in an effective response, both in small-scale frequent emergencies and large-scale crises. Crises and emergencies, such as the widespread wild forest fires of 2014 and 2018 in Sweden, the 2010 earthquake in Haiti, and flooding in Central Europe in 2013, all demonstrate the importance of collaboration between different actors in the response. This includes collaboration both between professional response organizations (e.g. inter-municipality network collaboration) and with citizen volunteers, which could be used more effectively (the Swedish Ministry of Justice, 2015; SOU 2019:7; Rogstadius et al., 2013; Johansson et al., 2018; Murphy, 2020).

Greater attention has thus been paid to engaging citizens, and research within the area is now extensive. For example, there are several studies on spontaneous engagement of citizens and large citizen-generated content during a response (e.g. Kawasaki et al., 2013; Ludwig et al., 2015; Palen et 
al., 2010). This research mostly concerns crisis response (large-scale crises). Involving citizen volunteers in smaller emergencies - i.e. frequent accidents - has still not been studied to the same extent (Ringh et al., 2011; Berglund et al., 2018; Pijls et al., 2016.). To understand the response domain and how citizen volunteers can be engaged, additional research into the response to these emergencies may be useful. Experiences gained from day-to-day emergency response and increased knowledge about managing uncertainties can also provide knowledge for managing larger crises (Weick and Sutcliffe, 2007). However, there are also differences between crisis and emergency response, such as the frequency and scale of this response. In terms of impact, emergencies are normally on an individual level while crisis are on a societal level. Nevertheless, both crisis response and emergency response are key activities for municipalities, and involve responding to uncertainties which are not always easy to anticipate in advance. In other words, there are interconnections between responses to crises and emergencies. Thus, it could be beneficial to take a holistic view and study the response, no matter whether it relates to a crisis or an emergency.

Moreover, despite the recent rapid increase in literature on coproduction (and the similar concepts of co-creation and co-design), there is scarce literature on co-production studying pre-planned volunteer engagement where citizens are involved in the actual delivery of the response together with the professional response. This is the case both for crisis and emergency response and generally. With co-production, new challenges arise such as who should collaborate with whom and how, which new problems or questions may arise that need to be resolved, and which needs may arise. In order to understand these challenges and be able to manage them, new knowledge is necessary; knowledge which is currently largely lacking.

Additionally, there has been increased digitalization within both society and public service (Tilson et al., 2010; Sørensen, 2016). ICT itself has developed rapidly during the time period, as have the use and understanding of technological possibilities and technological competence within public service (Bason, 2018; Bonsón et al., 2012). Thus, ICT provides new ways to collaborate between different actors, not least between local government and citizen volunteers within the response domain (e.g., Berglund et al., 2018; Schönböck et al., 2016; St. Denis and Hughes, 2018).

With the development of ICT, the possibilities for enabling co-production have increased significantly (Linders, 2012). One example of this is that municipalities in Sweden are currently engaging citizen volunteers as first responders in the event of accidents or medical incidents using mobile apps, in order to achieve a faster response (Ringh et al., 2011; Pilemalm, 2020). 
Thus, Sweden is an interesting setting to study in order to gain knowledge about the emerging phenomenon of ICT-enabled co-production within the response domain.

However, for ICT to be an enabler for crisis and emergency response collaboration, suitable ICT systems must be developed and adapted. From a sociotechnical systems approach, both social and technical components have to be considered in order to achieve an adapted ICT system (Bostrom and Heinen, 1977a; Markus, 1983; Iivari, 2010; Moynihan, 2009). Thus, social components - i.e. the responders and their environment, such as their organization - should be considered together with the technology. Hence, the users' contexts and needs need to be studied in order for the ICT to support the response. If there is no support for sharing information and communicating with each other during a response, it will be less effective and take longer. This can have negative consequences in terms of saving lives or preventing material damage or interruptions to critical infrastructure. Without suitable ICT, professional responders may have difficulties receiving the information they need to create an accurate picture of the event, and may therefore make incorrect assumptions and decisions. Also, volunteers who do not have suitable ICT, for instance a mobile app for first response dispatch, may not be able to reach the incident site quickly enough or may not be able to carry out initial actions. In other words, paying attention to ICT-enabled co-production is necessary for an effective response. However, research into ICT-enabled co-production within the crisis and emergency response domain is still very limited, especially on a practitioner level and with an end-user focus. Previous literature emphasizes the role of ICT for collaboration and involving volunteers in the response, but not in connection with co-production (Havlik et al., 2016; Ferguson et al., 2016; Meissen et al., 2017; Schmidt et al., 2018; Schönböck et al., 2016). Also, regarding the ICT focus, previous and contemporary literature usually focuses directly on the existing ICT system. Thus, the process by which the ICT system is developed and obtained is seldom explored in detail (e.g. Ferguson et al., 2016; Ringh et al., 2011) ${ }^{2}$.

Meanwhile, previous research in other contexts addresses challenges in this process, such as involving end-users in the ICT development processes and identifying ICT functions from an end-user perspective (e.g. Havlik et al., 2016; Holgersson and Karlsson, 2014; Roberts et al., 2014). Without end-user involvement in the development process, it is difficult to develop ICT systems that are suitable for end-users (Gulliksen et al., 2003; van den

\footnotetext{
${ }^{2}$ In some earlier studies it is possible to obtain information about identified needs and requirements, even though this is not the core focus of the studies (see Table 1 in paper V).
} 
Besselaar, 1998; Vines et al., 2012). Much of the previous literature focuses on methodological techniques for addressing end-user involvement (e.g. Bjerknes et al., 1987; Tollmar, 2001; Iversen et al., 2010) and user satisfaction (Verdegem and Verleye, 2009). Although this is important, it is also important to study end-users' actual needs and the implications of involving end-users in general, as well as in crisis and emergency response and in co-production literature. This especially concerns citizens as endusers, as their non-organizational affiliation can lead to specific considerations (Holgersson and Karlsson, 2014). With increasing digitalization, this perspective also has to be included when studying citizen end-user involvement and the ICT development process.

On a more general level, while collaboration in other public service domains has been studied using different forms of network perspectives including co-production, and from different research disciplines, one thing that the perspectives have in common is that they seldom explicitly focus on the ICT, but rather on politics, policies, values, and economic and welfare aspects (e.g. Agranoff, 2007; Carlsson, 2000; Janowski et al., 2012; Loukis et al., 2016). To explore the perceived knowledge gap in terms of identifying suitable ICT systems for end-users in co-productions within crisis and emergency response, the rapid increase in ICT and ICT use, digitalization, and the transformation of the crisis and emergency response domain must thus be taken into account. If there is no understanding of the recent past and present, it is difficult to understand the future transformation of the response domain, the influence of digitalization, and suitable ICT systems for end-users in the event of a response.

\subsubsection{Knowledge gaps}

There are thus perceived knowledge gaps concerning:

- the transformation of ICT-enabled network collaboration among response actors, specifically ICT-enabled co-production as a rapidly emerging network collaboration type within crisis and emergency response,

- the focus of ICT-enabled co-production where the citizen becomes involved in the actual delivery of the response, and

- the lack of end-user involvement in the transformation of the response domain and in the ICT development process, in order to develop adaptable ICT - particularly for the citizen volunteers as responders (who are end-users with non-organizational affiliation).

In order to bridge these perceived knowledge gaps, the thesis's research objectives are described below. 


\subsection{Research objectives}

The problem description above is used as a point of departure for exploring how network collaboration, and particularly co-production, has gradually been enabled by ICT during a period in which local government, technology, and the crisis and emergency response domain have all undergone dramatic changes. Thus, the objectives of this thesis are:

a) to describe the transformation from ICT-enabled intermunicipality network collaboration toward ICT-enabled coproduction within crisis and emergency response, and

b) based on the above description, to identify implications, i.e. the challenges and opportunities involved in developing future ICT-enabled co-production.

The ICT-enabled co-production in this thesis is between municipalities (professional responders) and citizen volunteers (non-professional responders). The overall domain is thus public service, but the specific application domain is crisis and emergency response.

\subsection{Research design to answer the research objectives}

In order to answer the research objectives, the thesis's research design is interpretive case study research consisting of two interrelated case studies in crisis and emergency response, conducted during two different time periods. The first case study was conducted in 2006-2007, and addresses ICT-enabled network collaboration between municipalities in crisis response. The second case study was conducted in 2014-2017, and explores ICT-enabled network collaboration between municipalities and citizen volunteers, i.e. co-production, in emergency response. By comparing the two case studies, the thesis thus explores and describes the transformation toward ICT-enabled network collaboration in crisis and emergency response.

In both of the case studies, a sociotechnical systems approach is used, i.e. both social and technical components of the ICT were studied. In connection with the sociotechnical systems approach, an end-user perspective was applied. Also, an analytical framework with a theoretical foundation was used in both of the case studies, including essential aspects to consider when developing ICT-enabled network collaboration, including co-production.

Both case studies are used to answer the two objectives of the thesis. To answer the first objective, the two case studies are contrasted and compared 
with each other to describe the transformation in crisis and emergency response. To answer the second objective, both case studies are also used in order to study what may potentially differentiate ICT-enabled co-production from ICT-enabled inter-municipality network collaboration, and to be able to identify challenges and opportunities with ICT-enabled co-production.

The two case studies have several similarities. Both take place in the same application domain (the response domain). Both are at local government level and share the same problem: to provide high quality response service despite budget deficit and increased uncertainties. The municipalities in both case studies use the same approach: collaborating with other actors. However, in the first case study the municipalities chose to collaborate with other municipalities while in the second case study the municipalities took an additional step and also collaborated with citizen volunteers. Even though different municipalities are studied in the two case studies, the case studies are perceived to be comparable on an overall level, since the municipalities in the second case study collaborated in similar ways (i.e. with other municipalities at the time when the first case study was conducted). This implies that the two case studies can be compared as overall phenomenon, even if they do not involve the same municipalities.

Based on the two case studies, five papers have been written - two papers from the first case study and three papers from the second case study. Thus, this is a compilation thesis.

\subsection{Delimitations}

There are some delimitations connected to the thesis's objectives which are important to clarify, namely:

- The thesis's scope is within crisis and emergency response, i.e. the response phase. Crisis and emergency management is broader, and also includes other phases linked to the management of the crisis or emergency. These other phases are not studied in the thesis.

- Numerous types of collaboration exist within crisis and emergency response. However, only two types of network collaboration are studied in the thesis: inter-municipality network collaboration and co-production.

- In the thesis, the theoretical foundation is confined to the sociotechnical systems approach, end-user involvement, and network collaboration with a particular focus on co-production. Other theories are not taken in account, and thus nor are potential 
findings which other theories and approaches could have contributed to.

\subsection{Knowledge contributions}

The main scientific contribution of the thesis is a description of the development toward ICT-enabled co-production of crisis and emergency response. This is intended to give an in-depth understanding of the response domain's transformation and related opportunities and challenges. More specifically, the thesis provides knowledge about essential aspects for developing ICT-enabled co-production from an end-user perspective.

The description of the transformation from ICT-enabled intermunicipality network collaboration toward ICT-enabled co-production between municipalities and citizen volunteers is a result in itself. However, the results and conclusions also include related identified implications of the change in terms of challenges and opportunities to develop ICT-enabled co-production. This is important, since both ICT and the application domain are developing rapidly, and it is necessary to find new solutions for providing an effective response. An understanding of the past and the present can help to provide an understanding of this transformation and direction for similar future ICT-enabled co-production in crisis and emergency response. The thesis can also contribute toward understanding in a wider public government context, for example which challenges and opportunities exist to involve volunteers to provide public service enabled by ICT, as well as helping to enrich knowledge about end-users' needs, especially end-users with non-organizational affiliation.

Regarding specific theoretical contributions, the thesis provides knowledge of co-production as a potential merger of the research domains of IS and public administration based on a theoretical foundation of network collaboration, a sociotechnical systems approach, and end-user involvement.

Additionally, the thesis makes a practical contribution by providing "hands-on" knowledge which can be used as lessons identified for future ICT-enabled co-production in crisis and emergency response, for example when needs arise regarding new methods for citizen engagement to provide qualitative service despite resource deficit and increased uncertainties. More specifically, the thesis identifies challenges and opportunities concerning ICT and its contextual surroundings that are necessary for developing ICT-enabled co-production in crisis and emergency response. 


\subsection{Target audience}

The thesis's expected contributions have several target audiences. It is directed primarily toward researchers and practitioners within the application domain of crisis and emergency response and within the IS discipline. Within the IS discipline, researchers focusing on co-production (collaboration between government and volunteers) and ICT development processes with end-user involvement (e.g. participatory design (PD), usercentered design (UCD), and user innovation (UI)) are target groups, as are researchers within co-design, co-creation, and e-government. Researchers within other closely connected disciplines, such as, public administration, may also be a target audience because both the application domain response and the network collaboration approach of co-production are multidisciplinary.

An example of a target audience in terms of practitioners is local governments within the response domain (municipalities responsible for local rescue services), regional governments (e.g. county administrative boards), voluntary organizations (NGOs), and national agencies that plan and manage the direction of the application domain. Another example is professional responders, who may use the hands-on aspects to develop ICTenabled co-production within their own work.

Moreover, identified implications of the response domain's transformation can be used by future research and practitioners, since society will probably continue to develop rapidly, not least through increased digitalization. These implications may be of interest not only to researchers and practitioners within the application domain, but also to other areas within public service and ICT-enabled co-production, and to governments in general.

\subsection{Outline of the thesis}

The following chapter, Chapter 2, describes the research approach and the method of the thesis, including the research process, the research perspectives, i.e. a qualitative approach based on hermeneutics, and how theory and the analytical framework are viewed in the thesis. From this outlook, the case study research is described followed by the data collection, the data analysis, and the validity of the thesis's findings.

Chapter 3 provides the theoretical foundation for the thesis and presents an analytical framework. First, the chapter gives an overall introduction to digitalization in crisis and emergency response. This is followed by a description of the ICT approach applied in the thesis, i.e. the 
sociotechnical systems approach and end-user involvement, and ICT in network collaboration with a specific focus on co-production and end-user involvement. Based on the theoretical framework, an analytical framework is built. Thereafter, the thesis's application domain of crisis and emergency response is described. Finally, in the last section, reflections and implications for the thesis are summarized.

Chapter 4 presents the aggregated results from the two case studies based on the five included papers. First, the chapter presents a summary of the included papers, emphasizing the contributions to the thesis. Thereafter, an aggregated analysis is conducted of the results from the two case studies (based on data from the included papers).

Chapter 5 further analyzes and discusses the aggregated results, i.e. the transformation of the application domain toward ICT-enabled coproduction and its challenges and opportunities, in the light of end-user involvement and digitalization.

Finally, Chapter 6, provides the thesis's conclusions, contributions, and reflections on transferability, and discusses the limitations of the thesis's findings and future research. 

Chapter 2

\section{Research approach and methods}

In this section I describe the methods applied in the thesis. Multiple methods have been used in the papers, and in the thesis they are combined in an aggregated analysis. Firstly, the research process and the way in which the work was conducted are described. Thereafter, the overall research perspectives and approach are described to clarify my baseline and development as a researcher. Then, the building of a theoretical foundation and an analytical framework are described. Thereafter, the case study research is described followed by the data collection, the data analysis, and the validity of the thesis's findings.

\subsection{Research process}

The research process is described by first briefly give the author's background and then turning the focus to the research process of the papers' included in the thesis.

\subsubsection{The author's background}

I will here give a brief description of my academic background and the conditions which have shaped me as a researcher and consequently also influenced the thesis.

I started my academic journey with a master's degree in political science at Linköping University in 2006. I completed my master's degree as part of the "Emergency management for technical infrastructure - regional and municipal strategies for co-ordination and implementation" research program, funded by SEMA (the forerunner to MSB). After my master's degree, I continued to work as an investigator on the research program, while also teaching public administration at Linköping University. I then left academia to work as a practitioner within crisis and emergency management. I first worked at Östergötland County Administrative Board and thereafter at the Government Offices of Sweden. When starting the latter job, I also had the opportunity to study for a licentiate thesis in political science and was able to use some of my work as an investigator. In 2010 I defended my licentiate thesis on "Local Crisis Management: Development through Collaboration and Information Systems". After 
having completed my thesis, I continued to work as a practitioner/desk officer.

In 2014, after a period working within the same field as an advisor at the company Combitech, I had the opportunity to take up my research and continue my PhD studies, again at Linköping University but within another discipline, information systems (IS) at the Center for Advanced Research in Emergency Response (CARER). I conducted my PhD studies part-time while working as an advisor at Combitech. During this period I also took parental leave on two occasions (two years in total).

Although I have worked in the same field since 2006, I thus have an interdisciplinary background which gives me several different perspectives on how research can be conducted methodologically. My decision to change disciplines has allowed me to see the field with new perspectives and methods. This has both enriched me and challenged me as a researcher. The thesis contains different methods from two research disciplines. Also, I have never worked full-time as a researcher, and there is a time lapse between my licentiate thesis and starting my thesis work. This has resulted in long period as a PhD student. It has allowed me to accumulate knowledge over a long period of time and to take part in various academic discussions and environments. I believe this has been especially important when changing or adding another discipline. However, it can also be a challenge when aiming to produce a coherent and rigorous thesis.

\subsubsection{The overall focus of the included papers and the connection to the research process}

Five papers are included in this thesis compilation. The focus of each paper is described below and connected to the research process.

Paper I was published in the academic discipline of political science in 2007. The main purpose was to explore how inter-municipality network collaboration is developed within the domain of crisis response. At the time of the study, this was rather a new policy area and thus enabled me to consider how inter-municipality collaboration could be developed.

The paper is based on a case study (the thesis's first case study) where the municipalities were all small, and they started on their own collaboration initiatives to improve their crisis response and their resource-effectiveness. Since the municipalities were not focused on using ICT at that time and wanted to develop the "social" collaboration first, the paper studies the social components of the ICT system.

With the knowledge gained from paper I, I wanted to further explore technological possibilities for supporting collaboration. Thus, in paper II which was published in 2012, also within the discipline of political science - 
my ambition was to study ICT in the inter-municipal network collaboration. I also had the ambition to advance inter-municipality collaboration and study municipalities' ICT collaboration with citizen volunteers in crisis response (citizens with non-specific competence but a willingness to provide support in a crisis, thus not citizens involved in formal volunteer organizations). However, the municipalities were not focusing on this type of collaboration with citizens, and paper II thus also focuses on intermunicipal network collaboration.

The same case study was reused with the addition of larger municipalities to explore any differences between municipalities, users and organizational size. Paper II explores how the use of ICT systems can enable network collaboration. The focus is also on end-users' needs when developing ICT, which is explored by studying end-users' choices between different ICT systems and whether these systems meet the needs of the end-users. Two ICT systems were studied: a national web-based information system developed by SEMA (the predecessor to the agency MSB), called WIS, and a locally developed ICT system with a broad perspective including crises and emergencies, called eNavet.

In 2014, I had the opportunity to take this further within the discipline of IS at the Center for Advanced Research in Emergency Response (CARER). As a consequence of changing research discipline, ICT became more central to my research and I broadened my application domain to include emergency response.

I now made a second attempt to advance inter-municipality collaboration and study municipalities' ICT collaboration with citizen volunteers. The municipalities included in the first case study did not collaborate with citizen volunteers. This was not unusual, since the phenomenon was still relatively new within the response field. However, I identified another inter-municipal network collaboration which just had started working with citizen volunteers, which in the thesis is referred to as ICT-enabled co-production. To gain a deeper practical understanding of ICT-enabled co-production within the response field, the three following papers were conducted within local emergency response. In this context, the papers study one of the first cases in Sweden of municipalities developing ICT-enabled coproduction with citizens, with the goal of requiring lower resources from the municipalities (emergency services) while also providing an effective first response.

Paper III, written in 2017, explores the development of ICT-enabled coproduction and its implications within a specific case study (although not referred to as co-production in the paper; instead, the broader concept of 
ICT-enabled network collaboration is used here). The paper focuses on both social and technical aspects when developing ICT-enabled co-production.

Paper IV, produced in 2016, also studies ICT-enabled co-production, but at a government level with a focus on the social components of the ICT system (here, too, co-production was not the concept used in the paper). Then, in paper V, completed in 2019, the technical components of coproduction are explored as an enabler of collaboration, but in more detail and with a narrower scope compared to paper III. In other words, paper V focuses on response alerts through mobile apps for citizen volunteers, with an emphasis on the associated needs and functions.

With a change of research discipline to IS, the end-user focus was also emphasized more and was analyzed in greater detail in the three last papers compared to the previous papers (papers I and II). The previous papers focus on the end-users of ICT, but not to such a degree as in the last three papers. Overall, my research process is summarized in Figure 2.1 below, structured by the time period when the case studies were conducted.

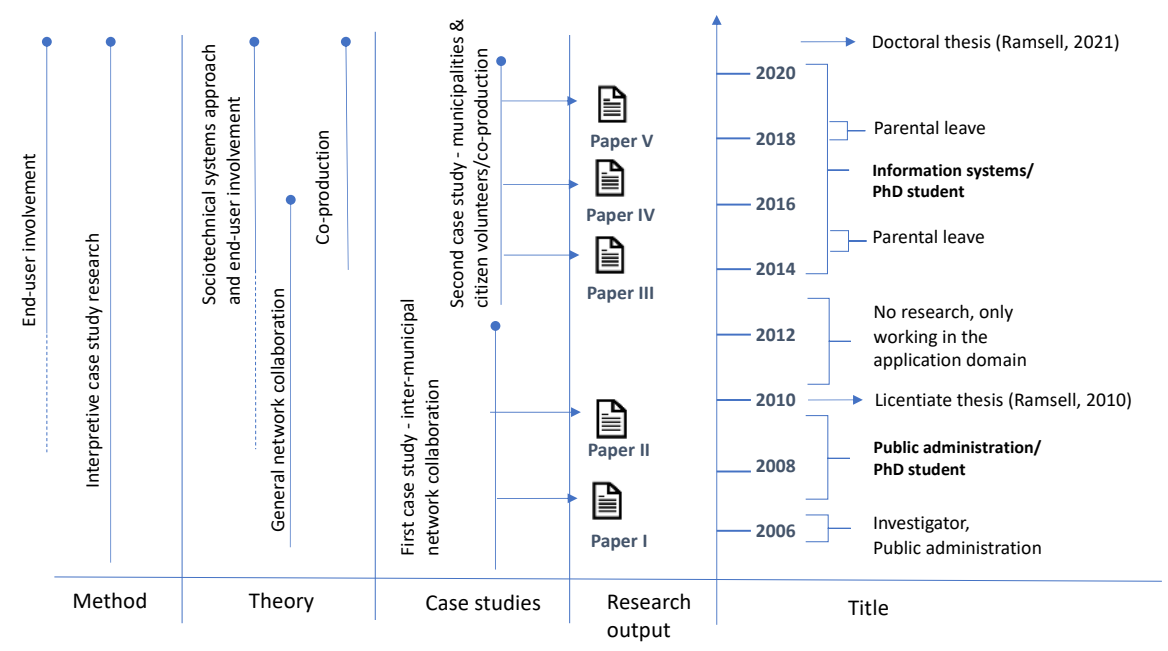

Figure 2.1. Timeline of the research process. 


\subsubsection{The papers' contributions to the thesis objectives}

This section further connects the papers' specific contributions to the fulfilment of the thesis objectives.

All papers help to answer the thesis objectives but in different ways, to different extents, on different levels and from different perspectives. In Table 2.1 below, each paper's contribution is described in connection with to the objectives of the thesis: a) to describe the transformation from ICTenabled inter-municipality network collaboration toward ICT-enabled coproduction between municipalities and citizen volunteers, and b) its implications.

Table 2.1. Each paper's contribution in connection with the thesis objectives.

\begin{tabular}{|c|c|c|}
\hline Paper & Contribution to objective a) & Contribution to objective b) \\
\hline I & $\begin{array}{l}\text { Development of inter-municipality } \\
\text { network collaboration }\end{array}$ & $\begin{array}{l}\text { Challenges and opportunities of } \\
\text { developing ICT-enabled network } \\
\text { collaboration - social components }\end{array}$ \\
\hline II & $\begin{array}{l}\text { - Development of ICT-enabled inter- } \\
\text { municipal network collaboration } \\
\text { - Requirements/functions for ICT } \\
\text { systems and end-user choices in ICT- } \\
\text { enabled inter-municipal network } \\
\text { collaboration }\end{array}$ & $\begin{array}{l}\text { Challenges and opportunities of } \\
\text { developing ICT-enabled network } \\
\text { collaboration - technical components }\end{array}$ \\
\hline III & $\begin{array}{l}\text { - Development of ICT-enabled co- } \\
\text { production } \\
\text { - Requirements/functions of ICT } \\
\text { system and end-user choices }\end{array}$ & $\begin{array}{l}\text { Challenges and opportunities of } \\
\text { developing ICT-enabled co-production } \\
\text { including end-user needs - technical } \\
\text { and social components }\end{array}$ \\
\hline IV & $\begin{array}{l}\text { Development of ICT-enabled co- } \\
\text { production }\end{array}$ & $\begin{array}{l}\text { Challenges and opportunities mostly } \\
\text { regarding end-user involvement and } \\
\text { their needs (technical as well as } \\
\text { material needs) }\end{array}$ \\
\hline V & $\begin{array}{l}\text { Use of ICT systems and ICT needs and } \\
\text { functions in co-production }\end{array}$ & $\begin{array}{l}\text { End-user needs of ICT functions in co- } \\
\text { production }\end{array}$ \\
\hline
\end{tabular}

The papers contribute to different analysis levels of the thesis objectives, both macro level (i.e. societal and organizational levels - papers I, II, and to some extent IV) and mixed or micro level (i.e. individual or small groups papers III, V, and IV). In this way, the thesis draws advantages from both 
levels: the macro level's overall concept and the micro level of individuals' objectives and behaviors (Markus and Robey, 1988). Moreover, the papers make different theory contributions; general network collaboration (papers I, II, and III), co-production (i.e. a specific type of network collaboration paper V), and end-user involvement (papers III-V). All papers are also based on the sociotechnical systems approach, albeit not explicitly in paper I.

The papers' degrees of contribution differ. In some papers, the whole paper contributes to the thesis. In other papers, certain parts (i.e. other case studies) are not included in the thesis. The main reasons for not including them in the thesis are that they do not relate to the thesis objectives, i.e. they would hamper rigor and the aim of gaining a deep understanding. Nevertheless, this is not necessarily linked to the importance of the papers' contribution. For example, in paper $\mathrm{V}$ the network collaboration between municipalities and citizen volunteers is specific to co-production, while in earlier papers the collaboration is only defined by network collaboration, which is a broader concept where co-production is also included. This means that paper $\mathrm{V}$ makes an essential theory contribution to the thesis. It consists of two case studies, but only one is included in the thesis since the other case study has a different focus. However, this does not mean that paper V's contribution to the thesis is not important.

Concerning papers I-III, the papers are included in the thesis in their entirety. All three papers use a network collaboration approach. Even if the theoretical part concerning network collaboration with citizen volunteers is then further specified to co-production, the network collaboration approach is an important foundation on which to understand inter-municipality network collaborations as well as the network collaboration type coproduction.

The contributions of papers I-III and paper V are empirical, as well as providing a basis for the theoretical contribution and the analytical framework. Paper IV only makes an empirical contribution and does so to a lesser extent, while only one of the paper's three case studies is included in the thesis because of its different focus. Thus, paper IV does not make as substantial a contribution compared to the other papers.

The papers have also different degrees of linkage between each other. Each subject addressed in papers I and II is also addressed in paper III. Thus, paper III is closely linked to both paper I and paper II. Paper III is also closely linked to paper IV, as the same case study is used in both papers and they study similar questions. However, the analysis level differs; in paper III, the emphasis is on the specific collaboration, while in paper IV the emphasis is on the response. 


\subsubsection{The author's role in each paper}

Five papers have been written and included in the thesis. Because the papers also have other authors, I will here describe my contribution to each of them.

Paper I: I conducted the case study, chose the theory and developed the analytical framework, analyzed the data, wrote the discussion, and drew the conclusions. The other author helped me with the translation into English, establishing the structure, and narrowing it down.

Paper II: I conducted the case study, chose the theory and developed the analytical framework, structured the empirical data and analyzed the results of the case study, drew conclusions, and wrote most of the paper. The other author helped me with the translation into English, structuring the paper, and formulating the conclusions.

Paper III: I conducted the case study as part of a larger research project. A team of other researchers also participated in the project, but I was responsible for my own case study within the data collection. I chose the theory, created the analytical framework, structured the empirical data, and performed the analysis (the results and the discussion). I produced the majority of the discussion and the conclusions, with assistance from the other authors.

Paper IV: In paper IV, I conducted one of the case studies, and structured the empirical data and the findings for this case study. I helped with the writing, the theoretical decisions, and the analysis of the paper. Thus, I did not play a leading role in this paper compared to the other authors.

Paper V: I conducted one of the two case studies (the one included in this thesis), and for this I structured the empirical data, identified the findings, and carried out the analysis. For the whole paper (i.e. also the other case study which I did not conduct), I analyzed the empirical data, identified the findings and results, chose the theoretical approach, and created the analytical framework. I produced the majority of the paper, and received support from the other authors in terms of structuring the paper and providing overall comments on improving it.

\subsection{Research perspectives}

My ontological assumption is based on the outlook that there is not just one true reality - the reality changes depending on who the viewer is. This ontological assumption influences how I perceive the way in which knowledge is created, or the epistemology. In the thesis, the epistemology assumption is that knowledge is constructed by our experiences and interactions (Biggs and Tang, 2011). This assumption is cross-disciplinary - 
it is not constrained to one specific discipline. Thus, this assumption has guided my Licentiate Thesis in public administration and continued to do so when I changed discipline to IS.

My research perspective is influenced by my ontological and epistemological assumptions. With support from constructivism, also known as interpretivism (Myers, 2009; Orlikowski and Baroudi, 1991), the thesis is based on a qualitative research perspective and hermeneutics (Kvale, 1996). Thus, ICT-enabled network collaboration within the response domain is seen in this thesis as a social phenomenon where individuals' perceptions and attitudes about the research problem is of special interest. Basically, it is about how to understand and interpret a human being's reality. The knowledge is socially and individually constructed. In other words, the knowledge is created through understanding and interpreting individuals' perceptions and experiences in their own situations and contexts. Thus, ICT is understood as being closely connected to interactions with human actors and how these human actors are organized, here called a sociotechnical systems approach.

With a qualitative research perspective, the research can contribute to new perspectives and understanding on both individual (micro) and group/organizational/societal (macro) levels (Markus and Robey, 1988).

In my role as a qualitative researcher, the empirical data is the driving force in my research. Without empirical data, it would be difficult to answer the thesis's objectives since there is no other data which can be used. Theory building is developed from the empirical data. However, I also base the empirical data on previous research and theories. I use theory as to support my analysis using an analytical framework, and I aim to add theoretical contributions from the empirical data. Thus, I would frame my research as abductive. How theory and the analytical framework are viewed in the thesis is described in greater detail below.

\subsection{Building a theoretical foundation and an analytical framework}

This section first describes how theory is perceived and defined in the thesis, followed by a methodological description of how theory is used in the thesis - referred to as a "theoretical foundation" in the thesis. Thereafter, the thesis's analytical framework is methodologically described. For information regarding the content of the theoretical foundation and the analytical framework (the specific aspects), see chapter 3. For the application of the analytical framework, see chapter 4 . 
There are multiple views about what constitutes a theory and what constitutes a framework (Gregor, 2006). Within the IS discipline, I belong to the researchers dealing with social science. Thus, there is not only one "right" or "true" theory (Berger and Luckmann, 1991). Several theories applied in IS have their origin in other disciplines, which also applies to the thesis's theoretical foundation. Moreover, the focus and the interaction between the technology and the surrounding context are specific to theories when applied within IS. The definition of theory in this thesis is that theory allows knowledge to be "accumulated in a systematic manner and this accumulated knowledge enlightens professional practice" (Gregor, 2006: 613).

The construction of the theoretical foundation can be described with the support of Weber's (2012) methodological guidelines. I focused on the phenomenon: the development of ICT-enabled network collaboration, which I later specified as ICT-enabled co-production. I ensured that I defined and described the theoretical foundation. This is also how the theoretical foundation can be verified, i.e. through "precise definitions or specification of the theory's parts" (Weber, 2012:25). To support the construction of the theoretical foundation, I used previous frameworks based on comprehensive theories when constructing my own theoretical foundation. These theories and approaches were within the sociotechnical systems approach, network collaboration, co-production, and ICT development with end-user involvement. I used previous frameworks and comprehensive theories to learn from previous research, to this as a starting point, and to develop it further instead of creating something completely new with no support from previous research.

In the thesis, an analytical framework is created based on the thesis's theoretical foundation and used as a support for the analysis. Like the majority of the theoretical foundation, the framework consists of identified important aspects to consider when developing or studying ICT-enabled network collaboration, with an emphasis on co-production. Thus, the analytical framework is closely connected to the theoretical foundation of the thesis. The framework in the thesis is analytical in that it describes and contributes to understanding whether certain aspects or elements are present in the studied phenomenon (Gregor, 2006). My ambition was to ensure that the analytical framework was sufficiently narrow so that only aspects essential to the understanding of the phenomenon were included, while at the same time ensuring that it comprised all vital aspects for understanding the phenomenon (Weber, 2012).

The framework has been applied to the empirical findings to support the analysis. In other words, the framework was applied both in the case studies 
and in the aggregated analysis of the thesis. The framework was successively built alongside the completion of the papers, and then further developed and used in the thesis. The framework builds on aspects identified as essential, primarily by Carlsson (2000) and Linton (2002). These were then supported with other literature and further developed, for instance adding end-user involvement perspectives to the aspects (Gulliksen et al., 2003; Markus, 1983; Iivari, 2010; Bjögvinsson et al., 2012).

In more detail, the framework has been used to support the analyses in three papers (I, II, and III). Different aspects of the framework are emphasized in each paper, depending on the paper's focus. In the thesis's aggregated analysis, the framework is structured based on the papers' frameworks, but is further developed and specified. Thus, the final framework version which is created in the thesis cannot be found in any paper - only parts of it. The framework presented in the thesis is a new structure. Most of the aspects are the same, but they are formulated differently or divided into more aspects or grouped into one aspect, for an overview how the framework has developed, see Figure 2.2. below.

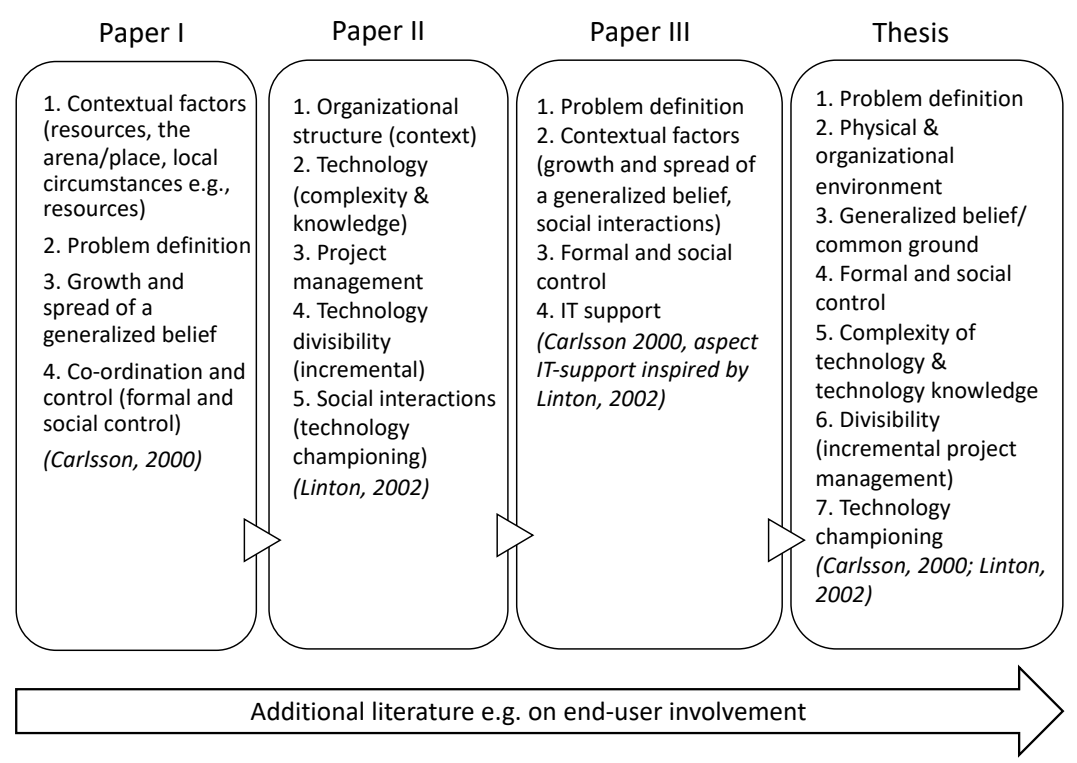

Figure 2.2. How the framework was developed during the research process. 


\subsection{Case study research}

Following my research perspectives, the thesis is conducted using interpretive case study research (Myers, 2009). The thesis includes two case studies and can thus be specified as an interpretive multiple case study (Myers, 2009). Interpretive case studies examine real-world phenomena which often are complex to study and demand a holistic view (Flyvbjerg, 2006; van Wynsberghe and Khan, 2007; Ragin, 1999; Myers, 2009), for example of an individual, an organization, a setting, a process, a situation, an incident, or an ICT system. In this thesis, the real-world phenomenon is ICT-enabled network collaboration with a special focus on co-production in the response domain. An important feature of case study research is the closeness to real life situations and the opportunity to generate data with a wealth of details (Flyvbjerg, 2006). This has influenced my methodological choice of data collection and data analysis in the thesis works, choosing methods that allow closeness to the individuals, organizations, and ICT systems in the network collaboration which I study (Ragin, 1999). This feature of closeness is especially important in social science, where general and context-independent knowledge is difficult to achieve (Flyvbjerg, 2006:227). Case studies can also be used to "clarify the deeper causes behind a given problem and its consequences" (Flyvbjerg, 2006:229) and for "making facts understandable" (Ragin, 1999: 1139). The research problem in this thesis is how network collaboration and especially co-production have been enabled by ICT in a period when government, technology, and the crisis and emergency response domain have experienced dramatic changes and rising demand.

Case studies can be exploratory, descriptive, or explanatory in character (Myers, 2009). The two case studies in this thesis can be labeled as exploratory, referring to case studies that investigate and characterize phenomena in relatively new domains. The two case studies are examples of ICT-enabled collaboration in crisis and emergency response. The first case study was conducted within the field of crisis response regarding intermunicipality collaboration, which at that time was a rather new policy area and thus also the phenomenon of inter-municipal collaboration in this policy area (crisis response). The second case study was within emergency response regarding collaboration between municipalities and citizen volunteers, here labelled "co-production", and was also a new phenomenon at the time of conducting the case study.

To fulfill the thesis's objectives - to explore the transformation from inter-municipality collaboration to co-production and its implications - the first case study represents inter-municipality collaboration while the second 
case study represents emerging co-production where municipalities collaborate with citizen volunteers. Both case studies are used to answer the thesis's two objectives. To answer the first objective, the two case studies are contrasted and compared with each other to describe the transformation in the crisis and emergency response. To answer the second objective, both case studies are again used, in order to study the potential differences in coproduction from inter-municipality network collaboration, and to identify challenges and opportunities with ICT-enabled co-production.

\subsubsection{The case of inter-municipal network collaboration - "Extended VÖKBYT" (the first case study)}

The first case study was conducted in Östergötland and Småland counties in eastern Sweden among several municipalities in 2006-2007. The case study was selected to study how inter-municipality collaboration is developed within crisis management, including crisis response. The case study initially consisted of a network of six municipalities. These municipalities were all small, and for reasons of resource effectiveness they launched their own collaboration initiative called VÖKBYT (from the first letter of each municipality's name: Vadstena, Ödeshög, Kinda, Boxholm, Ydre, and Tranås). One of the collaboration areas was crisis management, including crisis response. To further study ICT's role in the collaboration, additional municipalities in the county were added: Linköping, Mjölby, Motala, and Norrköping. The reason for this was to represent both large and small municipalities with a variety of ICT systems in crisis response. Three of the original municipalities were not included in the second part, to create a balance between large and small municipalities. In total, ten municipalities were included in the case study. The table below lists all the municipalities included in the case study.

Two ICT systems were studied in this case study: one local municipality initiative, eNavet, and one national online platform, WIS, owned by the national agency SEMA (and later MSB). Both systems aim to support information sharing in crises. 
Table 2.2. Municipalities included in the first case study. Municipalities which were included in both steps of the case study (resulting in papers I and II) are marked with italics and bold, while municipalities only participating in the first step (resulting in paper I) are in normal style, and municipalities participating only in the second part (resulting in paper II) are in italics.

\begin{tabular}{lll}
\hline Municipality & Inhabitants & Geographical size $\left(\mathrm{km}^{2}\right)$ \\
\hline Boxholm & 5,300 & 530 \\
Kinda & 9,900 & 1,140 \\
Linköping & 140,000 & 1,440 \\
Mjölby & 25,000 & 550 \\
Motala & 42,000 & 990 \\
Norrköping & 125,000 & 1,500 \\
Vadstena & 7,500 & 180 \\
Ydre & 3,800 & 680 \\
Tranås & 17,700 & 405 \\
Ödeshög & 5,400 & 430 \\
\hline
\end{tabular}

Source: SCB.

\subsubsection{The case study of ICT-enabled co-production - "Enhanced Neighbors" (the second case study)}

The thesis's second case study was conducted in 2014-2017 within a project initiated by the Medelpad municipality association rescue service, situated in a sparsely populated area in the north of Sweden. The Medelpad rescue service association consists of three municipalities (Sundsvall, Timrå, and Ånge) collaborating to provide rescue services. In order to provide a faster response for remote villages, the rescue services started involving volunteers as first responders. When the case study began, there were five remote villages (and subsequently ten villages) participating in the project. The villages are situated at a distance from Sundsvall that makes it impossible for the rescue services to reach the villages in less than 25 minutes. Citizen volunteers in these villages receive basic training, for example in cardiopulmonary resuscitation (CPR) and extinguishing small fires, and are alerted when an emergency occurs nearby. Participation is voluntary. The citizen volunteers are not expected or accounted for in the response - at best, they are a complement. If the citizen volunteers choose to attend an alert, they start initial tasks while waiting for the professional rescue services but never replace them.

The case study was selected because it was an existing inter-municipality network collaboration (as the thesis's first case study), but with a new 
network collaboration initiative with citizen volunteers. This was one of the first initiatives of ICT-enabled co-production within Swedish response services. The case study was conducted in a research project together with other researchers, as part of a joint inter-disciplinary research project.

In this case study, one ICT system - a basic SMS technology - was primarily studied, but other potential ICT systems (in particular, a dynamic resource allocation ICT system, DHR, and the Swedish national digital communication system, Rakel) were also discussed. The aim of these ICT systems was to alert first responders.

Table 2.3. Municipalities/villages with citizen volunteers included in the second case study. The municipalities to which the villages belong are in italics, while the villages with citizen volunteers are in normal style.

\begin{tabular}{lll}
\hline Municipality/village & Inhabitants & Geographical size $\left(\mathrm{km}^{2}\right)$ \\
\hline Sundsvall & 99,376 & 4,446 \\
Timrå & 17,996 & 1,235 \\
Ånge & 9,329 & 3,296 \\
Skatan & Approx. 200 & 121 ha \\
Holm & $347^{*}$ & 304 \\
Ljusdal & N/A 1-300 & N/A \\
Norrhasel & N/A 1-300 & N/A \\
Överturingen & 60 & 33 ha \\
\hline
\end{tabular}

Source: SCB; skatan.nu, *Number from 2000.

\subsubsection{Differences and similarities between the two case studies}

The two case studies feature both similarities and differences. They are both at local level, examining how municipalities collaborate with other actors to ensure an effective response and how ICT can facilitate this intermunicipality network collaboration and co-production. However, they were conducted during different time periods and therefore in different contexts regarding collaboration, digitalization, ICT development, and the response field. All these areas have undergone transformation, with conditions changing between when the first and second case studies were conducted. Thus, the two case studies represent different cases of response collaboration and are connected to its context.

The two case studies are compared to each other, even though different municipalities have been used. The reason for this is that the municipalities in the first case study did not have any collaboration with citizen volunteers. This was not unusual, since the phenomenon was relatively new in the response field. Thus, in order to fulfil the thesis's objectives, I had to 
investigate whether there was any other inter-municipal collaboration engaging citizen volunteers. I identified the inter-municipal collaboration in Medelpad Province as one of the first to initiate collaboration development with citizen volunteers. These municipalities were therefore included in the second case study. Otherwise, I could not have studied the phenomenon.

Regarding the second case study, I initially asked the municipalities open questions about their existing perceptions of citizen volunteers (around the time when the first case study was conducted). Basically, they had the same perceptions as the municipalities from the first case study. They also brought up the resource deficit, which was already a challenge at the time when the thesis's first case study was conducted, and which then decreased even further.

\subsection{Data collection}

The purpose of the data collection was to capture the phenomenon, the development of ICT inter-municipal collaboration or the development of ICT-enabled co-production, and to determine whether there were different perceptions of the phenomenon, i.e. different interpretations (Kvale, 1996). Different types of data collection have been used in the thesis: interviews, focus groups, literature reviews, the "future workshop" technique, and test of a prototype. These data collection methods were chosen in order to use different data sources to obtain the triangulation and multiple perspectives usually associated with collective knowledge creation, enhanced understanding, and credibility of case study research (Flvvbjerg, 2006; Myers, 2009). When conducting context-bound case studies which are difficult to study in other ways, the use of multiple methods is deemed to be vital (Ragin, 1999).

\subsubsection{Methods used in the data collection}

Several different methods have been used in the thesis. It also shows my development as a researcher and different traditions within the disciplines of public administration and IS. To begin with, I mostly conducted interviews and extensive literature and document reviews, but as my $\mathrm{PhD}$ studies continued I also used multiple data collections methods involving active user participation techniques from the IS discipline. Thus, my role as a researcher differed to some extent over time. In the first case study, which was conducted within the discipline of public administration, my role as a researcher was more that of an observer. In the second case study, which was conducted within the discipline of IS, I had a more active role as a researcher, for instance conducting workshops and tests, and may thus have 
influenced more directly the process and the phenomenon that I was studying.

The data collection was conducted before each paper; papers I and II were based on the first case study (for which the data collection was performed in two steps), and papers III to $\mathrm{V}$ were based on the second case study (for which the data collection was performed in three steps). No new data collection has been conducted for the thesis, except additional literature and document reviews. Also, some more data from the case studies regarding the municipalities reasons for collaborating has been added in the thesis. The collected data from both case studies and the thesis is summarized in Table 2.4 below.

Table 2.4. Summary of collected data.

\begin{tabular}{|c|c|c|c|c|c|}
\hline $\begin{array}{l}\text { Case study/ } \\
\text { Thesis }\end{array}$ & $\begin{array}{l}\text { Interviews } \\
\text { (1-1.5 hours } \\
\text { each) }\end{array}$ & $\begin{array}{l}\text { Focus groups } \\
\text { (approx. } 2 \\
\text { hours each) }\end{array}$ & Workshop & $\begin{array}{l}\text { Prototype } \\
\text { tests }\end{array}$ & $\begin{array}{l}\text { Literature and } \\
\text { document review }\end{array}$ \\
\hline
\end{tabular}

First case 21

study

c. 100 documents

(80 literature reviews, 10 governmental investigations)

Second case 6

study $3(6+4+3$ respondents)

1 (11

2

C. 50 documents

Thesis respondents)

$(5+12$ (mostly literature$$
-
$$

\author{
respondents) reviews)
}


questions could influence the respondents. The questions I asked were open, in order not to lead them indirectly to a certain answer.

\subsubsection{Selection of case studies and respondents}

Strategic sampling (also known as judgement sampling or purposeful sampling) implies that the researchers choose the most productive sample in order to answer defined research questions (Marshall, 1995). In this thesis, both case studies were chosen with this perspective.

In the first case study, the first contact was with an informal "project leader" who gave me contact details for the other municipal officials working in the project. The data collection was conducted in two steps. In the first step, data was collected from the inter-municipality project of five small municipalities. This data showed that one area was more central in the collaboration than others, namely ICT for the collaboration. To further investigate this, more municipalities were added to the case study meaning that the work and discussion of the ICT took place with a larger group than the original municipalities. The new municipalities were also chosen to represent different municipality/organizational size, since the data from the first collection indicated that this could be important.

Strategic sampling was also used in the second case study. Respondents were actively chosen together with the project leader, and the sample was intended to reflect the organizations and actors actively participating and working together in the collaboration. In other words, the respondents were chosen to include the various roles involved, i.e. municipal officials (from the rescue service) and citizen volunteers (Table 2.4). The volunteers were also chosen to represent different villages geographically dispersed across the province of Medelpad.

In both case studies, collaborating with the project leaders in the selection process gave smooth access to respondents who were open and accommodating, and provided rich information. However, this might also have led to a risk of bias, for example that only respondents with a positive view of the collaborations were represented in the sample. On the other hand, the respondents provided broad input on the subject, including challenges and problems. All the interviews and workshop were organized with the intention of providing opportunities for the participants to share information openly, and sought to establish reasonably uniform pictures from multiple perspectives. 


\subsubsection{Interviews and focus groups}

The interviews were semi-structured and involved pre-formulated questions or themes that kept a focus on the subject without adhering to it rigidly (Stake, 2010). In the focus groups, respondents were asked about their perceptions, opinions, and experiences in a similar way, but from a group perspective (Myers, 2009).

Semi-structured interviews were performed in both case studies, while focus groups were held only in the second case study. The reason for this was the geographical dispersion of the volunteers, which made individual interviews difficult. An additional reason was that the interviewed volunteers would feel confident and at least on the same "level" as me, the researcher. Compared to them, I had a formal professional role - a researcher - while they were not there in any professional role, "only" in their own personal capacity. To minimize the risk of a power imbalance between me as a researcher and the respondents, focus groups were considered to be a suitable choice. In the first case study I conducted all the interviews alone, while in the second case study I was part of a research group with other researchers, albeit with responsibility for my own research questions.

All the interviewees, including the focus groups, were asked about their respective experience of the collaboration form, and its perceived strengths, problems, and further needs. The interviews were documented using notes, and were also audiotaped for further transcription and analysis.

In the first case study, a total of 21 interviews were performed, including five telephone interviews (eight interviews for paper I, including three telephone interviews, and 13 interviews for paper II, including two telephone interviews). Telephone interviews were mostly used at the end of the data collection process when I needed confirmation or when the respondent was short of time. The municipalities featured organizational differences in terms of officials working with crisis response. Some municipalities had administrative desk officers at the head office, while in other municipalities they were based at the rescue services. Therefore, the type of respondent varies depending on each municipality's organizational structure. At the beginning of the data collection process, I was referred to local politicians. Three interviews were conducted with local politicians, after which I was referred to municipal officials for more detailed information. Additionally, one official from the county administrative board and one from the national agency responsible for the area were interviewed.

In the second case study, five interviews were performed with the project manager, rescue service managers and with the operator from the Swedish Public Safety Answering Point (PSAP) handling the alert calls. In addition, 
three focus groups were held with volunteers from three villages. One telephone interview was also conducted with a volunteer from a fourth village. The telephone call for this interview was made from the rescue service in Sundsvall, but no representatives from the rescue service were present. Thus, regarding interviews, totally six respondents were interviewed in the second case study.

\subsubsection{Future workshop - a participatory design technique}

A half-day "future workshop" was arranged as part of the second case study. "Future workshop" is a design technique emerging from participatory design, with a specific focus on end-user participation (Kensing and Madsen, 1992). Future workshops allow users - who know their own work environment best - to reflect upon their work situation and any improvement needs, thus identifying realistic and innovative organizational and technical solutions. Future workshops are usually divided into the critique phase, the fantasy phase, and the implementation phase. The first phase focuses on the work situation, potential problems, and improvement needs. Futuristic solutions to the identified needs are the focus of the second phase. In the third phase, the identified solutions are transformed into realistic, organizationally and technically feasible implementations (Kensing and Madsen, 1992).

Actors from the rescue services and volunteers from different villages were represented at the future workshop. A total of 11 participants took part, including the project initiator, the project leader, and an informant from the rescue service. The other eight participants were volunteers, some of whom also participated in the focus groups. I conducted the future workshop with a colleague, and was responsible for leading and collecting the data for the second case study. My colleague had a different focus - to test a guideline that was not related to the thesis's second case study.

The emphasis of the workshop was on the collaboration between the rescue service and the volunteers, and on improvements regarding response operations. The future workshop was documented using memory notes and sticky notes, and was audiotaped.

\subsubsection{Prototype testing}

I carried out two tests (on my own) in the second case study. A prototype mobile app was developed to test and evaluate end-user requirements identified in earlier interviews. 
Before the first test, the five participants had to download and install the app on their own Android smartphones. During the test, alerts were sent to the participants who could accept or decline them according to their own preference. The aim was for the participants to become familiar with the app and its functions. About a week after the test, I held a (physical) group interview.

I arranged the second test partly as a consequence of the low number of participants in the first test, since the requirements of having one's own Android smartphone, and installing an app (which proved to be too high for many potential participants). Thus, this test was performed as a physical workshop, with prepared smartphones that the participants could borrow. This resulted in 12 participants receiving alarms and testing and discussing the app during the test.

\subsubsection{Literature and document reviews}

In both case studies and in the thesis, I have used literature and document reviews as a data collection source. Literature and documents have been used both as a background and to place the case studies in their broader context, and for the theoretical foundation and the analytical framework.

Literature has been collected from well-known journals and researchers in the two disciplines and the application domain. The literature and documents were chosen in view of their relevance for local crisis and emergency response and/or their connection to ICT and co-production. Because of the emerging state of the study area, in which there is a lack of consistent use of specific concepts, there could be a risk of missing relevant literature in the data collection. Since the concept of "response" is not always widely used, the keywords "crisis management" and "emergency management" have also been used, as well as "disaster management", to minimize the risk of missing relevant literature. As well as "co-production", similar words such as "collaboration" and "networking" have also been used as keywords. Regarding documents, the Swedish Government's official investigations (SOU), Swedish regulations, and agency reports have been collected, as well as information from relevant agencies' websites.

\subsection{Data analysis}

I have used two overall perspectives when conducting the data analysis: first hermeneutics, as a basis for the analysis, and then - to provide a more hands-on "guide" in the analysis - the analytical framework.

The two approaches have been used both in the papers and in the thesis's data analysis. The data analysis in the thesis is an aggregated analysis based 
on the analysis from each paper. In other words, the thesis's data analysis is new - it is an aggregated analysis which combines all the papers' separate data (partially or entirely) in a joint analysis. The thesis's aggregated analysis ties the separate papers together at an aggregated analysis level, where it is possible to explore the transformation of crisis and emergency response with ICT as the enabler.

A more detailed description of how these two methods have been used in the analysis is provided below. Using an analytical framework has been described and justified above (section 2.3). In this section, I describe how the framework has been used in the data analysis in the thesis.

\subsubsection{Hermeneutic understanding as a basis for narrative analysis with the support of an analytical framework}

The analysis emanates from a hermeneutic approach, in which understanding and interpretation of a person's experience are central (Kvale, 1996). Thus, the hermeneutic perspective has guided me in my research in terms of interpreting data. To obtain a more concrete guide, I have followed Kvale's (1996) "analysis steps" for conducting and analyzing the data.

Kvale (1996) stresses seven important steps in order to gain scientifically quality: purpose (of the collection methods), design (of the collection methods), execution (e.g. selection of interviewees and risk of interviewer's influence), transliteration (documentation and corroboration), analysis (analytic framework, categorize, selection, capture the overall picture), authentication (triangulation, validity, generalizability), and presentation (structure, scientific standard). Kvale's (1996) steps are directed to interviews, but are used in the thesis for the whole analysis of all collected data, regardless of the collection method. The reason for this is that I found them to be general and applicable for analyzing all data collection methods and techniques, not only for the interviews. Some of Kvale's steps (1996) have already been described above (sections 2.4 and 2.5), and will thus not be repeated here, namely purpose, design, execution (selection of respondents and risk of interviewer's influence, which is further addressed below), and transliteration.

The process to understand a text can be visualized as a circle, a process where the interpretation of the whole text influences the interpretation of different parts of the text and vice versa. There should not be any contradictions in order to understand the text (Kvale, 1996). I searched for an overall picture throughout the analysis, and when I thought this had been accomplished, I studied the different parts of the data collected once more 
to see if I could discover any aspects that had not been analyzed. In other words, I worked with the data material until there were no contradictions left between different parts and the overall data.

In the data analysis, the emphasis was on the content and the substance - what respondents said about the subject being studied. The focus was on identifying implicit and explicit ideas and patterns in the data (Guest, 2012). The focus of the analysis was on understanding the respondents' expressions, such as what volunteers need in order to engage in the response operations.

At the same time, as the interviewer/facilitator and the interpreter/analyst, I tried to be aware that I was also influencing the process - which is addressed in Kvale's (1996) execution step. I might influence the respondents to answer in what they think is the "right" way, or to say what they think I want to hear (Kvale, 1996). Thus, I emphasized that there were no right answers, and that I wanted to hear their experiences. I also asked open questions. Another way to influence is through the interpreter having his or her own experiences which influence the interpretations (Kvale, 1996). I tried to pay close attention to how this influence could be kept to a minimum. One way to minimize it is to support the interpretation with a theoretical foundation and by using an analytical framework, which I did (Kvale, 1996). Regarding using a theoretical foundation and an analytical framework, the analysis has not only been theory-driven. In the analysis, it has been essential to keep an open mind about other themes which have not been identified in the framework, but which are still shown in the data. In other words, the data analysis has been both theory-driven and data-driven.

Regarding Kvale's (1996) authentication step, several respondents in the paper's collected data expressed similar narratives, for example experience of the development of the collaborations. Thus, there was a correspondence in the data which increases the reliability of the findings. Moreover, triangulation was created through different data collection methods (in all papers which form the base for the thesis's aggregated analysis). I also used a theoretical foundation, and in some papers and in the thesis's aggregated analysis an analytical framework, which provided theoretical support throughout the analysis. Also, for both the papers and the thesis's aggregated analysis, I compared the findings with the theoretical foundation used and previous research literature to be able to discuss potential generalization of the results and put them in a wider context. Concerning the theoretical foundation of the thesis's aggregated analysis, it was supplemented with extensive research literature comparing the papers' theoretical foundation. The theories and approaches used in the papers were 
further elaborated on, and the individual analytical frameworks applied in the papers were combined. (For more information about the analytical framework, see chapter 3 concerning the framework content and aspects.)

According to Kvale's (1996) presentation step, it is important to spend time finding a structure that can communicate the analysis. In other words, it is vital to reach a scientific standard, i.e. to enable readers to easily follow the steps conducted and to ensure that all necessary parts are included. Both in the papers and in the thesis's aggregated analysis, I have tried to accomplish this by letting the text "rest" and then looking at the text again to identify any necessary updates, and by having other researchers comment on the text.

For more detailed information about how I conducted the respective papers' data analyses, see each paper. This concerns Kvale's (1996) "analysis" step in particular, since this step also contains specific parts - not only parts that are general for the whole thesis. In the thesis, the analytical framework was used throughout the data analysis both as a guide and to structure the analysis. First, I collected the data from each paper and structured it using the two case studies. Second, I grouped the data according to the analytical framework's aspects and in terms of challenges and opportunities - both separately for each case study and then as a crosscomparison using the same structure. Third, I went through the data once more to get a more detailed understanding and to compare the two case studies - for example, to see whether similarities could be identified in both case studies (i.e. challenges and opportunities), and what differences there were. Additional findings were added. Fourth, I summed up the analysis, with the support of the analytical framework, to create an aggregated analysis with a focus on the network collaboration type co-production, namely a) the transformation from ICT-enabled inter-municipality network collaboration toward ICT-enabled co-production, and b) its implications in terms of challenges and opportunities.

\subsection{Interpretive quality criteria}

Interpretive case study research has been used as the overall collection method in the thesis. There are different ways to evaluate the quality of conducted case studies. In interpretive case study research, the plausibility of the narrative and the general picture of the phenomenon studied define the quality - not the validity (Myers, 2009). However, other case study literature argues that validity can in fact also be studied in case study research, albeit in a different way (Flyvbjerg, 2006). Generalization is often mentioned when arguing about validity of findings. However, generalization 
is only one way to "measure" validity (Flyvbjerg, 2006). Whether or not this measurement is suited to the specific study depends on the research method. In this thesis, close connection to a theoretical foundation supported in practical terms, while conducting the work involved in the thesis using an analytical framework, increases the possibility for generalization. However, another way to "measure" the validity of the thesis is to establish whether the thesis provides knowledge which can "... enter into collective process of knowledge accumulation in a given field or in a society" (Flyvbjerg, 2006:227). In this thesis, the research problem is explored closely and in detail in real-life situations, and thereby accumulates advanced understanding and a "collective process of knowledge", in accordance with Flyvbjerg (2006:227). Thus, this is also a way to evaluate validity for the thesis. To be more precise about how to evaluate the thesis's quality and validity, Kvale's (1996) seven steps for reaching a scientific standard are used for the thesis as a complement to Flyvbjerg's (2006) overall evaluation criteria for qualitative research and case study research. In addition, the ethical considerations addressed below help to ensure quality when conducting research and evaluating the thesis.

\subsection{Ethical considerations}

There are several ethical considerations when conducting case study research and the specific data collection methods used in connection with this. Ethical considerations are defined here as "respect and protection for the people actively consenting to be studied" (Payne and Payne, 2004: 66). More specifically, this includes the planning of the thesis, as well as how the thesis is conducted and how the findings are reported. Myers (2009) mentions several ethical principles, and I will elaborate on some of these principles which are particularly important according to the thesis's research method.

Myers (2009) argues that the most fundamental principle, and a basis for all other principles, is the golden rule. The golden rule involves treating the people involved in one's research as one would like to be treated (Myers, 2009). Throughout my work on this thesis, I have followed my own moral compass - not doing anything that I would not feel confident about vouching for, and always putting the well-being of the people involved first - ahead of the goal of collecting data and producing new knowledge.

Informed consent is about asking respondents in advance for their consent to participate (Myers, 2009). In all my collection methods, this has been possible. In some collection methods I have not had direct contact with all the respondents in advance, and have therefore asked for their consent 
before starting the data collection. This may be a problem - respondents might feel obliged to participate because their "manager" invited them to participate. However, I did not observe any evidence of this; instead, they perceived my questions about "being there of their own free will" and "participation being completely voluntary" as being unnecessary and taking up important time - they were eager to start sharing their thoughts and experiences. I have elaborated on this further in section 2.5 .

Interviews and fieldwork concerns the need to ask for consent to use the data from interviews and other fieldwork (Myers, 2009). I have used the collected data in the way I described it to the respondents. One concern may be that the first case study was conducted a long time ago, and respondents may be surprised that I am now including it in my thesis. However, papers I and II, which are based on the first case study, were published quite soon after the case study (i.e. also a long time ago). Thus, I do not perceive this to be an ethical dilemma.

To sum up, with the support of Myers (2009), I have reflected on the ethical principles of the golden rule, informed consent, and interviews and fieldwork. I have considered any ethical considerations while completing my thesis. This also supports the thesis's validity and scientific quality, as addressed above. 

Chapter 3

\section{Theoretical foundation and analytical framework building}

The focus of this thesis is on the role of information communication technology (ICT) in transforming crisis and emergency response, and this is also the emphasis of the theoretical foundation and the analytical framework building.

The chapter's first section consists of an overall introduction to digitalization in crisis and emergency response. This is followed in the next section by a description of the ICT approach applied in the thesis, the sociotechnical systems approach and end-user involvement. These ICT approaches are then connected in the following two sections, first to general network collaboration, and then specific to the network collaboration type co-production. Since crisis and emergency response is a public service, the theoretical foundation consists of public service literature. In the next section, based on the theoretical foundation, an analytical framework is built for important aspects of developing ICT-enabled co-production (i.e. between governments and citizen volunteers). Thereafter, the thesis's application domain of crisis and emergency response is described (e.g. by elaborating on the concepts of crises and emergencies, defining citizen volunteers in the domain, and presenting Swedish response as study setting). Finally, the last section, summarizes and reflects upon the thesis theoretical foundation.

\subsection{Digitalization in crisis and emergency response}

The use of ICT is continuously increasing in society, and ICT use is a common element in actors' and organizations' everyday lives which can be referred to as digitalization. More specific defined, digitalization is "a sociotechnical process of applying digitizing techniques to broader social and institutional contexts that render digital technologies infrastructural" (Tilson et al., 2010:749). Another, shorter way, to define digitalization is "the wholesale digitalization of previously analogue aspects of life" (Sørensen, 2016:58). 
On a societal level, several different ICT systems are often used, and new ICT solutions are constantly being developed. Public services, i.e. services for citizens that are financed by the government, are no exception (Bason, 2018; Bonsón et al., 2012). Together with organizational changes and progress, the ambition of ICT in public service is to improve citizens' possibilities to interact with government authorities, to increase authorities' efficiency by reducing manual routines, and to generally increase democracy in society through greater governmental transparency (Axelsson et al., 2013; Dawes, 2009). An increased emphasis on ICT's possibilities and support in public services can be seen in several areas (e.g. Cordella and Tempini, 2015; Gil-Garcia et al., 2018 ).

Within the field of ICT, there has been a successive development whereby the use of ICT was at first primarily emphasized in terms of more effective internal routines within public agencies (Asgarkhani, 2005; Layne and Lee, 2001). Then, social media and the Internet became "the ICT" and were seen as channels for information that provided accessible online services for individuals (Archer, 2005; Anthopoulos et al., 2007). At that time, ICT in public service was largely about individual action and the automation of information gathering. The citizen was seen as a user of public services. Later, other aspects were emphasized to increase democracy by focusing on citizenship and citizens' possibilities, such as expressing their opinions on how public services should be shaped (Sæbø et al., 2008; Asgarkhani, 2005).

There are also new and increasingly complex digital government initiatives taking place in parallel with more traditional initiatives. The new initiatives involve interdepartmental collaborations, where ICT is one of the driving forces behind increased interconnectedness between authorities, the private sector, non-profit organizations, and citizens within public services (Cordella and Tempini, 2015; Gil-Garcia et al., 2018; Lu et al., 2010; Babiak and Thibault, 2009; Meijer, 2012). ICT can reduce costs, and it can create new innovations for interactions that would be difficult to accomplish otherwise, both from a time perspective (24/7) and regarding content, areas, tasks, and assignments (Meijer, 2012). Moreover, ICT enables communication and interactions, such as applications tailored for specific users and tasks in public services (Meijer, 2012). One of the emerging initiatives in public services is ICT-enabled collaborations, in which governments collaborate with citizen volunteers. These complex digital initiatives are developing alongside the development of ICT itself. In other words, the users of ICT - individuals and organizations - and the ICT become more interconnected (Alter, 2003). These emerging ICT-enabled collaborations are the focus of this thesis, and therefore also of this chapter. 


\subsection{An ICT approach when studying collaboration to transform crisis and emergency response}

ICT is thus essential in the digitalization of public services. ICT can be understood in different ways, and this influences the study of ICT. This thesis applies a sociotechnical systems approach, which is supplemented with end-user involvement.

\subsubsection{Sociotechnical systems approach}

In this thesis, ICT is defined according to a sociotechnical systems approach and thus includes both social and technical components which are interrelated and interdependent on each other (e.g. Bostrom and Heinen, 1977a; Trist, 1980; Kling and Scacchi, 1982; Mumford, 1995; Alter, 2002b; Land, 2000). This means that the technology component of the ICT system is interconnected with its social context, i.e. humans and the human environment, including their organization. The ICT system can thus be described as a sociotechnical system or a work system (e.g. Bostrom and Heinen, 1977a; Trist, 1980; Alter, 2002b).

There are different definitions in the sociotechnical literature of what the two components (social and technical) specifically include. One way to describe it is that social components involve humans, e.g. attitudes, values, and culture, and also the environment of humans, organizations and regulations, and the community (Bostrom and Heinen, 1977a and 1977b). The technical components can be described as containing tools and techniques that humans use while doing their assignments (Alter, 2002b), for example mobile phones and GPS tracking. Processes and tasks may also be included in the technical components (Bostrom and Heinen, 1977a). This could be how the technology is developed, such as in increments and by divisibility (Linton, 2002). In short, the technical component does not include the human (social components), but is related to the human and his environment.

With a sociotechnical systems approach, it is equally essential to include social components and technical components in the study of ICT - e.g. how they interact and influence the development of ICT and how successful the ICT system is at supporting and improving the work assignment(s) (Trist, 1980; Markus, 1983; Bostrom and Heinen, 1977a and 1977b). The thesis's application domain, crisis and emergency, is no exception - here, as argued in sociotechnical literature overall, it is also important to include the social components such as regulations and norms (Nævestad, 2009).

In order to achieve an effective ICT system, it is necessary to include both the social components and the technical components (Bostrom and Heinen, 
1977a). Only studying the technical components of ICT is not enough to capture its complexity and its dynamic dimensions (Markus, 1983; Alter, 2003). Increased use of ICT does not mean a sharper focus on the technical components (Alter, 2003). Technological change creates new forms of organizations where a sociotechnical systems approach offers answers, while users' needs are still important in future ICT (Mumford, 2000).

Connected to the importance of including both technical and social components, the sociotechnical literature emphasizes the inclusion of others in addition to professional system designers in the ICT development process. "Others" can be "all people who influence" (Bostrom and Heinen, 1977a:19), for instance engaging users through end-user participation and a decentralized system design (Markus, 1983: Mumford, 1995; Bostrom and Heinen, 1977a). Users need to be involved and have real control of the design of the ICT, otherwise it can lead to system failure (Markus, 1983; Iivari, 2010).

In the thesis, with a sociotechnical systems approach to crisis and emergency response, an ICT response system consists of the organizations, personnel, information, technology, methods, equipment, training, etcetera involved in carrying out the assignments in a crisis or an emergency response situation. In other words, both the technical components and the social components are considered in this thesis when studying ICT systems and the ICT development process. Thus, a broad definition of an ICT system is used in the thesis. Here, the technology includes tools (e.g. devices such as mobile phones) and techniques (e.g. applications and functionalities) (Alter, 2002b), and is included in the technical components. In addition to the technology itself, technical components also include tasks and structures connected to the technology (Bostrom and Heinen, 1977a).

One criticism that is sometimes made in the literature is that it can be difficult to separate the social and technical components (Alter, 2003; Lin and Cornford, 2000). This is also shown in the components studied in the thesis, some of which are easier to divide into a social or technical component, while others may be classified as either or be a mixture. (The social and technical components which are the focus of this thesis are described in section 3.5.) Therefore, in the thesis the emphasis is on the importance of including both social and technical components, while less attention is given to how much a specific component is technical or/and social.

To sum up, the sociotechnical systems approach in the thesis is used as a background for the thesis's theoretical foundation and to support the analysis of the ICT response systems. 


\subsubsection{End-user involvement}

When using the sociotechnical systems approach as a basis on which to study ICT and ICT development processes, end-user involvement is commonly underlined (Mumford, 1995). If the end-users, together with the technology, are influential in creating and shaping the ICT artifact, then the users are also important to consider in the ICT development process. Without end-user involvement, it could be difficult to develop an adapted ICT system, and this could lead to low recognition from the end-users and difficulties in the implementation of the system (e.g. Gulliksen et al., 2003; van den Besselaar, 1998; Vines et al., 2012). Through end-user involvement in the ICT development process, both the technical and social components of the ICT system can be based on the end-users' actual needs, and can therefore provide more effective support when responding to a crisis or an emergency (Moynihan, 2009).

There are different perspectives and methods for addressing end-user involvement. Three of the most common are participatory design (PD), usercentered design (UCD), and user innovation (UI), which have different focuses while also featuring similarities. PD has an ideological (democratic and social) dimension as well as a practical dimension (Bjerknes et al., 1987; Tollmar, 2001; Iversen et al., 2010). As the name implies, PD focuses on the design process when developing ICT systems. The goal is to create an ICT system that is adapted not only for the assignments of the end-users, but also for those of other stakeholders (Mumford, 1981; Kensing and Blomberg, 1998). UCD also focuses on user design in the ICT development process, with a specific focus on the user interface (Norman and Draper, 1986; Marti and Bannon, 2009). This process also involves the end-users, but not as actively as in PD. In UCD, the stakeholders and the end-users usually have a more peripheral role and provide information about their needs to the developers of the ICT system (Gulliksen et al., 2003; Gould and Lewis, 1985; Karlsson et al., 2012). UI also emphasizes the design of the ICT, but here with an innovative focus on ICT functionalities for a defined problem and context (Karlsson et al., 2012). UI pays attention only to specific key users who are also considered to represent other users' needs (von Hippel, 1986).

In this thesis, end-user involvement is seen as essential and is used as an approach in the ICT development process. Here, the concept of end-user involvement is used in line with this thesis's emphasis on the end-users and the active involvement of the end-users in the ICT development process in general, rather than explicitly leaning on one of the approaches above. Thus, end-user involvement is included in the theoretical foundation of ICTenabled network collaboration, and is further described in the following sections. 


\subsection{Network collaboration - one solution to meet public service challenges}

In parallel with digitalization and ICT development, public challenges are becoming increasingly complex and extensive, reflecting current societal challenges such as climate change, financial crises, pandemics, ageing populations, migrations, war, and terrorism (Haddow and Bullock, 2013). This coincides with the inter-dependency and high interconnectedness of the whole world. For instance, a crisis in one city or province can quickly and easily spread to other countries and continents. Public services also face funding cuts and shortages of human and information resources, while at the same time demands for increased efficiency and service quality have risen. Thus, it is difficult for public services to maintain adequate service levels (Wankhade and Murphy, 2012).

The challenges of modern society create and demand new models of policymaking and structures for steering society (Bekkers and Thaens, 2005). Through network collaboration, societal challenges and complex interdependencies can be managed and effective solutions can be reached. The collaboration form is sometimes seen as a necessary process in order to adjust to changing conditions and achieve innovative and flexible public service solutions (Alter and Hage, 1993). Extensive collaborative efforts are thus continuously developed between actors to deliver public services, including different public actors as well as private actors and volunteers (e.g. Agranoff, 2007; O'Leary and Bingham, 2009; Wankhade and Murphy, 2012). The actors involved can play several roles and engage in different collaborations aimed at creating redundancy in public systems (Goldsmith and Eggers, 2004; Agranoff, 2007). In network collaborations, the actors exchange resources informally, and social interactions are essential here. The different actors are united by the common interest of providing more effective and flexible public services (Kickert et al., 1997; Börzel, 1998; Carlsson, 2000).

Network collaborations are often described using network concepts such as collective action (e.g. Carlsson, 2000), policy networks (e.g. Carlsson, 2000; Rhodes and Marsh, 1992), collaborative networks (e.g. Agranoff, 2007), and network governance (e.g. Loukis et al., 2016). In other words, various perspectives from different research disciplines are applied to similar societal network collaboration trends. They share the same goal: to describe and explain the intricate interactions between various actors when providing public services, with the government being just one of the actors (e.g. Rhodes and Marsh, 1992; Agranoff, 2007). The various perspectives have several similarities and often overlap. One example is the suggestion 
that policy networks gain support from collective action to better explain policy outcomes (Carlsson, 2000).

This thesis uses the concept of network collaboration. This is a broad concept and was chosen intentionally to reflect the various types of network concepts displayed in public services. Thus, in this thesis it is not important which network concept is used - the important thing is that network collaborations take place as a solution to public service transformation.

\subsubsection{The sociotechnical systems approach to ICT in network collaborations}

Taking a sociotechnical systems approach on network collaboration, both the social components as well as technical components have to be implemented. Poole and DeSanctis (1990) describe this in terms of the influence of technology and the importance of the social context in which the technology is used. The technology should not be seen as a separate actor, and it should be studied in the context of the interactions between the technology, social relations, and individuals. The collaboration form is sometimes seen as a necessary process in order to adjust to changing conditions and to be able to achieve innovative and flexible solutions in the public sector (Alter and Hage, 1993). ICT becomes a necessity in the networks, whereby ICT "helps connect various actors to the network, build relationships between them, [...] and manage[s] and sustain[s] the networks themselves" (Janowski et al., 2012:52).

However, one thing that the various network collaborations have in common is that they seldom explicitly emphasize the ICT and instead emphasize politics, policies, values, economics, welfare aspects, etc. (Carlsson, 2000; Agranoff, 2007; Loukis et al., 2016). Nevertheless, ICT is seen as important for network collaboration and for networks in general. For instance, Janowski et al. (2012:52) refer to "Government Information Networks", where a common denominator is the necessity of ICT in the networks. ICT is regarded as essential for realizing the increased collaboration between various actors (Bannister and Connolly, 2011), and it plays an important role in handling the information and knowledge created in networks where channels are less formal or regular than traditional channels (Margetts, 2005). ICT thus fosters and stimulates new forms of collaborations, and can therefore be seen as a driving force for several of the network collaborations. Margetts (2005) highlights how ICT is an integral part of public organizations and not something external. In other words, technological innovations also drive public service collaborations to a high degree. In the same way, network collaborations can enhance the development of ICT. Agranoff (2007) asserts that network collaboration 
eases the development of new ideas regarding technology. If the current ICT does not support the network's needs, the network may develop new ICT systems (Agranoff, 2007).

In short, ICT is vital for network collaboration and it is therefore necessary to explore the link between them further. In this thesis, "ICTenabled network collaboration" is used as the concept for network collaborations where ICT is crucial for the network collaboration to function.

\subsection{Co-production - one type of network collaboration}

Building on network collaboration, the concept of co-production can be used to further describe the specific network collaboration between governments and citizen volunteers in public services (Ostrom, 1996; Alford and O'Flynn, 2012; Whitaker, 1980; Brandsen et al., 2018).

In network collaboration, the emphasis is usually on collaboration between formal organizations. Citizens may be included in volunteer organizations' network collaboration with governments, while at the same time citizens increasingly engage in ways other than through formal volunteer organizations (Brandsen et al., 2018). This phenomenon is described in this thesis using the concept of co-production in relation to Enhanced Neighbors' project, the second case study. Previous literature describes the phenomenon in various terms. Bekkers and Homburg (2007) partly address this diversity by speaking about "self-government", i.e. how network collaborations imply a shift toward self-organization and selfregulation. By studying strategic policy documents in four European countries concerning the modernization agenda of public administration, the authors conclude that there is, at least rhetorically, an apparent societal shift toward self-government (Bekkers and Homburg, 2007). This is described as a new culture within public services, where citizens act as coproducers of public services (Linders, 2012; Ostrom, 1996; Alford and O'Flynn, 2012). Again, the concept of co-production is used in this thesis to describe these network collaborations between government actors and citizens.

\subsubsection{Definition of co-production}

Co-production thus occurs when individuals or groups of individuals act outside their regular production roles (Alford, 2014). In 1996, Ostrom (1996) re-defined the original definition and claimed that co-production is "the process through which inputs used to produce a good or service are 
contributed by individuals who are not 'in' the same organization" (Ostrom, 1996:1073). This is usually interpreted as collaboration between government bodies and citizen volunteers (e.g. Whitaker, 1980; Bekkers and Homburg, 2007; Linders, 2012). The citizens who co-produce do not have to belong to an organization, and they can be individuals who are loosely connected by wanting to help with public services and/or their neighborhood, for example by improving safety and response in their village. When citizens are involved in the delivery of a public service, they take on certain tasks from the authorities for themselves and/or for their cocitizens (Bekkers and Homburg, 2007; Linders, 2012). The citizen become one part of the service delivery rather than, as previously in public service, only being conferred with (Ostrom, 1996; Alford and O'Flynn, 2012). Based on the co-production literature, network collaboration between government and citizen volunteers is referred to in this thesis as co-production of public service delivery.

Because increased attention has been paid to co-production, and because it is multidisciplinary in character, several other concepts are used to further define co-production and/or add other dimensions. Two examples are the concepts of co-creation and co-design (Jukić et al., 2019; Brandsen et al., 2018; Toots et al., 2017; Sanders and Stappers, 2008). These concepts have different meanings and interpretations, which are very much dependent on the research discipline, for instance IS and public administration (e.g. Brandsen et al., 2018; Toots et al., 2017). When co-creation is used in disciplines other than IS, i.e. public administration, it is mostly used to describe when citizens are involved in planning and decision-making for public services. The level of analysis is therefore often at a strategic level (e.g. Brandsen and Honingh, 2018). The concept of co-design can also be interpreted as creating and shaping the public service (Brandsen et al., 2018; Pestoff et al., 2012). In the IS literature, however, co-creation rather emphasizes the involvement of end-users when creating the technology and technical infrastructure needed for co-production (Toots et al., 2017). The other concept connected with co-production, co-design, also emphasizes the design of the technology - at least within IS research (Sanders and Stappers, 2008).

In this thesis, co-production is used as the concept that includes the codesign and co-creation of the technology used in co-production. Thus, as illustrated in Figure 3.1 below, in this thesis the strategic planning and decisions in connection with the public service are excluded from the definition of co-production and the sub-concepts of co-creation and codesign. The definition therefore follows how the concept is usually understood within the IS discipline. 


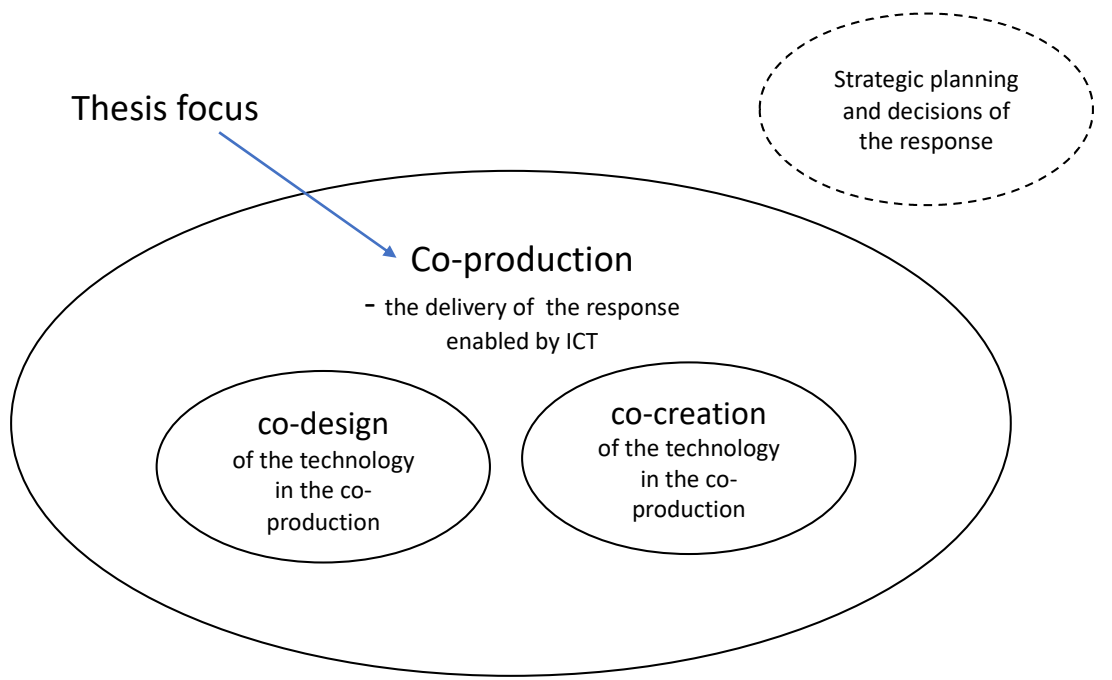

Figure 3.1. How co-production is defined in the thesis in relation to other similar concepts.

\subsubsection{ICT-enabled co-production in transforming public service}

With digitalization, the possibilities for co-production have increased (Linders, 2012). The actors interact with the technology used in an ongoing process within co-production, which has been described above by the sociotechnical systems approach (Alter, 2003 and 2002b; Bostrom and Heinen, 1977a), and the technology is often a pre-requisite for the coproduction in the first place. Thus, ICT provides citizens with new possibilities to receive and use public services, and ICT can create innovations to solve some of the challenges that governments face. Citizens can also influence the ICT to meet their specific needs (Janowski et al., 2012; Margetts, 2005).

Previous studies underline that the emerging ICT-enabled co-production needs to be further studied (Lember et al., 2019; Paletti, 2016). Other research disciplines, for instance public administration and public management, also apply co-production. In the past they seldom focused on ICT, but with the general digitalization of public services, disciplines other than IS have also put more emphasis on ICT within co-production. This can be seen, for example, in public administration when comparing earlier 
research (e.g. Pestoff et al., 2012) with later research (e.g. Brandsen et al., 2018).

The literature within ICT-enabled co-production comprises numerous technologies - including the Internet of Things, blockchains, crowdsourcing, algorithm-based decision-making models, 24/7 data access, and platforms/applications - as well as different data sources (e.g. social media and geodata) and/or open and big data (e.g. Janssen and van den Hoven, 2015; Toots et al., 2017; Whicher and Crick, 2019, Gascó, 2017; Steen et al., 2018; Meijer, 2012; Linders, 2012). One of the most common technologies today is smartphone apps. These are easily accessible, and allow citizens to be online to receive information and take actions. There are also several studies in which smartphone apps have been used for coproduction in crisis and emergency responses (e.g. Havlik et al., 2016; de Lanerolle et al., 2010; Meissen et al., 2017; Schmidt et al., 2018; Schönböck et al., 2016; Paletti, 2016, Ringh et al., 2011).

All these technologies can change, substitute, or transform the traditional ways that public services are delivered to citizens. The technology changes traditional public service delivery by improving information management, information flows, and the exchange of information. The technology also transforms public services by enabling new ways of delivery, e.g. through mobile apps (Lember, 2018). This thesis studies how ICT-enabled coproduction is transforming the traditional ways public services are delivered.

\subsubsection{Various roles and degrees of involvement for citizens in co-production}

The role of the citizen and the degree of the citizen's involvement in the actual delivery of the public service vary in different types of co-production. Thus, it is important to clarify the role and the involvement of the citizen in co-production when studying and defining the type of co-production taking place.

In some types of co-production, the citizen might be not involved in the delivery of the public service and might not be the end-user of the ICT system. The citizen is then only contributing to separate parts, such as the design of the technology (Lember, 2018). By contrast, in other coproductions the citizen might be involved in the delivery of the public service and be the end-user of the corresponding ICT system. Here, the citizen participates actively in delivering and designing the services received as a citizen - for instance, in emergency CPR (Ringh et al. 2011). This type of coproduction, which features a high degree of citizen participation and requires collective action, can be referred to as "heavy" co-production, 
according to Pestoff (2012). The emphasis is on the citizen's delivery of public services as a complement and in addition to professionals (van Eijk and Gasco, 2018). In previous research, several studies consider "light" coproduction, where the citizen is passive or only participates in limited parts of the ICT-enabled co-production (e.g. development and testing), participating on an individual basis rather than in the actual service delivery (Nabatchi et al., 2017; Brandsen et al., 2018).

To sum up, in this thesis the citizen's role in co-production is in line with Ostrom's (1996) view. This means that the citizen is closely involved in service delivery and becomes a partner and provider of the service, not just a consumer. Through this role in co-production, the citizen is also an enduser of the ICT system in the co-production.

\subsubsection{Criticism of co-production}

The criticism directed to co-production includes general criticism directed to all different types of network collaborations, but specific criticism is also directed to co-production. One general criticism relates to rising and hidden transaction costs that are not always taken into account, for instance the increased need for information and communication activities, and different opinions between actors leading to delays (Agranoff, 2007; Weber, 1998). Specifically for co-production, there could also be incremental costs for service users and communities, such as sponsorships, donations, and crowdfunding (Loeffler and Bovaird, 2018). Other possible drawbacks of network collaborations in general are poor service quality, inequality of power relations, unclear responsibility, and loss of legitimacy and even democracy (Agranoff, 2007; Weber, 1998). In co-production, these drawbacks are argued to be due to the professionalization of the voluntary engagement (Steen et al., 2018). Moreover, participation possibilities in network collaborations, particularly concerning co-production, are connected to social and cultural capital (Brandsen et al., 2016). Thus, if citizens are well educated and have high income, the degree of inclusion in co-production is higher.

Another criticism is that co-production is seen as the cure for all problems in public services - including budget constraints, aging populations, and the rising expectations of the welfare society - and this is even more true with the accentuated digitalization of society. This criticism is countered by arguing that co-production can be one of the solutions for specific problems where the contextual prerequisites are present, but is not - as with other forms of network collaborations - the universal solution for public service challenges (Pestoff et al., 2012; Brandsen et al., 2018). 


\subsection{Developing ICT-enabled co-production - analytical framework building}

Previous research has emphasized aspects that are deemed important in order to develop ICT-enabled network collaboration, including coproduction. These theory-based aspects will be used here to build an analytical framework for the thesis's analysis.

The same aspects can be applied to developing both inter-municipal network collaboration and co-production. However, some of the aspects might become more complex in co-production, and this is addressed below when describing the aspects.

With support from the sociotechnical systems approach (e.g. Bostrom and Heinen, 1977a and 1977b; Mumford, 1995), both the technical components and the social components are considered in this thesis when studying essential aspects. These aspects are grouped into seven aspects and described below.

End-user involvement concerns all the aspects, and is thus incorporated into all aspects below (rather than being grouped as a specific aspect). Before describing the aspects, however, the previous research which is used for the analytical framework building is described in greater detail.

\subsubsection{Previous research used for the analytical framework}

The previous research used to build the analytical framework emanates from various disciplines and approaches in order to capture the phenomenon. Thus, in order to identify essential aspects for developing ICT-enabled coproduction in this thesis's theoretical foundation, several disciplines and approaches are combined, namely: 1) the IS discipline regarding collaborations (in some literature, this is referred to as "innovations"), 2) end-user involvement, 3) co-production where ICT is studied, and 4) research on general network collaborations from different disciplines. Two frameworks from previous literature are used as a basis for the analytical framework: Carlsson's (2000) and Linton's (2002) frameworks, which will be described in more detail below.

To gain a better understanding of the development of ICT collaboration and specifically its context, ideas from network collaboration can be used. Carlsson (2000) argues that network collaboration, or "policy network" as he calls it, is not yet fully developed and thus cannot completely explain the outcomes and effects of collaborations within a policy area - for instance, the response domain. He believes that a change in focus is needed, whereby networks are regarded as explaining different outcomes instead of just being 
a dependent variable. Carlsson (2000) has suggested that network theory would benefit from the discussion of collective action, with reference to the institutional analysis and development (IAD) framework. Ostrom (1994) has also suggested using this framework for studying community government.

From the IAD framework and collective action theory, Carlsson (2000) has formulated six hypotheses covering different aspects of network collaboration. Four of these are applicable to this thesis, and are therefore elaborated on below, namely problem definition (of the policy problem to be solved), contextual factors (i.e. physical and organizational), the growth and spread of a generalized belief, and co-ordination and control (referred as formal and social control below).

Further, based on an essential research overview of the implementation of digital innovations in sociotechnical contexts, Linton (2002) concludes that there are a number of central aspects for successful implementation of innovations, namely organizational structure (e.g. size and culture), the complexity of the technology, project management, divisibility (dividing the process into smaller segments), and social interactions including technology championing. These aspects, as with Carlsson's (2000) hypothesis above, will be further described and elaborated on with support from additional literature. Therefore, some of the aspects are not specifically structured and named according to how Carlsson (2000) and Linton (2002) describe and group them. Thus, seven aspects based on previous research, which are deemed important when developing ICT-enabled network collaboration including co-production, are described below.

\subsubsection{Problem definition}

In the general network literature, it is claimed that network collaborations emerge and take shape depending on the definition of the policy problem in question, and on whether the actors have a mutual problem definition, for example how the project is defined and how the scope of the collaboration is described and perceived (Kickert et al., 1997; Carlsson, 2000). A "problem" is seen in this thesis as a broad concept, and can contain both needs and challenges. The clearer the problem definition, the easier the framing of the collaboration will be. Within the end-user literature, this means that users will have a clear basis on which to develop the collaboration (Gulliksen et al., 2003). For example, clarifying the purpose and the limits/borders of the collaboration will help to identify the needs of the end-users. 


\subsubsection{Physical and organizational environment}

Network collaborations emerge and are shaped differently in different contexts. Within the network literature, this can be referred to as the physical and organizational environment, such as organizational structure, resources, skills, and geographical aspects. Different local environments display different social and cultural qualities (Carlsson, 2000), and from an IAD framework perspective one could say that local action arenas are always different and are always framed by different resources and constraints. In co-production, the local action arenas - the geographically confined places - become especially important, as this is where the citizens engage, for example in their village (Ostrom, 1994; Carlsson, 2000). This is still the case even if the engagement only takes place online (Dunleavy and Margetts, 2010). It is important to note that, even if the local action arena encourages the citizen to co-produce, it can also constrain the collaboration (Ostrom, 1994; Carlsson, 2000). Thus, central questions within this aspect include which environmental factors are present in the collaboration being studied and their influence on how the collaboration emerges and takes shape (Carlsson, 2000).

Organizational environment is defined in the network literature in terms of the organization's characteristics, size, structure, and culture, as well as the interplay of actors and structures in the choices of ICTs and their implementation (Linton, 2002). The impacts of the organizational culture and traditions are also emphasized in the IS literature and the end-user literature (e.g. Axelsson and Melin, 2014; Gulliksen et al., 2003). Smaller organizations usually have fewer resources, which restricts the choice of (possible) ICT solutions, while larger organizations have more resources and can demand a higher technology specialization. The physical environment also has to be taken into account in the ICT development process (Gulliksen et al., 2003), for instance if the end-users are citizen volunteers (Pilemalm, 2018a).

\subsubsection{Generalized belief and common ground}

According to the network literature, actors in a collaboration need a common ground, a mutual understanding of what is perceived as "good, bad, acceptable, possible, desirable, etc." (Carlsson, 2000:515) if they are to prioritize their actions and develop a solution to a problem. This aspect includes social interactions and interplay, cultural qualities such as demographics, and generalized belief systems (Börzel, 1998; Linton, 2002). The actors usually become dependent on each other and exchange resources (Rhodes, 1997). 
In the end-user literature, it is claimed that if the users are a heterogenous group, for instance citizens as users of a public service, this may pose challenges compared to a homogenous group (Holgersson and Karlsson, 2014). Motivated users are also important, as is a thorough analysis of which roles, competences, values, and norms the users have (Svejvig and Blegind Jensen, 2013).

\subsubsection{Formal and social control}

The network literature claims that network collaborations are subject to both social control, emerging from the interaction processes between the actors, and formal control, which can stem from regulations, agreements, and laws. Here, this involves investigating which kinds of control aspects affect the actors' engagement and whether these can influence the development of the collaboration (Carlsson, 2000).

In the co-production literature, it is argued that the ICT is entangled in the collaboration and can thus lead to control of the collaboration. In other words, the technology can frame the collaboration and thereby shape the development of the collaboration. Rapid technology development and new innovations might diminish and hinder actors' engagement (Lember, 2018). Also, ICT is an enabler, and might thus also steer actors' engagement regarding what can be collaborated on and how (Kitchin, 2016; Ashton et al., 2017).

\subsubsection{Complexity of technology and technology knowledge}

In the network literature, it is argued that the more complex a technology (or innovation) is, the more complicated the implementation process will be (Linton, 2002). Complexity is connected to technology knowledge within the organization and among the actors, as well as the knowledge from earlier similar experiences of innovations and ICT. However, the knowledge within the organization/within the actors and earlier experiences are linked together and also influence the knowledge. In Linton's (2002) theoretical overview, this is labeled "absorptive capacity" and means the extent to which an organization or an actor is able to absorb technological knowledge.

The question of who should have the opportunity to be the developer of the ICT system is especially discussed in the co-production literature (e.g. Meijer, 2012; Lember, 2018). Various perspectives and approaches in the IS literature and the end-user literature also highlight the importance of enduser involvement (Gulliksen et al., 2003; van den Besselaar, 1998; Vines et al., 2012). Several co-production studies conclude that involving end-users 
in ICT development has been mostly non-existent in the past decade (e.g. Kotamraju and van der Geest, 2013; van Velsen et al., 2009). Others in the co-production literature have reported on attempts to include users in ICT projects, but describe related challenges and a lack of success (e.g. Lember et al., 2019; Meijer, 2012).

Within the IS literature, it has been shown that volunteer citizens/endusers in particular are generally willing to participate, but their ability to do so is limited, often due to limited resources (Holgersson and Karlsson, 2014). Townsend (2013) argues that smartphone apps for co-production are best developed by end-users - the citizens - because they have knowledge of the technologies at hand and formal developers (governments and companies) have little understanding of creating adaptable ICT system for this kind of collaboration. Here, the users' perceptions are central within the end-user literature, involving their actual requirements, and not only what is available or possible from a technical perspective (Ferguson et al., 2016).

\subsubsection{Technology divisibility (incremental project management)}

Divisibility, as Linton (2002) labels it, is closely related to technology and builds on an incremental approach, dividing the process into small segments that can be chosen and implemented as such, which is also argued for in the IS literature (Svejvig and Blegind Jensen, 2013). Further, within the IS literature, limitations are also argued to be important regarding which work assignments the ICT system should support, and simple assignments as early as possible will ease the introduction of the new ICT system (Svejvig and Blegind Jensen, 2013). The divisibility depends on the form of the technology, the organization, and the policy ambitions (Linton, 2002).

Thus, how the collaboration is managed and led is considered a determining factor for its success. Linton (2002) connects this to project leadership, and argues that it is about both the project's organization and the capacity of the participating actors to lead the projects. Here, Linton (2002) presupposes that the actors involved all belong to the same organization.

Within the IS literature and the end-user literature, other aspects are also underlined as distributers of resources, for instance assigned resources for user design assessments and evaluations, clear and communicated project goals, user involvement, and defined project boundaries (Gulliksen et al., 2003; Bratteteig and Wagner, 2016). The IS literature argues that involving the end-users in the project is challenging. It is time-consuming both for the project as a whole and for the end-users. Therefore, it is argued that enduser involvement should focus on those activities with the greatest effect 
rather than embracing all end-users (Pilemalm et al., 2007; Bratteteig and Wagner, 2016). However, other challenges are also described in the end-user literature. These difficulties include planning and timing the involvement of the end-users in the development process. In addition, the motivation of the end-users to participate can be low, not least due to a lack of time (Wilson et al., 1997; Gulliksen and Eriksson, 2006; Holgersson and Karlsson, 2014). Moreover, end-user studies show a shortage of methods that can be applied in practice (Pekkola et al., 2006; Pilemalm, 2018a).

\subsubsection{Technology championing (key actor)}

Technology champions are the individuals or groups of individuals who act as system builders or ICT entrepreneurs (Linton, 2002). The technology champion within the process manages social interactions and reduces resistance to the changes. Communication and learning are outcomes of a functional social interaction in this type of process (Linton, 2002).

Besides the network literature, the end-user literature stresses that a technology champion (although different concepts are used) is important, and is perceived as the individual or group with user design competence or the promoter of user design (Gulliksen et al., 2003). Another similar concept mentioned in the IS literature is image-builders (Melin and Axelsson, 2014).

Government bodies can be seen as technology champions in the coproduction literature when they provide arenas for collectively developing adapted technologies. These arenas can be innovation labs, digital workshops, or hackathons (Lember, 2018; Linders, 2012). However, these initiatives usually demand technology knowledge from the participants/users, and therefore the target group may not be representative or capture "all" end-users' needs - only the ones with technology knowledge and an interest in the technology (Dodge, 2012). This can be connected to the "absorptive capacity" mentioned above (Linton, 2002).

\subsubsection{Summary of the analytical framework for essential aspects when developing ICT-enabled co-production}

From previous research, it is possible to identify several aspects that are essential when developing ICT-enabled co-production. These aspects can be structured and labeled, especially with support from Carlsson (2000) and Linton (2002), using seven aspects: problem definition, physical and organizational environment, generalized belief and common ground, formal and social control, complexity of technology and technology knowledge, technology divisibility (i.e. incremental project management), and 
technology championing (key actor). Although the framework is divided in separate aspects, the aspects are interlinked and are only a simplification of the reality, as are all frameworks and theories.

End-user involvement is underscored in the literature regarding ICT development, and the development of ICT in co-production is no exception. Thus, the end-user involvement approach is emphasized in the framework by incorporating it into all seven aspects of the analytical framework. In this way, end-user involvement is highlighted in the ICT development process, which is underlined in the previous literature (Gulliksen et al., 2003; Markus, 1983; Iivari, 2010; Bjögvinsson et al., 2012). Needs and functions are the main focus in this thesis when studying end-user involvement. However, other surrounding needs may also be important for coproduction, for example, "physical materials" (e.g. fire extinguishers and heart defibrillators), as well as education and training.

The essential aspects of the theoretical foundation for developing ICTenabled co-production are summarized in Table 3.1 below, with references from previous research from which the aspects are derived.

Table 3.1. Theoretical foundation of aspects that are important for developing ICT-enabled co-production from previous research.

\begin{tabular}{|l|l|}
\hline Aspects in the analytical framework & References from previous research \\
\hline Problem definition & $\begin{array}{l}\text { Carlsson (2000); Kickert et al. (1997); Gulliksen } \\
\text { et al. (2003) }\end{array}$ \\
\hline Physical and organizational environment & $\begin{array}{l}\text { Carlsson (2000); Linton (2002); Ostrom (1994); } \\
\text { Dunleavy and Margetts (2010); Gulliksen et al. } \\
\text { (2003); Axelsson and Melin (2014); Pilemalm } \\
\text { (2018a) }\end{array}$ \\
\hline Generalized belief/common ground & $\begin{array}{l}\text { Carlsson (2000); Börzel (1998); Rhodes (1997); } \\
\text { Linton (2002); Holgersson and Karlsson, (2014); } \\
\text { Svejvig and Blegind Jensen (2013) }\end{array}$ \\
\hline Formal and social control & $\begin{array}{l}\text { Carlsson (2000); Lember (2018); Kitchin, (2016); } \\
\text { Ashton et al. (2017) }\end{array}$ \\
\hline $\begin{array}{l}\text { Complexity of technology and } \\
\text { technology knowledge }\end{array}$ & $\begin{array}{l}\text { Linton (2002); Meijer (2012); Lember (2018); } \\
\text { Lember et al. (2019); Gulliksen et al. (2003); van } \\
\text { den Besselaar (1998); Vines et al. (2012); } \\
\text { Kotamraju and van der Geest (2013); van Velsen } \\
\text { et al. (2009); Ferguson et al. (2016); Holgersson } \\
\text { and Karlsson (2014); Townsend (2013) }\end{array}$ \\
\hline
\end{tabular}




\begin{tabular}{|l|l|}
\hline $\begin{array}{l}\text { Technology divisibility (incremental } \\
\text { project management) }\end{array}$ & $\begin{array}{l}\text { Linton (2002); Svejvig and Blegind Jensen } \\
\text { (2013); Gulliksen et al. (2003); Pilemalm et al. } \\
\text { (2007); Wilson et al. (1997); Gulliksen and } \\
\text { Eriksson (2006); Holgersson and Karlsson (2014); } \\
\text { Pekkola et al. (2006); Pilemalm (2018a); } \\
\text { Bratteteig and Wagner (2016) }\end{array}$ \\
\hline Technology championing (key actor) & $\begin{array}{l}\text { Linton (2002); Gulliksen et al. (2003); Melin and } \\
\text { Axelsson (2014); Lember (2018); Linders (2012); } \\
\text { Dodge (2012) }\end{array}$ \\
& \\
\hline
\end{tabular}

In Figure 3.2 below, the seven aspects which all include end-user involvement are illustrated. Together, they constitute the ICT system, or in Alter's words the "work system" (2002a; 2002b). For information about how the analytical framework is used methodologically, see chapter 2.

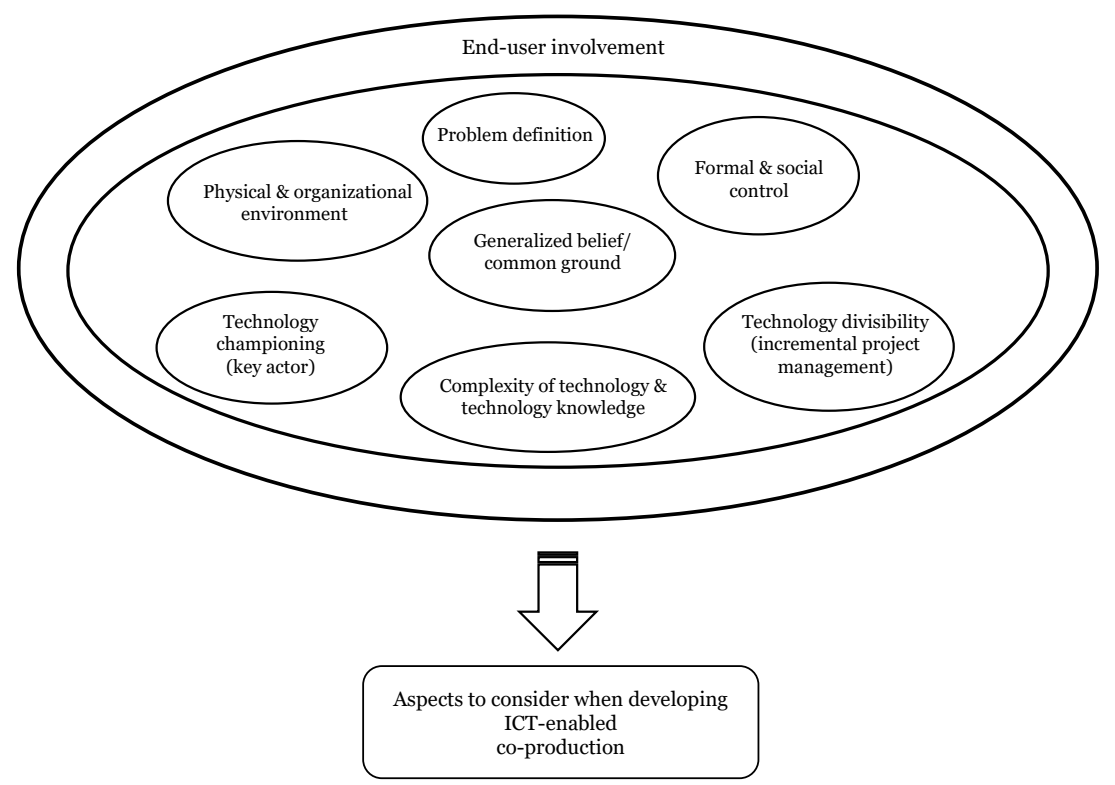

Figure 3.2. Aspects to consider when developing ICT-enabled co-production. 


\subsection{Application domain: crisis and emergency response}

This section describes the thesis's application domain of crisis and emergency response, by elaborating on the concepts of crisis and emergencies, and by defining citizen volunteers in the domain, network collaboration (especially co-production) within the application domain, and elaborate on Sweden as a setting.

\subsubsection{The interlinked concepts of crises and emergencies}

The application domain consists of two areas: emergency response and crisis response. The concept of "response" is one phase in crisis and emergency management. Besides response, emergency and crisis management also comprises other phases linked to the management of an emergency or a crisis. The phases of crisis and emergency management can be divided into a) preparedness - planning before an alert, b) mitigation - preventive actions, c) response - the alert phase, including the initial actions in a crisis or emergency, and d) recovery - repair of damage (Haddow et al., 2013; Bram and Vestergren, 2012; Salasznyk et al., 2006).

The two concepts of crises and emergencies are related to each other, and the concepts are not used consistently in practice or in the literature. Within emergency management, the concept of "response" is frequently used and is a well-known concept (Bram and Vestergren, 2012; Salasznyk et al., 2006). The broader concept of "crisis management" is also used in the literature, even if the focus may be on crisis response (e.g. several articles in the Journal of Contingencies and Crisis Management focus on crisis response, even though the description of the journal does not mention the concept of response (JCCM, 2020). Moreover, research journals may have one of the concepts ("crisis" or "emergency") in their titles, but they usually include articles related to both concepts, e.g. the Journal of Contingencies and Crisis Management and the International Journal of Emergency Services. Thus, different uses of the concepts are also a part of the transformation of the application domain.

Another example of interconnectedness between the concepts, on a practical level, is that a crisis may start with an alert to the emergency services - for instance, forest fires or a terror attack. The shift whereby an "emergency" becomes a "crisis" is not always easy to grasp or define, and this shows that the concepts are interlinked (Bram and Vestergren, 2012). Thus, there is a need to study the concepts of crisis and emergency together. Only studying one of the concepts risks missing important findings, which 
might lead to unnecessary silos with parallel solutions. For instance, it would be beneficial to use the same ICT and citizen volunteers no matter what the type of response (Chen et al., 2007; Bharosa et al., 2011).

To summarize, in this thesis the concept of response is used as an umbrella term for the initial phase of managing an emergency or a crisis. Response can be described as the action immediately following the crisis or emergency, where the priority is to save lives, assist the injured, and mitigate the consequences for people, infrastructure, property, the environment, and society (Salasznyk et al., 2006; Bram and Vestergren, 2012).

\subsubsection{Definition of citizen volunteers within crisis and emergency response}

Awareness of the role of citizens as an important part of crisis and emergency response has increased (Johansson et al., 2018; Díaz et al., 2016). There are several different kinds of citizen volunteers in crisis and emergency response, and various definitions (e.g. Whittaker et al., 2015; St. Denis and Huges, 2018; Berglund et al., 2018; Ringh et al., 2011). The definition applied in this thesis is:

“... volunteerism refers to the activities of people who work outside of formal emergency and disaster management arrangements to help others who are at risk or are affected by emergencies and disasters." (Whittaker et al., 2015:361)

Whittaker et al. (2015) thus defines volunteers by describing them as people who do not belong to formal emergency and crisis management. In other words, people working in formal response organizations, i.e. municipalities, are not volunteers, but are people who work informally to help others. However, this definition is broad, and it does not exclude other forms of volunteers who do not act in their roles as citizens. Whittaker (2015) clarifies the concept of volunteers further by explaining how volunteers can participate in a crisis or an emergency:

“... volunteers may participate as individuals or as part of a group, on a short or longer-term basis, regularly or irregularly, and in situ or ex situ. Their participation may be spontaneous and unplanned, or deliberate and carefully planned." (Whittaker et al., 2015:361362)

This kind of perspective on volunteers, who are informal but collaborate with professionals, is usually applied within the crisis and emergency literature. To define it further, the concept of "emergent volunteerism" can 
be used, which defines informal volunteers who fill a need that is not met by other actors, and in particular may arrive as first responders at the incident site and conduct the first initial actions (Dynes, 1970; Whittaker et al., 2015; Johansson et al., 2018).

There are several examples of citizen volunteers in crisis and emergency response. Whittaker et al. (2015), for instance, describe "spontaneous organization volunteers" who, for example, "carry out disaster-related tasks within a loose, informal network" (Whittaker et al., 2015:361). Díaz et al. (2016) argue that in order to improve incident response, citizens can act as agents to whom professional emergency managers can delegate actions and specific activities with support from mobile technology; for example, they can receive directions for performing an evacuation process. St. Denis and Huges (2018) reported an online application whereby trusted volunteers in the affected community help with the local community response. In short, it is possible to distinguish some keywords used to describe citizen volunteers in the literature. Citizen volunteers are defined as informal, spontaneous, or preplanned, performing tasks as directed/instructed by the professional response - online and/or on site. The engagement of citizen volunteers also requires some kind of ICT.

In this thesis, the definition of citizen volunteers follows the definition prevalent in the literature. However, the type of citizen volunteers studied in this thesis can be further clarified. Here, citizen volunteers are defined as citizens who act in their role as citizens. Citizen volunteers have no obligations, their participation is voluntary, and they do not formally belong to any public or voluntary organization. Their collaboration is preplanned and on-site, as well as online, where citizen volunteers use ICT in their response. There are no demands for specific competence or skills for citizens in order to engage, but they may receive basic education and training as first responders from the professional responders.

\subsubsection{ICT-enabled network collaborations including co-production in crisis and emergency response}

In Sweden and internationally, there are currently efforts to compensate for the decreasing number of professional response resources available from governments and to create redundancy in the response domain (e.g. Pilemalm, 2020; Whittaker et al., 2015; St. Denis and Hughes, 2018). There are various forms of network collaborations taking place within the response domain. These include "traditional" network collaborations where professionals employed by local governments collaborate together in rescue services associations or share staff resources, for example two small 
municipalities sharing one fulltime crisis official. Another example is looser network collaborations where local governments come together depending on their needs. Besides the traditional network collaborations, there are emerging collaborations in crisis and emergency response with other actors, especially citizen volunteers. One example of this type of network collaboration, referred to in this thesis as co-production, is mentioned by Alford (2014), where the Metropolitan Fire and Emergency Services Board of Melbourne, Australia co-produces for the "protection of life, property and the environment" (Alford, 2014:302). The emergency services expand the role of owners and occupants who perform different preventive tasks, for instance installing smoke alarms, removing fire hazards, practicing fire drills, and ensuring that buildings are fire resistant (Alford, 2014). Largescale crises also show the need for citizen volunteers, for instance in the most extensive joint fire emergency response in the $\mathrm{EU}$ - the 2018 wild forest fires in Sweden (Johansson et al., 2018; Murphy, 2020), but there are also other international examples such as the global COVID-19 pandemic which started in 2019/2020 (Cheng et al., 2020). Thus, there are many national and international examples of co-production, as well as a need for increased co-production.

In all of these responses, ICT-enabled collaborations are vital. ICT is increasingly highlighted, for instance using online platforms and smartphone apps (e.g. Havlik et al., 2016; de Lanerolle et al., 2010; Meissen et al., 2017; Schmidt et al., 2018; Schönböck et al., 2016; Paletti, 2016). However, most of these international studies tend to focus on issues such as online volunteers, large-scale crisis management, and crowdsourcing. Thus, long-term and preplanned engagement with citizen volunteers who are both online and onsite - as studied in this thesis - is not explored to the same degree.

\subsubsection{Swedish crisis and emergency response as the setting}

At the local level, the municipalities in Sweden are responsible for organizing fire and rescue services (FRS) and crisis management services (the latter normally belonging organizationally to the FRS or a municipal administrative unit). Other actors are also involved in crisis and emergency response, including both private and public actors from other public organizational levels, such as the police, the national public safety answering point (PSAP - in Sweden, this is SOS Alarm, which has an assignment from the government and public services), and the ambulance services (consisting mostly of public actors, but also some private actors). Additionally, the Swedish Civil Contingencies Agency (MSB) at the national level and the 
County Administration Boards at the regional level have responsibilities for Swedish crisis and emergency response (SFS 2003:778; SFS 2017:870; SFS 2015:1052).

Swedish crisis and emergency response policies aim to develop an overall system that helps actors to prepare to deal with both crises and emergencies. The Swedish multi-level societal structure is characterized by strong local autonomy for the municipalities, as stated in Swedish legislation (SFS 1991:900). Local autonomy was strengthened in the 1990s when the national government allowed for more governance-oriented network structures and co-operative structures (Sørensen and Torfing, 2007). This general foundation of network structure is also prevalent in Swedish crisis and emergency response (Bram and Vestergren, 2012).

Within crisis response, the need for network collaboration was especially highlighted after two crises in Sweden where preparedness was shown to be lacking, namely the tsunami in Southeast Asia in 2004, in which many Swedes died, and storm Gudrun in 2005, which had devastating consequences (the Swedish Association of Local Authorities and Regions, 2005; SEMA, 2005a and 2005b; SOU 2005:6). One of the solutions for a more efficient response was to increase collaboration between the actors involved, for instance inter-municipality collaboration and public-private collaboration (SOU 2005:104). The Swedish crisis management legislation for municipalities (SFS 2006:544) underlines the need for collaboration between actors in order to attain an effective and rapid response. Local governments and municipalities receive support from national agency in their pre-planned and formalized collaboration with citizen volunteers, called voluntary resource groups [frivilliga resursgrupper, FRG] (MSB, 2020a). Volunteers in FRG receive training, for example in cardiopulmonary resuscitation (CPR) and preventive fire protection. FRG belongs organizational to some of the voluntary defense organizations [frivilliga försvarsorganisationer, FFO] (MSB, 2020b; SFS 1994:524).

Within emergency management, Swedish legislation (SFS 2003:778) also supports collaborations with other actors, and there is a long emergency management tradition of collaborating with volunteers who are specifically trained to respond or who have a specific competence, such as volunteer fire brigades. In 2009, the Swedish government assigned a mission called "Strategy for strengthening the societal resources in coping with emergency situations" to the MSB (Fö2009/1451/SSK). The strategy highlights different types of collaboration, for example involving citizens (MSB, 2009). The need for collaborations with citizen volunteers in crisis and emergency response has also been highlighted in recent crises and emergencies, such as large forest fires, and in investigations following such events (the Swedish 
Ministry of Justice, 2015; SOU 2019:7; SOU 2018:54). New directions for emergency management underlines the need for inter-municipality collaboration and makes it easier for professional responders to collaborate with other actors, such as citizens, in the initial actions of an emergency (Government bill 2019/20:176; SFS 2020:882).

To sum up, both legislation and national agencies support a network structure with collaborations in crisis and emergency response. The Swedish response reflects the ongoing public sector trends in collaborations. The emerging collaborations with citizen volunteers have developed rapidly, and one of the first projects in Sweden - which is studied in this thesis as the second case study - was initiated in 2014. Through the exchange of experience and knowledge between networks, this kind of collaborative initiative has spread to several other municipal rescue services in just a couple of years.

Using the Swedish emergency response as the setting for the application domain is of specific interest because Sweden is perceived to be one of the forerunners in terms of organized, long-term citizen engagement in such responses. In the literature, there are only a few similar initiatives and studies on organizing citizen volunteers as first responders in relation to common accidents on a smaller scale (e.g. Berglund et al., 2018).

\subsection{Summary and reflections of the thesis theoretical foundation}

In order to maintain high quality and adequate service levels in crisis and emergency response despite uncertainties, decreased budgets, and demands for increased service, one solution is to develop new forms of collaboration between local government and citizen volunteers. Previous research argues that network collaboration, and specifically co-production, can support an understanding of the development of new emerging collaboration initiatives within crisis and emergency response, in which citizen volunteers are also involved. However, network collaboration literature seldom explicitly emphasizes ICT. With digitalization, the possibilities for co-production have increased. ICT is increasingly highlighted as enabling new ways to deliver crisis and emergency response, for instance using online platforms and smartphone apps. Thus, it is necessary to explore this further. To fill this knowledge gap, this thesis studies how ICT-enabled co-production transforms the traditional ways of delivering crisis and emergency response. There are previous studies of engaging volunteers in crisis and emergency response, but they rarely study the ICT more closely than simply describing the ICT systems. This thesis takes this further by studying, in the light of 
digitalization, the ICT development process, and takes an end-user perspective, i.e. examining what the end-user's needs are.

This thesis defines citizen volunteers as volunteers who act in their role as citizens and are involved in the delivery of the response, and who thereby become partners and providers of the service, not just consumers. Through this role in co-production, citizens are also end-users of ICT in the coproduction. Moreover, previous literature refers to various types of volunteers engaged in crisis and emergency response. Most of it tends to focus on types of volunteers other than those on whom this thesis focuses. Thus, long-term and preplanned engagement with citizen volunteers who are both online and onsite - as studied in this thesis - is not explored to the same degree.

As emphasized in previous literature, there is a need to cross-fertilize across different research disciplines in order to gain a full understanding within the area of emerging network collaborations as co-production (GilGarcia et al., 2018; Melin and Wihlborg, 2018; Janowski et al., 2012). Thus, this thesis uses research from various research disciplines, which is reflected in the theoretical foundation and in the analytical framework. This makes this thesis distinctive and increases the possibility to capture the multiple dimensions that the area of study is characterized by.

By cross-fertilizing across different disciplines and taking a sociotechnical systems approach, essential aspects for developing ICTenabled co-production have been identified from previous literature, and are used in the theoretical foundation and the analytical framework of the thesis. These aspects are also used to support the analysis of the results. I will also use them to support the analysis of the thesis in order to understand the results theoretically, and in a wider setting and application than the case studies. However, the analysis is not confined to the aspects of the framework; other findings from the case studies are also included in the analysis. (The way in which the aspects are further methodologically applied is described in chapter 2.)

This thesis uses Sweden as the setting when studying ICT-enabled coproduction within crisis and emergency response, and Sweden is perceived as a forerunner in using citizen volunteers. Thus, this setting is deemed particularly interesting when studying this emerging phenomenon and offers good opportunities to provide an enhanced understanding of the field. 



\section{Chapter 4}

\section{Aggregated results}

The five papers included in this thesis are based on two case studies. The first case study, 'Extended VÖKBYT', covers essential aspects of developing ICT-enabled inter-municipal network collaboration in the response field. This case study is used as the empirical basis for papers I and II. The second case study, 'Enhanced Neighbors', also covers essential aspects for developing ICT-enabled network collaboration in the response field, but between municipalities and citizen volunteers, called co-production. The second case study is used as the empirical basis for papers III-V.

When putting together the results from all five papers, new results appear which could not be seen in the separate analysis for each paper. Thus, the aggregated analysis differs from the results from each paper. In other words, the aggregated analysis cannot be found in any paper; it is new. The analysis conducted in this chapter builds on data from the papers, but is aggregated. Some additional data from the case studies regarding municipalities' reasons for collaborating is included, but there was no room for this data in the papers.

This chapter initially provides a summary of each paper. After the summaries of the five papers, the chapter's focus turns to an aggregated analysis of the results from the papers. Each of the two case studies in the thesis is first analyzed and aggregated separately. The case studies are then compared and cross-analyzed, i.e. they are compared and contrasted. Throughout the aggregated analysis and the cross-analysis, the analytical framework built in the thesis is used to support the analysis. (For information about the analytical framework and its aspects, see chapter 3.5.)

\subsection{Summary of included papers}

Each paper's contribution to the thesis can be briefly summarized as follows:

- Paper I describes essential aspects concerning what may be referred to as social components when developing ICT-enabled inter-municipal network collaboration, including opportunities and challenges involved in the collaboration.

- Paper II describes essential aspects to consider when developing ICT-enabled inter-municipal network collaboration, including 
opportunities and challenges involved in the collaboration, as well as understanding end-user involvement in the ICT development process and identifying ICT functions.

- Paper III describes essential aspects when developing ICTenabled co-production, including opportunities and challenges involved in the collaboration, as well as identifying ICT functions.

- Paper IV describes challenges when developing ICT-enabled coproduction and implications of end-user involvement in related ICT development processes.

- Paper V has a detailed focus on identifying ICT functions when developing ICT-enabled co-production with end-user involvement.

Below, the content of each paper is summarized with a focus on parts which are relevant to the thesis, especially concerning results and conclusions. For information about the author's role in each paper, see chapter 2.1.4.

\subsubsection{Paper I}

Palm, J., \& Ramsell, E. (2007) Developing Local Emergency Management by Co-ordination Between Municipalities in Policy Networks: Experiences from Sweden, Journal of Contingencies and Crisis Management, 15(4), 173-182, December

This paper aimed to provide a greater understanding of how ICT-enabled inter-municipal network collaboration can be developed, with a focus on the social components of the ICT system. The paper explored how a network collaboration between five municipalities emerged and took shape within crisis management, including crisis response. In doing so, the paper drew on policy network theory including collective action in the institutional analysis and development (IAD) framework. The emphasis was on essential aspects in order to understand how and why the collaboration occurs, based on Carlsson's (2000) framework. The following aspects were analyzed: problem definition (to obtain a common definition of the problem which the collaboration is supposed to resolve), contextual factors (networks emerge and are shaped differently in different contexts), growth of general belief (actors in a network need a mutual understanding of what is perceived as good, bad, effective, and desirable), and co-ordination and control (networks are subject to social control, which is in turn related to coordination). These aspects are also used as an analytical framework in the study. 
The case study took place in Östergötland and Småland counties in southern Sweden, and used previously established collaboration, called VÖKBYT, in many different areas. One of the collaboration areas was crisis management, including crisis response. All these municipalities are small and would be unable to organize professional response services individually. Participation was voluntary on the municipalities' part. Some financial resources were invested in the network, but the exchange of resources mainly involved time, staff, information, policy formulations, basic data for decision making and plans, etc.

The paper concluded that sharing resources is seen as crucial when establishing - and not least financing - efficient, high-quality response. The municipalities' lack of resources for providing effective emergency services, as required by law (SFS 2003:778), makes them dependent on each other. Limits for the inter-municipal network collaboration were connected to aspects such as a lack of growth of general belief (i.e. no mutual understanding) and a prior barrier to network collaboration between smaller and larger municipalities (i.e. different organizational structures and conditions).

The results from paper I are included in this thesis to compare opportunities and challenges identified in the later development toward ICT-enabled co-production, i.e. the differences and the similarities. The analytical framework used in the paper also provides a basis for the analytical framework used in the aggregated analysis of the thesis.

\subsubsection{Paper II}

Ramsell, E., \& Wihlborg, E. (2012) Governing Technical Information Systems in Local Crisis Management, Public Works Management \& Policy, 17(3), 303-318

The aim of the paper was to analyze how ICT creates the structural arena for inter-municipal network collaboration within crisis management, including crisis response. The paper is based on a bottom-up analysis of how municipalities choose ICT systems within crisis response, in other words how they identify important ICT functions. The same case study was used as in paper I, but larger municipalities were added to further explore the aspect of organizational context (size) which paper I showed to be important. Three of the original municipalities were excluded to create a balance between large and small municipalities.

Two ICT systems were studied: a national (WIS) and a local (eNavet) ICT system within crisis response. The municipalities' attitudes toward the national authority-owned ICT system and the locally developed system were 
studied and related to their choices and motivations. In other words, the paper's emphasis is on the choice of ICT systems in local crisis response and the needs and conditions that influence this choice. Five implementation principles based on Linton (2002) were used as an analytical framework: organizational structure, technology, project management, divisibility, and social interactions.

Conclusions were drawn regarding the municipalities' attitudes toward the authority-owned ICT system versus the private local ICT system, and whether and how they fulfilled the municipalities' requirements and needs. The paper showed that larger municipalities had their own resources with which to develop adapted ICT systems to meet their needs, while smaller municipalities with scarce resources did not have the same opportunities and had to use the national ICT system, even if it did not meet their user needs. In other words, whether or not the ICT system met the end-user's needs depended on whether they had their own resources. In conclusion, the paper identifies the importance of organizational structure and resources in order to reach an adapted ICT system. The paper also shows the demand for technological flexibility to meet end-user needs.

These results from paper II are included in the thesis to compare opportunities and challenges with the subsequent development of ICTenabled co-production, i.e. the differences and the similarities. The analytical framework used in the paper also forms a basis for the analytical framework used in the aggregated analysis of the thesis.

\subsubsection{Paper III}

Ramsell, E., Pilemalm, S., \& Andersson Granberg, T. (2017) Using Volunteers for Emergency Response in Rural Areas - Network Collaboration Factors and IT Support in the Case of Enhanced Neighbors, Proceedings of the 14th ISCRAM Conference - Albi, France, May

The aim of the paper was to analyze, in a public governance context, how a network collaboration between municipalities and citizen volunteer groups, i.e. co-production, chose an ICT system for its co-production in emergency response. The paper builds on a bottom-up analysis of how the actors chose an ICT system, and important needs and functions for the end-users.

The paper is based on a case study conducted in Medelpad Province in northern of Sweden (in Västernorrland County), called the Enhanced Neighbors project. The co-production consisted of three municipalities coproducing with five volunteer groups (at the beginning of the project), consisting of citizens living in rural areas within the province. The municipalities lacked the resources to fulfill their legal assignment (SFS 
2003:778) to provide same emergency response service to all citizens. The citizen in the co-production were voluntary engaged to respond to alerts near their villages. The goal for the co-production was thus to reduce the response time thereby comply with the Swedish Civil Protection Act (SFS 2003:778) by providing equal rescue services for all inhabitants, no matter where they live geographically.

An analytical framework was based on social and technical aspects that are essential for developing co-production, namely problem definition, contextual factors, formal and social control, and ICT support. The first three aspects were based on Carlsson's framework (2000), and the last aspect was inspired by Linton's framework (2002), but did not make direct reference to it.

The focus of the paper can be compared with papers I and II, which also had similar focuses, but for ICT-enabled inter-municipal network collaboration. However, compared to paper I and paper II, this paper studied the social and technical components in greater depth, in terms of training, equipment, communication, and end-users' ICT needs.

The paper shows that, due to budget constraints and regulations, implementing the most appropriate ICT system was problematic. The organizational structure made it difficult for the municipalities to find ICT providers within their budget and regulations. Other less expensive ICT systems were therefore prioritized (similar to the smaller municipalities in paper II). However, this led to end-users being able to use the chosen ICT system - regardless of their technological competence - when the system was developed incrementally.

Other important aspects were actors having social interactions, i.e. sharing a culture and a mutual understanding of the policy problem, and agreeing to solve the policy problem (as also shown in paper I) along the way. The paper also showed challenges when organizational actors and nonorganizational actors co-produce due to a lack of structures leading to challenges, for instance complexity concerning the integration of the ICT system, and legal and confidentiality issues. As in paper I, the lack of resources led to the co-production in the first place. However, contrary to the findings of paper I, geographical distance was a condition for the coproduction here, not a limitation.

To sum up, this paper explores important requirements and needs of the end-users, and challenges connected to these. Thus, the paper explores and identifies essential aspects to consider when developing ICT-enabled coproduction which are included in the thesis. In addition, the analytical framework used in the paper is a basis for the analytical framework used in the aggregated analysis of the thesis. 


\subsubsection{Paper IV}

Pilemalm, S., Lindgren, I., \& Ramsell, E. (2016) Emerging Forms of Interorganizational and Cross-sector Collaborations in e-Government Initiatives: Implications for Participative Development of Information Systems, Transforming Government: People, Process and Policy, 10(4), 605-636

The aim of the paper was to explore, in an e-government context, collaboration initiatives within emergency response to identify ICT challenges and connected general public sector challenges. The collaboration initiatives in the paper include both professional response organizations' network collaboration and co-production, and the emphasis is on end-user involvement (defined as user participation in the paper).

The paper was analytical and drew on three case studies. One of these case studies - in which municipalities co-produced with citizen volunteer groups - is included in this thesis, i.e. the second case study in the thesis described above in paper III.

In terms of the contribution to this thesis, the paper highlighted challenges such as identifying ICT needs for end-users, including clarification of responsibilities and tasks, and the importance of clarifying this before designing the ICT system. The end-users have to be involved early and actively in this process, in order to create adapted ICT to support long-term co-production initiatives. Other identified challenges included providing continuous training and meeting material needs (e.g. economic compensation for defibrillators). The paper shows that ICT-enabled coproduction that includes end-users who do not belong to any formal organizational structure leads to additional challenges compared to when end-users belong to formal organizations (e.g. municipalities). In other words, there is no foundation for the emerging co-production - most of its structures have to be created from scratch. Thus, several new questions arise which have to be analyzed, for example legal, safety, and ethical issues. Further, these issues demand specific expert competence to analyze and to develop corresponding ICT. 


\subsubsection{Paper V}

Ramsell, E., Andersson Granberg, T. \& Pilemalm, S. (2019) Identifying Functions for Smartphone Based Applications in Volunteer Emergency Response, Proceedings of the 16th ISCRAM Conference - València, Spain, May

Paper V aimed, in a co-production context, to study end-user-based functions for mobile phones applications in emergency response. Paper V builds on paper III, which also studied ICT requirements but had a broader perspective, i.e. ICT functions were not analyzed in detail. Therefore, in paper V, suitable ICT functions were identified and evaluated for smartphone-based applications for co-production.

The paper is a meta-analysis based on two case studies with different types of volunteer groups, one where municipalities co-produced with citizen volunteers (the second case study in the thesis) and one where a municipality collaborated with semi-professionals (i.e. employees such as security guards and rescue service administrative staff who voluntarily take on the additional assignment of acting as a voluntary first responder). The case study with semi-professionals is not included in this thesis, as it studies a different group of volunteers. Nevertheless, it indicates that the thesis could be put in a wider voluntary and end-user context.

In paper $\mathrm{V}$ the network collaboration between municipalities and citizen volunteers is specific to co-production, while in earlier papers the collaboration is only defined by network collaboration, which is a broader concept where co-production is also included. Thus, in paper $\mathrm{V}$ the concept of co-production is explicitly used to describe the network collaboration of municipalities and citizen volunteer groups within emergency response.

The paper identifies several ICT functions identified for mobile applications within volunteer response (and notes that similar functions can be used for different types of volunteers). The paper shows that even with basic technology including only essential functions, volunteers can support the response, sometimes saving lives. However, to contribute to a more effective response, and to long-lasting co-production and faster response, additional functions are important. These additional functions mostly concern two-way communication between the professional responders and the volunteers; the possibility to abort a mission if it is too dangerous for volunteers, the ability for volunteers to send GPS coordinates and provide updates on the best way to reach the incident site, and the option for volunteers to provide the professionals with pictures and videos of the incident site. 
Moreover, the paper shows that knowledge of how co-production is developed is essential; the presence of social interactions, i.e. common ground and a common understanding, agreement on the purpose of the coproduction and how to solve it, and dynamic and flexible professional response organizations. These results are useful for both professional response organizations, i.e. municipalities, developing co-productions and future research within the response field.

In short, the paper contributes a detailed analysis of functionalities for smartphone-based applications to the thesis, including an end-user perspective and the implications of these functionalities for the coproduction.

\subsection{Aggregated results from the first case study: ICT-enabled inter-municipal network collaboration}

The first case study focused on ICT-enabled inter-municipal network collaboration, i.e. collaboration between municipalities. For more information about the case study, see chapter 2.4.1.

This section is divided into four parts. The first part analyzes the reasons for developing the collaboration. The next part analysis aspects and implications of developing ICT-enabled inter-municipal network collaboration, with support and structure from the analytical framework. The following two parts, which are also supported by the analytical framework, further analyze the end-user involvement in the ICT development process, and identify ICT functions. For more detailed results, see papers I and II.

\subsubsection{Reasons for developing ICT-enabled inter-municipal network collaboration}

The first case study was conducted within the field of crisis response, and at the time of the study this was rather a new policy field, as was the question of how inter-municipality collaboration could be developed. The municipalities collaborated to use their resources more effectively. They received national agency grants for a part-time crisis manager, but they had to collaborate as the resources they received and their own resources were not enough to build up the new field of crisis response. Thus, resource deficit was a major reason for the network collaboration.

There was support from the national agency - SEMA, the forerunner to MSB - for municipalities to establish formal collaboration with citizen 
volunteers, known as voluntary resource groups [frivilliga resursgrupper, FRG] (SEMA, 2006), through agreements. At the time, municipalities perceived FRG as involving citizen volunteers with non-specific competence. The municipalities in the case study were not interested in collaborating with citizen volunteers - they found it hard to see how these citizen volunteer without any specific competence could provide support in crisis response. Instead, they had established collaborations with other types of volunteers who had specific competence that could be used to provide support. These volunteers were organized in formal volunteer organizations such as voluntary defense organizations [frivilliga försvarsorganisationer, FFO] (SEMA, 2006). In terms of citizen volunteers, the municipalities were more interested in how they could deter and manage spontaneous volunteers who get in the way of the professional response. Thus, the municipalities tried to keep citizen volunteer engagement to a minimum.

In short, the municipalities could see the benefits and advantages of developing ICT-enabled network collaboration with other municipalities, and were thus focused on developing this kind of network collaboration further to obtain a more effective response.

\subsubsection{Developing ICT-enabled inter-municipal network collaboration}

This section analyzes the development of ICT-enabled inter-municipal collaboration, with a focus on implications when developing this collaboration type.

The first case study illustrates the importance of sharing the same problem definition, i.e., how to ensure an effective response despite scarce resources. In relation, it is deemed central to share a generalized belief and common ground including long-term social relations in order to develop network collaboration. Likewise, the physical and organizational environment influenced the network collaboration, both strengthening but also limiting it due to different organizational structures and conditions between the municipalities. There were also technology champions (key actors) who were a driving force in the use of the ICT systems, however not in developing the technology further.

Formal and social control proved to be another aspect influencing the network collaboration. The network collaboration drew support from regulations and a national agency in terms of a free ICT system, subsides, and education. However, the municipalities in the network collaboration had different opinions about the degree of structure and control of the network collaboration. Smaller municipalities asked for more formal regulations than informal, "soft" regulations. Soft regulations such as 
education were appreciated, but they wanted clearer guidelines regarding which ICT system they were obliged to implement.

Regarding project management, ICT development and implementation was incremental and the technology had low complexity which, according to the analytical framework, should make it easy for end-users to get involved in the development process. However, the end-users felt that they had few opportunities to get an ICT system to meet their needs. In addition, the technology knowledge of the end-user was low - they had difficulties seeing how the ICT system could support them (which is further elaborated on in the section below).

The case study also showed the organizational environment to be connected to resources for developing an adapted ICT system. The ICT system with the lowest cost had to be chosen by most of the municipalities, even if it did not meet the users' needs. The largest municipalities, which had more resources, could choose other ICT systems. Thus, the organizational size (and thereby the amount of resources) influenced the types of suitable ICT system that could be chosen for the network collaboration.

Table 4.1 below lists all the implications - opportunities and challenges - identified when developing ICT-enabled inter-municipal network collaboration (based on papers I and II). The implications are structured by the aspects from the analytical framework, including both social and technical components.

Table. 4.1. Identified implications from ICT-enabled inter-municipal network collaboration structured by aspects from the analytical framework.

\begin{tabular}{|l|l|}
\hline \multirow{2}{*}{ Aspects } & Implications \\
\cline { 2 - 3 } & $\begin{array}{l}\text { Opportunities, marked with + } \\
\text { Challenges, marked with - }\end{array}$ \\
\hline definition & $\begin{array}{l}\text { + The professionals shared the same "problem" and were keen to solve it } \\
\text { - To define and continuously redefine the assignment, and to clarify } \\
\text { expectations } \\
\text { - Lack of experience from real crises, need for continuous drills and } \\
\text { training (received training in preparedness/planning activities) }\end{array}$ \\
\hline $\begin{array}{l}\text { Physical and } \begin{array}{l}\text { organizational } \\
\text { environment }\end{array} \\
\text { + Problem-solving-oriented professional management/response } \\
\text { (adaptable and flexible) } \\
\text { - Obstacles, e.g. organizational boundaries/size/structure and } \\
\text { geographical distances, yet these "obstacles" were also the reason for the } \\
\text { need to collaborate }\end{array}$ \\
\hline
\end{tabular}




\begin{tabular}{|c|c|}
\hline $\begin{array}{l}\text { Generalized } \\
\text { belief/ } \\
\text { common } \\
\text { ground }\end{array}$ & $\begin{array}{l}\text { + There was mutual understanding, common traditions and culture, and } \\
\text { trust between the actors (if not, there was no or limited collaboration) } \\
\text { + Homogeneous group (education, socio-economic status) } \\
\text { + Long-term social relations (mostly through work relations) }\end{array}$ \\
\hline $\begin{array}{l}\text { Formal } \\
\text { control and } \\
\text { social control }\end{array}$ & $\begin{array}{l}\text { + Support from regulations } \\
\text { + Support from national agencies (e.g. subsidies, ICT system training) } \\
\text { - /+ No formal obligation to support other municipalities, but the } \\
\text { professionals assumed the other municipalities would provide response } \\
\text { support } \\
\text { - Different opinions regarding degree/amount of structure and steering, } \\
\text { and agreements in the collaboration (small municipalities asked for more } \\
\text { formal steering from the national agency, but the opposite was expressed } \\
\text { in bigger municipalities) }\end{array}$ \\
\hline $\begin{array}{l}\text { Complexity of } \\
\text { technology } \\
\text { and } \\
\text { technology } \\
\text { knowledge }\end{array}$ & $\begin{array}{l}\text { + Low complexity of technology } \\
\text { - The basic level of the technology did not encourage the end-users to get } \\
\text { involved in developing the ICT and improving it } \\
\text { - Limitations in the ICT functionality (necessary functions versus functions } \\
\text { to maintain/increase collaboration) } \\
\text { - Low technology knowledge (understanding of how ICT could be an } \\
\text { enabler) }\end{array}$ \\
\hline $\begin{array}{l}\text { Technology } \\
\text { divisibility } \\
\text { (incremental } \\
\text { project } \\
\text { management) }\end{array}$ & $\begin{array}{l}\text { + Incremental development } \\
\text { - Difficult to develop and integrate the ICT system } \\
\text { - Difficult to accomplish end-user adapted ICT functions } \\
\text { - Lack of end-user-centered ICT development }\end{array}$ \\
\hline $\begin{array}{l}\text { Technology } \\
\text { championing } \\
\text { (key actor) }\end{array}$ & $\begin{array}{l}\text { - Difficulties developing the technology further, even with technology } \\
\text { champion } \\
\text { - Difficult to understand the potential of the technology }\end{array}$ \\
\hline
\end{tabular}

\subsubsection{End-user involvement in ICT development}

The case study shows that several aspects of the analytical framework for developing ICT-enabled inter-municipal network collaboration were present, albeit with at low degree for some aspects. In this case study, the ICT system had already been built. The end-users did not find the ICT system user friendly, and found it hard to see how it could support the network collaboration in a beneficial way. The difficulties in developing a useful and supportive ICT system seem to be connected to a lack of end-user involvement in the design of the technology and low technology knowledge on the part of the end-users. Although there were some end-user activities 
(e.g. national invitations to meetings with several different types of endusers), the end-users thought their needs were not taken into account. Moreover, in terms of low levels of technology knowledge, the end-users had difficulties seeing the usefulness and potential of the ICT systems - they were more used to meeting face-to-face or calling each other.

The analysis conducted with the support of the analytical framework showed that the owner of one of the ICT systems, the national agency SEMA (now MSB), could be seen as a technology champion - a so-called key actor for the ICT system. SEMA offered the ICT system for free, supported with training and administrative support. However, SEMA was not an actor within the network collaboration. The municipality which had developed the other ICT system (together with a company) could also be seen as a technology champion, although not to the same degree as SEMA. The municipal official was keen that other municipalities would also use the ICT system. However, besides holding meetings and giving presentations about the ICT system, the municipal official did not carry out any further supportive actions or activities to drive this process further.

\subsubsection{ICT functions for municipal professionals in crisis response}

In this first case study with municipal professionals, some additional functions were identified by the end-users, although the majority of the functions had already been integrated into the ICT system. In total, 13 functions were identified in the case study (including both those that were already integrated and additional functions).

Half of the ICT functions concerned supporting sharing information and the ability to document information (nos. 1-6 in the table below), for example publishing information and reading other actors' information. The end-users could choose which other actors they wanted to share which information with. The network collaboration could also use other solutions instead of the ICT systems. The other main communication channel was the telephone, which the end-users found to be easier and faster.

In addition to the fundamental functions, the end-users also identified several other functions which would further support their network collaboration: GIS maps, the ability to comment on posts/received information (a sort of two-way communication), interconnection with other ICT systems (there were some basic options for this in the existing ICT systems), the ability to use the ICT system in everyday work as well as during a crisis, and finally the ability to send sensitive and confidential information. The last function, sending sensitive information, was seen as an important function for the end-users. One ICT system, WIS, was not suitable for secret 
information, while the other, eNavet, had functionality for sending confidential information securely.

The end-users found redundancy important, i.e. that the ICT system could be used despite power cuts. This "function" differs from the other functions identified. It relates more to the infrastructure functionality supporting the interface for the end-users. Nevertheless, back-up power supply was seen as important by the end-users, and is therefore also addressed here. The reason why this was important may relates to when the case study was conducted. Immediately before the case study, Sweden experienced huge storms which lead to extensive, long-lasting power cuts. Thus, reducing the vulnerability of critical societal infrastructure was at the top of the agenda.

In Table 4.2 below, all the functions identified in the papers (papers I and II) from the first case study are listed, consisting of functions that already existed in one or both of the studied ICT systems (nos. 1-4, 6, 7, 10, and 11), or newly identified functions from the end-users (nos. 5, 8, 9, 12, and 13).

Table 4.2. Identified end-user functions in the first case study - ICT-enabled intermunicipal network collaboration. ID no. is not a prioritization of the ICT functions.

\begin{tabular}{|c|c|}
\hline $\begin{array}{l}\text { ID } \\
\text { no. }\end{array}$ & Identified function \\
\hline 1 & $\begin{array}{l}\text { Documentation and sharing of information (situational awareness reports, } \\
\text { decisions, diary posts, personal notes) }\end{array}$ \\
\hline 2 & $\begin{array}{l}\text { Sharing information within and between municipalities, as well as to inhabitants } \\
\text { and external actors, for example to the media }\end{array}$ \\
\hline 3 & $\begin{array}{l}\text { Viewing each other's emergency plans, risk and vulnerability analysis, and } \\
\text { exercises (if the actor approves, grants access) }\end{array}$ \\
\hline 4 & $\begin{array}{l}\text { Management during an incident (for example identification/information about } \\
\text { available resources) }\end{array}$ \\
\hline 5 & Interconnection with other ICT to enlarge the area of use \\
\hline 6 & Coordination between involved actors \\
\hline 7 & Virtual rooms (for private virtual group meetings) \\
\hline 8 & GIS maps \\
\hline 9 & Ability to comment on a post (a sort of two-way communication) \\
\hline
\end{tabular}




\begin{tabular}{|l|l|}
\hline 10 & Ability to use the system in everyday work as well as during a crisis \\
\hline 11 & Evaluation of the response \\
\hline 12 & $\begin{array}{l}\text { Ability to post sensitive and confidential information (to have the necessary } \\
\text { protection/security) }\end{array}$ \\
\hline 13 & $\begin{array}{l}\text { Redundancy, for example having a back-up server (protection against IT virus } \\
\text { attacks, power cuts) }\end{array}$ \\
\hline
\end{tabular}

\subsection{Aggregated results from the second case study: ICT-enabled network collaboration between municipalities and citizen volunteers, i.e. co-production}

The focus of the second case study was on network collaboration between municipalities and citizen volunteers. The second case study thus moves toward network collaboration that also includes citizen volunteers, not only inter-municipal network collaboration. This type of network collaboration is specified to co-production in the thesis. For more information about the case study, see chapter 2.4.2.

This section is divided into four parts. The first part analyzes the reasons for developing the collaboration. The next part analyzes aspects and implications for developing ICT-enabled co-production with support and structure from the analytical framework. The following two parts, which also draw support from the analytical framework, further analyze end-user involvement in the ICT development process and identify ICT functions. For more detailed results, see papers III-V.

\subsubsection{Reasons for developing ICT-enabled co-production}

The second case study was conducted within emergency response, which is a well-established domain with long traditions of collaborating with different actors. In the case study, an inter-municipal network collaboration and established formal collaboration with volunteers such as volunteer fire brigades and home guards, which take on certain tasks and are obliged to perform them, already existed. Even though different types of collaboration had been established, the municipalities had difficulties following the law which requires a fast and effective response for all citizen, no matter where 
they live - including those who live in sparsely populated and remote areas. In addition, they felt they had to invested significant resources in maintaining the existing formal collaborations with volunteers.

To provide a faster response for remote villages, the rescue services started involving citizen volunteers as first responders. This was an innovative way to engage citizens, and was one of the first of its kind in Sweden. The municipalities saw citizen volunteers as an important means for improving emergency response - to meet the public's demand for highquality public services while facing reductions in economic resources. In order not to increase the workloads of professional staff in terms of maintaining an additional collaboration, the municipalities wanted to develop an informal collaboration with the citizen volunteers which did not demand extensive resources for the municipalities to manage. In order to achieve this, professionals were willing to accept that they may not fully rely on the citizen volunteers.

\subsubsection{Developing ICT-enabled co-production}

This section analyzes the development of ICT-enabled co-production, with a focus on implications when developing this collaboration type.

In the second case study, there were few ICT choices available due to the organization size and resources. It was also seen to be difficult to meet endusers' needs. Thus, organizational size and resources influenced the choice of ICT for co-production. Additionally, citizen volunteers' lack of organizational affiliation and structure proved to be another challenge in terms of finding suitable ICT for co-production. Integrating citizen volunteers into the professionals' response ICT system - without organizational support, and with no formal control such as formal agreements - raised legitimacy and confidentiality issues. Nevertheless, technology championing involving key actors - especially in one volunteer group - drove the technology forward by finding complementary technologies (mobile applications and GPS) to make it more suitable for the responders. This was thus enabled by the low technology complexity and the open nature of the ICT response system, using mobile phones as the technical infrastructure. There was general technology knowledge and understanding about how ICT could enhance the collaboration.

One challenge identified in the analytical framework concerned the aspect of formal and social control and organizational environment of the co-production, i.e. its internal structure and non-formalization. Citizen volunteers preferred to have more structure in terms of meetings and drills with the professionals. They also expressed a need for material resources as the co-production evolved and the needs became gradually clearer and 
better defined. Most of the material needs were met, but the professionals did not have time to maintain the co-production to any greater extent. Even to maintain it at a basic level, the professionals had to use their spare time and often held meetings in the evenings when the citizen were available. The professionals preferred the citizen volunteers to be more or less self-driven and to train new volunteers by themselves. In short, the citizen volunteers wanted more support, which the professionals did not have the resources for.

Despite these challenges, the citizen volunteers perceived the ICTenabled co-production to be a positive symbol for strengthening the community and an improvement to public service - they were used to the opposite: a decline in public services, with schools, health care, and other public services closing down. This is connected to the aspect of generalized belief and common ground in the analytical framework. Moreover, in relation to this aspect, the citizen volunteers were highly committed to spending their spare time supporting this co-production. However, some of the citizen volunteers were only committed to their own village - their physical environment in the analytical framework. If there was an alert beyond the village, some of the citizen volunteers were not as eager to respond.

Table 4.3 lists all the implications - the opportunities and challenges identified when developing ICT-enabled co-production (based on papers III-V). The implications are structured according to the aspects from the analytical framework, including both social and technical components.

Table. 4.3. Identified implications from ICT-enabled co-production structured by aspects from the analytical framework.

\begin{tabular}{|c|c|}
\hline \multirow[t]{2}{*}{ Aspects } & Implications \\
\hline & $\begin{array}{l}\text { Opportunities, marked with + } \\
\text { Challenges, marked with - }\end{array}$ \\
\hline Problem definition & $\begin{array}{l}\text { + The actors shared the same "problem" and were keen to solve it } \\
\text { - To define and continuously redefine the assignment, and to clarify } \\
\text { expectations } \\
\text { - Lack of experience from real emergencies, need for continuous drills and } \\
\text { training }\end{array}$ \\
\hline
\end{tabular}




\begin{tabular}{|c|c|}
\hline $\begin{array}{l}\text { Physical and } \\
\text { organizational } \\
\text { environment }\end{array}$ & $\begin{array}{l}\text { + Actors' interest in engaging and willingness to devote their spare time - } \\
\text { both professionals and citizen volunteers } \\
\text { + Problem-solving-oriented professional management/response } \\
\text { (adaptable and flexible) } \\
\text { - Although the co-production was seen as an improvement to public } \\
\text { service, citizen commitment to the co-production could lead to a long- } \\
\text { term decline in professional response } \\
\text { - Obstacles, e.g. organizational boundaries/affiliation and geographical } \\
\text { distances, yet these "obstacles" were also the reason for the need to co- } \\
\text { produce } \\
\text { - Lack of organizational resources (economy) and staff resources to } \\
\text { develop the co-production (to perform training, drills) }\end{array}$ \\
\hline $\begin{array}{l}\text { Generalized } \\
\text { belief/common } \\
\text { ground }\end{array}$ & $\begin{array}{l}\text { + There was mutual understanding and trust between the actors } \\
\text { + Homogeneous group (education, socio-economic status, common } \\
\text { traditions, and culture) } \\
\text { + Long-term social relations (mostly through private relations) } \\
\text { + Perceived as positive for the community and an improvement to public } \\
\text { service (used to decline in public services, e.g. schools, hospitals, and } \\
\text { other welfare services closing down) } \\
\text { - Important to be accompanied when responding (not being alone) }\end{array}$ \\
\hline $\begin{array}{l}\text { Formal control and } \\
\text { social control }\end{array}$ & $\begin{array}{l}\text { + The co-production was appreciated by citizens and increased the } \\
\text { perceived safety } \\
\text { +/- No agreements between professionals and citizens - informal citizen } \\
\text { engagement } \\
\text { - The professionals cannot rely on the citizens to support/respond - no } \\
\text { obligation (e.g. rescue service cannot rely on the volunteers to respond) } \\
\text { - Insufficient insurance cover for citizens } \\
\text { - No financial compensation for expenses, e.g. equipment } \\
\text { - Open but sensitive personal information used by the actors - ethical, } \\
\text { confidentiality, privacy issues } \\
\text { - Different interpretations of regulations - different prerequisites for co- } \\
\text { production* } \\
\text { - Different opinions regarding degree/amount of structure and steering } \\
\text { and agreements in the co-production }\end{array}$ \\
\hline $\begin{array}{l}\text { Complexity of } \\
\text { technology and } \\
\text { technology } \\
\text { knowledge }\end{array}$ & $\begin{array}{l}\text { + Low complexity of technology } \\
+ \text { The basic level of the technology encouraged the citizens to get involved } \\
\text { in developing the ICT and improving it } \\
+ \text { General understanding of the potential of technology (technology } \\
\text { knowledge) } \\
+ \text { High engagement from end-users }\end{array}$ \\
\hline
\end{tabular}




\begin{tabular}{|l|l|}
\hline & $\begin{array}{l}\text { - Limitations in the ICT functionality (necessary functions versus functions } \\
\text { to maintain/increase the co-production) }\end{array}$ \\
\hline $\begin{array}{l}\text { Technology divisibility } \\
\text { (incremental project } \\
\text { management) }\end{array}$ & $\begin{array}{l}\text { + Incremental development } \\
\text { + End-user-centered ICT development } \\
\text { - Difficult to develop and integrate ICT system (due to resource deficit, } \\
\text { belonging/not belonging to the organization) } \\
\text { - Time consuming to involve end-user }\end{array}$ \\
\hline $\begin{array}{l}\text { Technology } \\
\text { championing (key } \\
\text { actor) }\end{array}$ & $\begin{array}{l}\text { + Where there was a technology champion (key actor), the technology } \\
\text { was developed further }\end{array}$ \\
\hline
\end{tabular}

*Some regions allow volunteers to respond even within health care (heart failure), while others do not.

\subsubsection{End-user involvement in ICT development}

In the second case study, the ICT system was not already built. Instead, it was developed together with the end-users as their needs became clearer as the co-production evolved, thus the end-users were actively involved in the ICT development process. It should be mentioned that this was not planned; it was due to delays in the original design and implementation of the ICT system. Also, the presence of the research project may have supported the end-user focus in the co-production.

Initially, an online platform was considered with an additional device (a tablet) only being used in the citizen volunteer response, but when citizen volunteers were consulted it emerged this was not what they were interested in. They wanted to be able to use their own mobile phones which they already knew how to use, and did not want to have an additional device. Thus, the end-users' personal mobile phones were used as the device.

The co-production started with a very basic level of technology, where end-user-based functions were added slowly and incrementally. Even with only general technology knowledge, which was the case for the majority of the end-users, this made it possible to participate and engage in the development of the technology.

Furthermore, there was also an end-user-driven implementation of additional functions. This evolution also started due to delays in the implementation of the ICT response system. Several end-user-based needs and ICT functions were identified, but far from all were implemented (due to delays from the developer and budget constraints). One end-user therefore took the matter into his own hands and searched for applications including the identified functions. The end-user found complementary applications which were then connected to the ICT system used in the co- 
production. The end-user, who could be called a technology champion according to the analytical framework, implemented the additional functions in his volunteer group (i.e. on his and the other volunteers' personal mobile phones). The other volunteers in the group did not have the technological knowledge to find or implement the additional functions. They were thus dependent on the technology champion in the group. The other volunteer groups did not have any technology champion. They therefore had to wait for the "formal" developer to implement the end-user needs. In other words, even if the end-user needs were identified, they were not implemented due to challenges linked to volunteers not belonging to the organization, delays from the developer and budget constraints.

\subsubsection{ICT functions for citizen volunteers in emergency response}

Most of the ICT functions involved two-way communication in some way, in other words how to receive information and how to send and transfer information to other users - both automatically and "manually" through the ICT system. The responders were thus dependent on the ICT system in order to co-produce.

There were basic functions and functions to make co-production easier and more effective (for example two-way communication). Basic functions which were necessary in order to co-produce included noticing the alert and receiving the address or a description of the incident site. Besides the basic functions, the end-users identified several functions which would further support the co-production: the ability to acknowledge the alert and then decline or accept it, information about whether other volunteers had accepted the assignment, information when professional rescue services arrive at the incident site, which equipment each volunteer is bringing, and sending information from the incident site to professionals (e.g. coordinates, photos, videos). The function for finding out whether other volunteers had accepted the assignment was emphasized by several of the volunteers, as they did not feel comfortable going alone. The social relations and interactions with other volunteers thus proved to be important, which is addressed in the aspect of generalized belief and common ground in the analytical framework. Other identified functions included the ability to abort an assignment and the need for checklists on how to act in the event of different types of incidents before an alert or as a quick drill.

Sensitive information, which is included in the aspect of formal and social control in the analytical framework, was addressed here when discussing with the users which information can and cannot be sent via the ICT system. The discussion was about what constitutes sensitive 
information, and the fact that citizen volunteers should not receive or handle sensitive information. However, the volunteers supplemented the ICT system with other technologies themselves - for instance with open source such as search engines - to obtain more information about the assignment which could then become sensitive. For example, it was not permissible (according to the law) to send information via the ICT system about which person(s) the assignment concerned - only the address. The volunteers resolved this by searching on internet to find out who lived at the address or near the position they had received, and they thereby obtained sensitive information. They could then use this information to locate the incident site more quickly, as they often knew where all neighbors lived but not the specific addresses. From another perspective, there were also functions which could lead to personal information about the citizen volunteers, for example GPS positioning. However, the citizen volunteers did not see this as an intrusion of their privacy - rather the opposite; they took a positive view of GPS positioning and perceived it as an important function for the coproduction. The volunteers seemed to trust the technology.

In Table 4.4 below, all 16 identified functions from this second case study are listed. One function already existed in the studied ICT system (no. 3), and there are also suggestions from the end-users for improvements to existing functions in the ICT system (nos. 8 and 14) or completely new identified functions (nos. 1, 2, 4-7, 9-13, 15, and 16).

Table 4.4. Identified end-user functions in the second case study - ICT-enabled co-production. ID no. is no prioritization of the ICT functions.

\begin{tabular}{|l|l|}
\hline ID no. & $\begin{array}{l}\text { Identified function } \\
\text { Check in/check out: The possibility to opt out of the role of responder for a } \\
\text { limited time }\end{array}$ \\
\hline 2 & $\begin{array}{l}\text { Loud and unique signal: It has to be possible to hear an alert at all times, } \\
\text { and it should not be mistaken for any other notification }\end{array}$ \\
\hline 3 & Information: A brief description of the event \\
\hline 4 & $\begin{array}{l}\text { Acknowledgement: The possibility to accept or decline an alert } \\
\text { Other voluntary responders: It is possible to see who else has accepted the } \\
\text { assignment }\end{array}$ \\
\hline 6 & $\begin{array}{l}\text { Professional responders: Information about when professional responders } \\
\text { will arrive }\end{array}$ \\
\hline 7 & $\begin{array}{l}\text { Equipment: Information about which equipment the responders are } \\
\text { bringing }\end{array}$ \\
\hline
\end{tabular}




\begin{tabular}{|c|c|}
\hline 8 & $\begin{array}{l}\text { Navigation: A map with the event site marked, navigation instructions, } \\
\text { voice navigation }\end{array}$ \\
\hline 9 & $\begin{array}{l}\text { Abort: Information if the assignment should be aborted, due to a } \\
\text { dangerous event site, or because the responder is no longer needed }\end{array}$ \\
\hline 10 & Abort status: The possibility to indicate that the assignment is aborted \\
\hline 11 & Arrival status: The possibility to indicate arrival at the event site \\
\hline 12 & $\begin{array}{l}\text { Coordinates: The possibility to send coordinates from the event site to } \\
\text { other responders }\end{array}$ \\
\hline 13 & $\begin{array}{l}\text { Checklist: Information helping with the practical response, e.g. how to act } \\
\text { in specific cases }\end{array}$ \\
\hline 14 & $\begin{array}{l}\text { Communication possibility: A quick way to contact professional responders } \\
\text { or emergency call operators directly via the application }\end{array}$ \\
\hline 15 & $\begin{array}{l}\text { Site information: The possibility to send pictures or video from the event } \\
\text { site }\end{array}$ \\
\hline 16 & Feedback: The possibility to fill out an assignment report \\
\hline
\end{tabular}

\subsection{Cross-comparison between the aggregated analysis of the two case studies - moving toward co-production}

Based on the aspects from the analytical framework, the implications of moving from ICT-enabled inter-municipal network collaboration toward ICT-enabled co-production is described in this section. The inter-municipal network collaboration case study is compared with the co-production case study to identify similarities and differences between the two case studies. In other words, this section focuses on what co-production could learn from earlier network collaborations, and which new implications need to be addressed and dealt with.

The section starts by analyzing the similarities and differences between inter-municipal network collaboration and co-production. Thereafter, the influences of end-user involvement and common ICT functions are analyzed.

\subsubsection{Similarities and differences between ICT-enabled inter-municipal network collaboration and ICT-enabled co-production}

Although the municipalities in the two case studies collaborated in different types of network collaborations - the first case study only between 
municipalities (actors belonging to a formal organization) and the second case study adding collaboration with citizen volunteers (with non-formal organizational affiliation) - there were similarities between them, as well as differences. The ICT-enabled co-production faced additional challenges compared to the ICT-enabled inter-municipal network collaboration.

In both case studies, the underlying reason for developing collaboration was resource deficit and the goal of the collaboration was to gain a more effective response. In the first case study, the municipalities saw a need to enhance inter-municipal collaboration within the response field. In the second case study, conducted almost ten years after the first case study, the inter-municipal network collaboration had already been developed and established, and a need to further develop their collaboration was identified. Given the resource deficit, the inter-municipal collaboration (as well as other established formal collaborations with volunteers) was not enough to improve the response. Thus, the municipalities in the second case study saw they had to think in new ways and engage other types of volunteers who had not been involved before. The solution was to include citizen volunteers with non-specific competence to be alerted to respond, albeit through more informal collaboration compared to earlier collaborations, in order to keep the municipalities' management costs (economic and staff resources) for the collaboration to a minimum.

In connection with the framework's aspects, it was essential in both types of network collaboration to have a problem definition of the collaboration, and for the actors to experience a growth and spread of a generalized belief and common ground, for example sharing traditions and social relations. Here, the challenges and opportunities seem to be similar regardless of the network collaboration type.

The differences between inter-municipal network collaboration and coproduction (between municipalities and citizen volunteers) identified with support from the analytical framework seem to concern organizational environment (e.g. organizational affiliation), social and formal control (e.g. regulations, confidentiality issues), and technology knowledge (how they perceived the technology as an enabler and how they could be involved in the ICT development process). The technology champion (key actor) role also differed between the case studies. In the co-production case study, the technology champion was not only a driving force in the use of the technology, but also developed the technology further.

In the co-production case study, citizen volunteers lack organizational affiliation which means there is no structure on which to base the collaboration. This therefore leads to challenges in terms of responsibility for the citizen volunteers (if they cause damage when responding or are 
injured), legal issues (citizen may receive sensitive information about their neighbors), and ICT system integration (the difficulty of integrating citizens into professionals' ICT response systems, which access citizen volunteers should receive, and how and who should be responsible for developing and adapting the ICT system for use by citizen volunteers). Nevertheless, the challenge of identifying the right level of structure and steering was present in both types of network collaborations, but was highlighted more in the coproduction case study.

Table 4.5 below lists all the implications - the opportunities and challenges - identified in both the case studies: ICT-enabled intermunicipal network collaboration and co-production within the response domain. The implications are structured according to the aspects from the analytical framework, including both social and technical components.

Table. 4.5. Identified implications of ICT-enabled inter-municipal network collaboration (first case study) and ICT-enabled co-production (second case study) structured by aspects from the analytical framework (present implications marked with "yes", non-present marked with "no", and not applicable marked with "N/A").

\begin{tabular}{|c|c|c|c|}
\hline \multirow[t]{2}{*}{ Aspects } & \multirow{2}{*}{$\begin{array}{l}\text { Implications } \\
\text { Opportunities, marked with + } \\
\text { Challenges, marked with - }\end{array}$} & \multicolumn{2}{|l|}{ Case study } \\
\hline & & $\begin{array}{l}\text { First case } \\
\text { study: } \\
\text { professionals }\end{array}$ & $\begin{array}{l}\text { Second case } \\
\text { study: co- } \\
\text { production }\end{array}$ \\
\hline \multirow[t]{3}{*}{$\begin{array}{l}\text { Problem } \\
\text { definition }\end{array}$} & $\begin{array}{l}\text { + The actors shared the same "problem" and } \\
\text { were keen to solve it }\end{array}$ & Yes & Yes \\
\hline & $\begin{array}{l}\text { - To define and continuously redefine the } \\
\text { assignment, and to clarify expectations }\end{array}$ & Yes & Yes \\
\hline & $\begin{array}{l}\text { - Lack of experience from real } \\
\text { emergencies/crises, need for continuous } \\
\text { drills and training }\end{array}$ & Yes & Yes \\
\hline \multirow{3}{*}{$\begin{array}{l}\text { Physical and } \\
\text { organizational } \\
\text { environment }\end{array}$} & $\begin{array}{l}\text { + Actors' interest in engaging and willingness } \\
\text { to devote their spare time }\end{array}$ & $\mathrm{N} / \mathrm{A}$ & Yes \\
\hline & $\begin{array}{l}\text { + Problem-solving-oriented professional } \\
\text { management/response (adaptable and } \\
\text { flexible) }\end{array}$ & Yes & Yes \\
\hline & $\begin{array}{l}\text { - Although the collaboration was seen as an } \\
\text { improvement to public service, citizen } \\
\text { comment to the collaboration could lead to a } \\
\text { long-term decline in professional response }\end{array}$ & $\mathrm{N} / \mathrm{A}$ & Yes \\
\hline
\end{tabular}




\begin{tabular}{|c|c|c|c|}
\hline & $\begin{array}{l}\text { - Obstacles, e.g. organizational } \\
\text { boundaries/affiliation/size and geographical } \\
\text { distances, yet these "obstacles" were also } \\
\text { the reason for the need to co-produce }\end{array}$ & Yes & Yes \\
\hline & $\begin{array}{l}\text { - Lack of organizational resources (economy) } \\
\text { and staff resources to develop the } \\
\text { collaboration (to perform training, drills) }\end{array}$ & No & Yes \\
\hline \multirow{5}{*}{$\begin{array}{l}\text { Generalized } \\
\text { belief/ } \\
\text { common } \\
\text { ground }\end{array}$} & $\begin{array}{l}+ \text { There was mutual understanding and trust } \\
\text { among the actors }\end{array}$ & Yes & Yes \\
\hline & $\begin{array}{l}\text { + Homogeneous group (education, socio- } \\
\text { economic status, common traditions, and } \\
\text { culture) }\end{array}$ & Yes & Yes \\
\hline & + Long-term social relations & Yes & Yes \\
\hline & $\begin{array}{l}\text { + Perceived as positive for the community/an } \\
\text { improvement in community service (used to } \\
\text { decline in public services, e.g. schools, } \\
\text { hospitals, and other welfare services closing } \\
\text { down) }\end{array}$ & $\begin{array}{l}\text { N/A (citizens } \\
\text { not aware of } \\
\text { the } \\
\text { collaboration) }\end{array}$ & Yes \\
\hline & $\begin{array}{l}\text { - Important to be accompanied when } \\
\text { responding (not going alone) }\end{array}$ & N/A & Yes \\
\hline \multirow{6}{*}{$\begin{array}{l}\text { Formal } \\
\text { control and } \\
\text { social control }\end{array}$} & $\begin{array}{l}\text { + Support from national agencies (e.g. } \\
\text { subsidies, ICT system training) }\end{array}$ & Yes & No \\
\hline & $\begin{array}{l}\text { + The co-production was appreciated by } \\
\text { citizens and increased the perceived safety }\end{array}$ & $\begin{array}{l}\text { N/A } \\
\text { (citizens/public } \\
\text { not aware of } \\
\text { the } \\
\text { collaboration) }\end{array}$ & Yes \\
\hline & $\begin{array}{l}\text { - The actors cannot rely on the other actors } \\
\text { to support/respond }\end{array}$ & No * & $\begin{array}{l}\text { Yes } \\
\text { (voluntary to } \\
\text { respond) }\end{array}$ \\
\hline & $\begin{array}{l}\text { - Insufficient insurance cover for the } \\
\text { actors/participants }\end{array}$ & No & Yes \\
\hline & $\begin{array}{l}\text { + Financial compensation for expenses, e.g. } \\
\text { equipment }\end{array}$ & $\begin{array}{l}\text { Yes } \\
\text { (compensated } \\
\text { through each } \\
\text { actors' } \\
\text { organization) }\end{array}$ & No \\
\hline & $\begin{array}{l}\text { - Open but sensitive personal information } \\
\text { used by the actors - ethical and } \\
\text { confidentiality issues }\end{array}$ & No** & Yes \\
\hline
\end{tabular}




\begin{tabular}{|c|c|c|c|}
\hline & $\begin{array}{l}\text { - Different interpretations of regulations - } \\
\text { different prerequisites for the collaboration }\end{array}$ & No & Yes*** \\
\hline & $\begin{array}{l}\text { - Different opinions regarding } \\
\text { degree/amount of structure and steering and } \\
\text { agreements in the collaboration }\end{array}$ & Yes & Yes \\
\hline \multirow{4}{*}{$\begin{array}{l}\text { Complexity of } \\
\text { technology } \\
\text { and } \\
\text { technology } \\
\text { knowledge }\end{array}$} & + Low complexity of technology & Yes & Yes \\
\hline & $\begin{array}{l}\text { + The basic level of ICT encouraged the end- } \\
\text { users to get involved in the ICT and to } \\
\text { improve it }\end{array}$ & No & Yes \\
\hline & $\begin{array}{l}\text { - Limitations in the ICT functionality } \\
\text { (necessary functions versus functions to } \\
\text { maintain/increase co-production) }\end{array}$ & Yes & Yes \\
\hline & $\begin{array}{l}\text { - Difficult to understand the potential of the } \\
\text { technology (technology knowledge) }\end{array}$ & Yes & No \\
\hline \multirow{4}{*}{$\begin{array}{l}\text { Technology } \\
\text { divisibility } \\
\text { (incremental } \\
\text { project } \\
\text { management) }\end{array}$} & + Incremental development & Yes & Yes \\
\hline & + End-user-adapted ICT system & No & Yes \\
\hline & $\begin{array}{l}\text { - Difficult to develop and integrate the ICT } \\
\text { system (due to resource deficit, } \\
\text { belonging/not belonging to the organization) }\end{array}$ & Yes & Yes \\
\hline & - Time consuming to involve end-user & N/A & Yes \\
\hline $\begin{array}{l}\text { Technology } \\
\text { championing } \\
\text { (key actor) }\end{array}$ & $\begin{array}{l}\text { + Where there was a key actor/technology } \\
\text { champion, the technology was developed } \\
\text { further }\end{array}$ & No & Yes \\
\hline
\end{tabular}

* Not mandatory, but in a response the actors assumed that the other municipalities would support them.

** One ICT system was not used for confidential information, while the other had the functionality to keep confidential information secure.

*** Some regions allow volunteers to respond even within health care (heart failure), while others do not.

\subsubsection{The influence of end-user involvement}

Differences concerning end-user involvement between the case studies are analyzed further in this section. Comparing the two case studies, one difference was how the ICT as an enabler of the collaboration was perceived by the end-users and the degree of support provided by the ICT system that the end-users experienced. The involvement of end-users in the development of the ICT system seemed to influence the perception and 
practical use of the ICT system among end-users. Also, technology knowledge among the end-users seemed to influence the development of ICT systems.

The differences between the case studies also seem to be connected to the different time periods during which the case studies were conducted. By the time of the co-production case study, which was conducted later, there had been a general increase in technology knowledge within society and among the users. Also, it had become quite easy to adapt the ICT and develop it further. The end-users in the co-production case study could enhance the official ICT response system with additional technologies, and one end-user in particular was a driving force in this, i.e. a technology champion (key actor). However, the ICT systems differed between the case studies, and this has to be taken into account.

Moreover, concerning the aspect of formal and social control in the analytical framework, the citizen volunteers were not constrained by the municipalities' regulations and could therefore use various technologies more easily. Consequently, adaptable basic ICT systems have enabled new forms of co-production and do not demand a high degree of technology knowledge from end-users.

Thus, the identified differences between the co-production case study and the inter-municipal network collaboration case study include interrelated aspects of time, technological development, and the degree of end-user involvement resulting in adapted ICT systems. In order for enduser involvement to make a difference, it seems to be necessary that this involvement takes place alongside the ICT development process, and that this involvement influences the development of the ICT system - that the ICT system meets the end-users' needs. In co-production, it may be more difficult to involve the end-user because of their organizational environment - they have no organizational affiliation, and thus there is no natural formal structure for involving them. Also, they may not be able to meet during office hours when the municipal professionals are at work. Thus, in order to involve citizen volunteers/the end-users in the ICT development process, the municipal professionals or the developers have to be flexible about meeting times.

\subsubsection{Common ICT functions for municipal professionals and citizen volunteers}

In the inter-municipal network collaboration case study and the coproduction case study, end-users' needs have been identified - both specific ICT needs and more general needs, such as instance material resources, training, and drills. In this section, identified ICT functions from the two 
case studies are analyzed and compared to explore potential similarities and/or differences in order to see whether there are lessons to learn for future ICT-enabled co-production in the response field.

The case studies differ in terms of the level and perspective of analyses. The inter-municipal collaboration case study focused on the ICT systems and whether or not the end-users experienced that the systems' functions met their needs. The aim was not to go further and study additional needs and functions, although some additional functions were identified by the end-users. The co-production case study focused in more detail on identifying functions for the end-users' needs. Thus, even though the case studies differ, it can be useful to compare them.

ICT functions in both case studies concerned the dissemination and sharing of information (although in different ways). Communication was lacking. In both cases studies, the end-users experienced a need for more functions to support communication with other end-users.

The functions identified in both case studies can be divided into two groups. One group includes necessary functions which were fundamental for the ICT system to support the network collaboration. The other group consists of additional functions to increase and strengthen the network collaboration.

The functions identified in the co-production case study (the second case study) were more specific than in the inter-municipal collaboration case study (the first case study). This may be because of the data collection method, but may also depend on the different time periods when the case studies were conducted. The second case study was conducted almost ten years after the first one. At that time, there was a higher degree of general knowledge regarding ICT in society and among users (see 4.3.3 for further analysis).

Both case studies addressed sensitive information, but in different ways. In the first case study, the ability to send sensitive information was seen as an important function for the end-users. In the second case study, this was not mentioned as a function but was addressed as a challenge. In the second case study, the end-users (citizen volunteers) could not receive all the information they wanted due to regulations. Therefore, the majority of the end-users supplemented the information they received from the ICT system by searching via open sources. By doing so they could get hold of more information and reach the incident site faster, although this information was sensitive. This is connected to another function, the ability to connect the ICT system to other technologies. In the first case study the end-users asked for this function, but it was not identified as a function by the end-users in the second case study. However, the end-users in the second case study still 
used this "functionality" when searching for more information. It seems that the end-users in the second case study took this functionality for granted, combining the ICT with other accessible technologies, and did not find it necessary to specify it as a function for the ICT system. This could be due to the different time periods in which the case studies were conducted. In the second case study concerning co-production, the general trend of increased ICT interactivity within society could have influenced how the end-users perceived the need for ICT functions.

To summarize, in both the inter-municipal network collaboration case study (the first case study) and the co-production case study (the second case study), the end-users identified basic functions and additional functions that were important for maintaining and increasing the effectiveness of the network collaborations (e.g. two-way communication). Sensitive information was addressed, albeit in different ways, as was the ability to connect and combine the specific ICT response system with other technologies. The differences can be explained by the general ICT development within society and by different end-user involvement. 


\section{Chapter 5}

\section{Discussion}

This chapter further analyzes the aggregated results of this thesis and discusses them in a wider context - the transformation of the crisis and emergency response domain toward ICT-enabled co-production in the light of digitalization and with and end-user involvement perspective. This is supported by the thesis's theoretical foundation and the analytical framework.

The chapter is structured into three sections. The first section focuses on the transformation of crisis and emergency response in the light of digitalization and taking an end-user involvement perspective. The second section takes this further by focusing specifically on the transformation from ICT-enabled inter-municipality network collaboration toward ICT-enabled co-production, with an emphasis on the latter. The third section focuses on related implications, namely challenges and opportunities, when developing ICT-enabled co-production.

\subsection{Transformation of the crisis and emergency response}

This section discusses the transformation of the crisis and emergency response. First, the transformation from ICT-enabled inter-municipal collaboration toward ICT-enabled co-production is discussed. Then, in the following two sections, this is further discussed in the light of digitalization and thereafter connected to argumentation for an end-user involvement perspective.

\subsubsection{Toward ICT-enabled co-production}

This thesis illustrates a transformation process for how ICT can be used to enable a new type of collaboration, referred to as ICT-enabled coproduction, in crisis and emergency response. The first case study examines the emphasis of the early 2000 s on inter-municipal network collaboration within the response domain in order to improve the response. The second case study shows that, given growing public service challenges (e.g. resource deficit, demands for high quality) and societal challenges (increased vulnerabilities and threats), the established inter-municipal network 
collaborations are no longer sufficient to achieve an effective response. Thus, the municipalities need to develop new collaborations to supplement the existing collaborations. One such emerging example involves municipalities collaborating with citizen volunteers, which the thesis describes using the concept of co-production.

In the thesis's case study of co-production, the citizen volunteers are engaged in the actual delivery of the response. Thus, co-production becomes a solution for achieving a more effective response. Although the second case study is conducted in relation to frequent small-scale emergencies, other contemporary literature within large-scale crises show similar findings that citizen volunteers are also necessary within crisis response (e.g. Schmidt et al., 2018; Meissen et al., 2017; St. Denis and Hughes, 2018).

Previous and current research within the response domain support the focus of the thesis - the need to engage citizens in crisis and emergency response (e.g. Ringh et al., 2011; Pilemalm, 2020; Díaz et al., 2016). However, in contrast to previous and current studies, this thesis outlines this transformation toward co-production empirically by comparing different time periods. This is not possible in previous and current literature, since only separate cases are studied (ibid.).

When considering previous literature on a general public service level, some literature studies the transformation toward increased citizen engagement connected to e-government (e.g. Holgersson and Karlsson, 2014; van Velsena et al., 2009; Cordella and Tempini, 2015). There is also previous and contemporary literature addressing co-production theoretically and/or in specific public service domains (Linders, 2012; Pestoff et al., 2012; Brandsen et al., 2018; Paletti, 2016), but not the thesis's co-production type in which citizens become involved in the actual service delivery and in which the ICT is studied in more detail. Thus, previous and contemporary literature is short on empirical studies on the transformation toward ICT-enabled co-production where citizens become involved in the delivery, which is the focus of this thesis.

Returning to co-production specifically within the response domain, here too the thesis's type of co-production - in which citizens are involved in the actual delivery of the response as first responders onsite, enabled by ICT has not been studied to any great extent in previous or contemporary literature. Only a few similar studies have been found, such as Pilemalm's (2020) study in which citizens were alerted as first responders in real incidents. There is also some previous and contemporary literature regarding citizen volunteers responding to cardiopulmonary resuscitation (CPR), but these studies are focused on assessing the ICT system in terms of improved survival (Ringh et al., 2011; Ringh et al., 2015; Berglund et al., 
2018; Pijls et al., 2016). In other words, there is a lack of studies on the type of citizen volunteerism which this thesis focuses on. This observation can be further highlighted by comparing the gap with the vast number of studies on other types of citizen volunteerism (sometimes referred to as coproduction), such as crowdsourcing, spontaneous engagement, and solely digital volunteerism facilitated by various technologies such as big data and social media (e.g. Janssen and van den Hoven, 2015; Toots et al., 2017; Whicher and Crick, 2019; Gascó, 2017; Whittaker et al., 2015). Thus, this thesis provides a deeper understanding of a specific type of co-production that previous and contemporary literature has not addressed to a greater extent.

In addition to the transformation of the response domain to include citizens in a new way, the thesis also notes another transformation concerning changed awareness of the response to crises and emergencies. Within society, there was initially a focus on how to improve the response to large-scale crises, based on the first case study. There then followed a growing awareness of the need to also improve the response to frequent small-scale emergencies, based on the second case study.

To summarize, this thesis shows the transformation within the response domain toward ICT-enabled co-production, which also correlates to increased awareness of a more effective response.

\subsubsection{Digitalization and understanding of the ICT as an enabler for the response}

In describing the transformation of the response domain above, the thesis also claims that digitalization leads to new possibilities - ICT has eased the collaboration with citizen volunteers within emergency and crisis response. The two case studies are concrete examples of this digitalization. In relation to previous research, this thesis's two case studies might be described in terms of low digitalization (the first case study) versus high digitalization (the second case study) (Sæbø et al., 2008; Asgarkhani, 2005; Layne and Lee, 2001; Sørensen, 2016; Bason, 2018; Bonsón et al., 2012; Nograšek and Vintar, 2014). This change in the use of ICT is described theoretically in previous and contemporary literature on general ICT-enabled coproduction (Linders, 2012; Voorberg et al., 2015; Paletti, 2016; Lember et al., 2019), but it is seldom studied empirically within the response domain. There are previous and contemporary empirical studies within the domain, but they only describe the ICT system overall - not the impact of the ICT and their focus is on one case study during a limited time period (e.g. Ringh et al., 2011; Berglund et al., 2018; Schmidt et al., 2018). I have not found any empirical study conducted in different time periods that explores the change 
in understanding of the ICT in the response domain in the way that this thesis does.

With the thesis's empirical focus on two case studies conducted in different time periods, a change in the end-users' understanding of the ICT as $a$ an enabler can also be studied. The different time periods influenced how the end-users perceived the ICT. In the thesis's first case study, the endusers had difficulties understanding the potential for how ICT could support them. At the time when the first case study was conducted, ICT within public services was mainly used as a channel for information sharing and the automation of information gathering (Layne and Lee, 2001). This was also observed in the thesis's first case study. There was a lack of technology knowledge (Linton, 2002; Cegarra-Navarroa, 2014) on the part of the endusers, i.e. thinking beyond the already known uses of the ICT.

During the period between the first and second case studies, there was a general development in the use of ICT within society as a whole and within crisis and emergency response in particular, in other words, increased digitalization (Tilson et al., 2010). ICT is also used as an enabler for creating new collaboration initiatives within public services (Lu et al., 2010; Sæbø et al., 2008; Sørensen, 2016). This development was also seen empirically in the thesis - there was an increase in the general technology knowledge (Linton, 2002) of the end-users in the second case study: they had an increased understanding of how ICT could support them.

This understanding in the second case study was also assisted by active end-user involvement in the ICT development process, which lead to an adaptable ICT system based on the end-users' needs, according to the sociotechnical systems approach (Bostrom and Heinen, 1977a; Markus, 1983; Iivari, 2010; Moynihan, 2009). Thus, in the second case study the sociotechnical systems approach is more evident compared to the first case study.

To sum up, this thesis argues that the different time periods are thus an essential explanation for the differences in how the end-users perceived how ICT could be an enabler for the response. Put differently, the thesis observes empirically within the response domain what previous research has claimed theoretically regarding citizen engagement in e-government collaborations and general ICT-enabled co-production (e.g. van Velsena et al., 2009; Linders, 2012). In a wider context, the thesis illustrates the change by comparing two different time periods in understanding of the ICT involving end-users in the co-production ICT development where a sociotechnical systems approach is important. The perception of ICT has shifted from being seen as a form of administrative support to being perceived as an enabler for emerging collaborations. 


\subsubsection{New possibilities of end-user involvement through digitalization}

With regard to the digitalization that is taking place, the thesis claims that this offers new possibilities for the citizen to be involved in the ICT development process. The thesis shows how the different time periods influenced the end-users' opportunities to be involved in ICT development. In doing so, the thesis adds understanding to the end-user literature whereas most previous end-user literature is focused on user satisfaction (Verdegem and Verleye, 2009), and on methods and techniques for addressing end-user involvement (e.g. Bjerknes et al., 1987; Tollmar, 2001; Iversen et al., 2010).

In the first case study, with low levels of digitalization generally within society, there was an administrative view (Layne and Lee, 2001). The endusers were invited to the ICT development process by those responsible for the ICT system with the aim of identifying their needs and implementing them in the ICT system. In the second case study, where there was a higher degree of digitalization generally within society, the ICT was seen as an enabler for emerging collaborations (Sæbø et al., 2008; Lu et al., 2010) - the end-users could, beyond formal involvement, also become involved in the ICT development process in their own right. This meant that the end-users could develop and improve the ICT themselves without the involvement of the official developer or the agency or company responsible for the ICT system (Tilson, 2010). Compared with the first case study, the technology itself was easier to handle and develop, which is supported by previous and contemporary literature (Meijer, 2012; Lember, 2018; Paletti, 2016; Tilson, 2010). If the end-users had general technology knowledge (Linton, 2002), they could act as developers themselves and add the technology they needed. Compared to one of the ICT systems in the first case study, WIS, this system was difficult to combine with other technologies such as using maps and sharing information. It was more of a so-called closed system, with an administrative view of functionality (Saarikko et al., 2020). In the thesis's second case study, the citizen volunteers were not confined to the specific ICT response system - they used the ICT that could help them, no matter whether this was via the specific ICT response system or open ICT sources such as search engines. A driven end-user, a technology champion (Linton, 2002), added other applications to the formal ICT system to adapt and improve it. This was not seen in the first case study. Here, the technology champion certainly mentioned the many possibilities for connecting to other ICT systems but within the specific response system - the formal ICT system of the network collaboration (Agranoff, 2007; Janowski et al., 2012). The possibility of the end-users doing so by themselves and outside the formal 
response system, i.e. adding other applications to the response ICT system to better suit their needs, was not perceived as an option.

The thesis's comparison of the two case studies shows a major change in how the end-users can be involved in the ICT development process. The endusers are not dependent on the formal developers to the same extent as before - they can get involved and influence the ICT system even if they are not formally invited to join the ICT development process. This can be referred to theoretically as the phenomenon of emergence, where the ICT system is developed in a way which the formal developers did not plan (Lin and Cornford, 2000).

In relation to previous end-user literature, recommendations to create formal design groups and invite end-users to participate in these to achieve an adaptable ICT system (Iversen et al., 2010; Gulliksen et al., 2003; Karlsson et al., 2012) thus seem less important. Digitalization seems to lead to parallel development processes (i.e. formal and informal processes). Thus, the different time periods with different degrees of digitalization are an essential explanation for the differences in the end-users' opportunities to get involved in the ICT system development (Tilson, 2010).

In summary, since the digitalization takes place within the response domain (and overall within public services), the thesis demonstrates the crucial importance of including the end-users of contemporary ICT development in the co-production. With the end-users' technology knowledge and understanding of the ICT, they can contribute effectively to narrowing the gap between the developers responsible for ICT development and the end-users, as noted in previous end-user literature (Iversen et al., 2010; Gulliksen et al., 2003; Karlsson et al., 2012; Hillgren et al., 2011). In fact, the end-users may even influence and shape the ICT system according to their needs, without coming into contact with the developers. Thus, this thesis points toward a shift in prerequisites for end-user involvement to increase end-user influence.

\subsection{Developing ICT-enabled co-production}

Following the above transformation in the crisis and emergency response domain in the light of digitalization and how this influences end-user involvement, this section goes further by focusing specifically on the transformation toward ICT-enabled co-production. The section first focuses on defining ICT-enabled co-production and then on why this phenomenon has emerged in emergency response. Finally, the section discusses the differences between ICT-enabled co-production and ICT-enabled inter- 
municipal network collaboration, i.e. essential aspects that are important when developing co-production.

\subsubsection{Understanding a new phenomenon - the lack of a coherent concept definition}

In this thesis, ICT-enabled co-production refers to when citizens are involved as volunteers in the delivery of a public service. When analyzing and discussing a new phenomenon such as the development of ICT-enabled co-production, it is first necessary to be clear about what the concept means. Several concepts are used in the literature, and there is no consistency in terms of how the different concepts are used. Some literature refers only to "co-production" or does not define it at all, while in other studies ICT is presented using the concept of "digital technologies in co-production", "digital co-production", or "we-government" (Lember, 2018; Brandsen et al., 2018; Linders, 2012).

The concept of we-government is associated with e-government. Even if the term "we-government" does not only include virtual activities, it can easily be misinterpreted in this way. Also, e-government was a well-used concept for describing the initial period of the digitalization of public services, where the emphasis was usually on increasing their availability through online services for individual citizens and providing public services more efficiently (Layne and Lee, 2001). The concept of e-government is still widely used, including to describe new and emerging ways of delivering public services with the support of citizens, usually collectively (Sæbø et al., 2008; Asgarkhani, 2005; Nograšek and Vintar, 2014). Thus, it is a broad concept and there may be concepts other than e-government/wegovernment which describe the specific characteristics of ICT used in coproduction more clearly.

The concept of "digital co-production" (Lember, 2018) might therefore be more appropriate when describing when the citizen becomes not only a user but also a supplier, and is closely involved in public service delivery not just individually, but often collectively with other citizens. However, the concept of digital co-production can also be interpreted to mean that the coproduction is only virtual - which is not usually the case. Thus, this thesis clarifies the concept and emphasizes both the digital and onsite activities by using ICT-enabled co-production.

There are also other concepts that are sometimes connected to coproduction, such as co-creation and co-design (e.g. Jukić et al., 2019; Brandsen et al., 2018; Toots et al., 2017; Sanders and Stappers, 2008). The definitions vary greatly, and there are no coherent definitions for these concepts. In this thesis, the concept of co-production was chosen, as 
described in chapter 3 , and defined as network collaboration between government and citizen volunteers in public service delivery. Here, both cocreation and co-design are included, i.e. the citizen volunteers are both involved as end-users in the development and design of ICT, and engaged in the actual performance of the co-production. This thesis notes that this definition of the concept can be used for co-production studies. However, in other studies within other disciplines, including within the IS discipline, the same phenomenon may be defined as only co-creation and co-design (with an emphasis on end-user involvement and the design of the ICT for coproduction respectively - at least within the IS discipline). It is essential to keep in mind that there is a lack of coherent concepts in the co-production literature. Therefore, it is important to not only look at studies using one of these concepts when studying this emerging phenomenon, at least without first being sure how the study defines the concept. Thus, even though the concept of co-production is used in this thesis, it also fills important knowledge gaps in understanding the underlying concepts of co-creation and co-design.

\subsubsection{Changed perception of citizen volunteers in crisis and emergency response}

By studying the transformation of the response domain, from ICT-enabled inter-municipal collaboration to ICT-enabled co-production, this thesis shows the municipalities' changed perception of citizen volunteers over time. In inter-municipal network collaborations, the professionals mostly saw the benefits of collaborating with each other, while this changed in the co-production to include seeing the strength of collaborating with citizen volunteers to improve the response. The changed perception of volunteers is also supported by previous and contemporary literature (van Eijk and Gascó, 2018; Brandsen et al., 2018; Pilemalm, 2020). However, the literature mostly focuses on other types of co-production in which citizens are not involved in the actual service delivery, and does not focus on the actual transformation toward co-production as this thesis does.

The thesis implies that this changed perception is connected to the degree of digitalization - with more accessible ICT and increased ICT use, it is easier to communicate quickly and reach larger groups of individuals (Linders, 2012; Lember, 2018; Sørensen, 2016). In addition, the thesis observes that the changed perception is connected to increased fiscal constrain within the response domain, together with higher demands for increased quality from the public and citizens (Bason, 2018). The municipal professional responders have to think of new resources and effective solutions to supplement the professional response. Digitalization then 
becomes an enabler for realizing these innovative new methods. This change in perception is further described below, based on the thesis's two case studies.

In the first case study, that of network collaboration between municipalities, there was skepticism toward engaging citizen volunteers without any specific response competence. The municipal officials in the case study had difficulties seeing how these citizens would be an asset. The municipalities were only positive toward collaboration with volunteers with specific competence, which is referred to as the professionalization of volunteer engagement (Steen et al., 2018).

However, in the second case study, the attitudes of the collaborating municipalities were very different. They perceived citizen volunteers as an important solution for improving the emergency response - meeting the public's demand for high-quality public services while at the same time facing reduced economic resources and high staff workloads. Thus, this thesis illustrates a new way for citizens to engage voluntarily, i.e. through co-production. The professionals within emergency response developed an informal collaboration with citizens. This new innovative way to engage citizens, one of the first of its kind in Sweden, was then spread from Medelpad Municipality's rescue service association (the thesis's second case study), to other rescue services in Sweden - including to cities, and not only to sparsely populated and remote areas (Pilemalm, 2020).

The results of this thesis are thus based on one of the first example of coproduction in Swedish emergency response. Sweden as a setting is of particular interest because the country is seen as progressive within the emergency response domain. Most of the literature on co-production within the emergency response domain emanates from Sweden, and there is a high degree of interest in previous and contemporary studies on Swedish emergency response (e.g. Pilemalm, 2020; Ringh et al., 2011; Berglund et al., 2018). While this thesis studies one of the first examples of coproduction in Swedish emergency response, there is ample scope to learn from and be inspired by this thesis - in terms of both the practical development of citizen volunteers as first responders and the international emergency and crisis response domain.

The thesis shows that citizen volunteers - even those without specific competence - are seen as valuable responders by professional responders. Hence, the risk of professionalization in co-production presented by contemporary literature (Steen et al., 2018) was not displayed in the thesis. As well as finding that there has been a changed perception toward citizen volunteers in emergency response, this thesis also shows how this perception has changed - the demand for specific competence is no longer 
a basis for excluding citizen volunteers, and these volunteers are now also seen as important contributors in the response.

Even though the main focus of the thesis is on ICT-enabled coproduction, inter-municipal network collaboration remain important, and are also essential to develop further. Collaboration between governments is vital for effective crisis and emergency response, and Covid-19 is a clear example of this (Huang, 2020). The thesis argues that co-production is an emerging phenomenon that has developed in parallel with inter-municipal network collaboration (Brandsen et al., 2018; Cheng et al., 2020). In other words, there is a growing understanding within the crisis and emergency response domain of the importance of co-production and citizen volunteer engagement, and of the need for this to develop further in order to cope with future emergencies and crises. Here, this thesis is of specific importance because it contributes to the knowledge of changed perceptions of citizen volunteers - i.e. their increased collaboration with professional responders in service delivery and a better understanding of this collaboration.

\subsubsection{ICT-enabled co-production - an increase in complexity}

The results of this thesis point toward certain essential aspects that are particularly important when developing ICT-enabled co-production compared to ICT-enabled inter-municipality network collaboration. Taking a sociotechnical systems approach, essential aspects of the ICT system are emphasized to include both social components and technical components (Bostrom and Heinen, 1977a and 1977b; Mumford, 1995; Land, 2000; Lin and Cornford, 2000). However, by adding complementary theory and approaches, the thesis further clarifies and describes these social and technical components which are mentioned in earlier sociotechnical literature (e.g. Bostrom and Heinen, 1977a and 1977b). The additional theories which are said to further describe the social and technical components, and are thus used in the thesis, are network collaboration, collective action with reference to the institutional analysis and development (IAD) framework (mostly Carlsson, 2000; Ostrom 1994), and the implementation of digital innovations in sociotechnical contexts (mostly Linton, 2002). The social aspects are important because they provide knowledge about how to shape each instance of co-production based on the specific context (Bovaird and Loeffler, 2012).

This thesis divides the social and technical components into seven aspects: problem definition, generalized belief and common ground, physical and organizational environment, formal and social control, complexity of technology and technology knowledge, technology divisibility 
(i.e. incremental project management), and technology championing (key actor) - see chapter 3.5 for information about each aspect.

End-user involvement is emphasized in previous literature (Gulliksen et al., 2003; Markus, 1983; Iivari, 2010; Bjögvinsson et al., 2012) regarding ICT development, and the development of ICT in co-production is no exception. Thus, the end-user involvement is underlined in the framework by including it in the framework's seven aspects.

By building an analytical framework, the thesis enhances our understanding of the social and technical components of the ICT system by further developing previous literature and identifying seven essential aspects for a sociotechnical systems approach to ICT-enabled coproduction. Drawing support from the aspects in the analytical framework, the thesis analyzes ICT-enabled co-production within the crisis and emergency response domain.

Some previous studies also describe certain aspects from a citizen volunteer perspective. This thesis complements this literature, as the previous studies only study one or a few aspects, or examine different perspectives to this thesis, such as cross-sector collaborations (Yousefi Mojir and Pilemalm, 2014) and citizen engagement through social media (Linders, 2012). Thus, the thesis provides a more comprehensive and enriched knowledge of what the components of the ICT system may be from a sociotechnical systems approach, and thus of what is important when developing ICT-enabled network collaboration.

When examining the differences between developing ICT-enabled coproduction and ICT-enabled inter-municipal network collaboration, the same aspects appear to applicable for both collaboration types. In other words, in the transformation of the response domain, the important aspects when collaborating are largely the same as before. (For a detailed analysis of these aspects, see chapter 4.3.2 for co-production and chapter 4.2.2 for inter-municipal network collaboration. For a comparison of these, see chapter 4.4.1.)

However, when developing ICT-enabled co-production, the thesis points out that some of the aspects increase in complexity compared to ICTenabled inter-municipality network collaboration. This especially concerns the aspects of organizational environment (e.g. how to integrate nonorganizational citizen volunteers into the ICT response system) and formal and social control (e.g. legal and confidentiality implications). The thesis also shows that these aspects are closely connected to technology knowledge. When adding the framework aspect of end-user involvement and the influence of digitalization, this also leads to additional challenges 
and opportunities when developing the co-production. These implications are further addressed in the next section.

\subsection{The opportunities and challenges of ICT-enabled co-production}

This section further analyzes and discusses the sociotechnical aspects identified above, and relates them to the opportunities and challenges of ICT-enabled co-production.

\subsubsection{Using citizen volunteers as responders: the impact on public service delivery}

The results of this thesis show that citizen volunteers can be an effective form of support in crisis and emergency response. For every response, at least one citizen volunteer responded even though this was voluntary - the citizen had no obligation to respond. In addition, there was an increase in perceived safety and a feeling of support from "society" - knowing that help is not far away if there is an emergency, and that "victims" do not have to be alone in a difficult situation.

However, in connection with the physical environment (Carlsson, 2000), the thesis notes that citizen volunteers' major engagement may be within confined areas - close to their neighborhood. Some of the citizen volunteers were highly engaged to respond close to their neighborhood, but if a response alert occurred "outside" this geographical area, they might not feel such a high engagement to respond. This can refer to the local action arenas for network collaboration and especially for co-production (Carlsson, 2000; Ostrom, 1994). However, the opposite attitude also existed among other citizen volunteers in the thesis's co-production case study - some citizen volunteers were not confined to their immediate geographical neighborhood when it came to responding. Thus, there seem to be different perceptions of local action arenas among citizen volunteers, based on the thesis's second case study of co-production. In other words, local action arenas can both encourage and constrain collaboration (Carlsson, 2000; Ostrom, 1994).

Despite the potential challenge of confined response arenas, the citizen volunteers facilitated the work of the professional responders by providing useful information that led to a faster professional response and improved the preparedness of the professional response. Similar benefits of coproduction are also supported by previous and contemporary literature which claims that co-production leads to better quality service (Pestoff et al., 2012; Loeffler and Bovaird, 2018; Lember, 2018). If successfully developed 
and conducted, co-production could represent "good value for money" (Loeffler and Bovaird, 2018:273). As a related example, it has been claimed that co-production can improve the quality and efficiency of public services in terms of reduced injuries associated with traffic accidents (Loeffler and Bovaird, 2018; Lember, 2018). At the same time, other literature argues there is always a risk of poor service quality in network collaborations (Agranoff, 2007; Weber, 1998). Several studies also argue that more research is needed into the effects and outcomes of co-production (Pestoff et al., 2012; Brandsen et al., 2018). This thesis supports the previous and contemporary literature which claims several benefits of co-production, and it enhances our understanding of how citizen volunteers can lead to a more effective response.

In summary, citizen volunteers are deemed to be effective responders and to improve the preparedness of the professional response. Further, this thesis provides an understanding of how citizen volunteers can be engaged in order to obtain a more effective response, despite resource deficits and in combination for higher quality.

\subsubsection{Mobile app technology for citizen volunteers as responders}

With an end-user perspective on ICT-enabled co-production, this thesis shows the importance of understanding the needs of citizen volunteers in the light of digitalization. Citizen volunteers might need forms of support and structures other than a completely new ICT system, and may already have sufficient ICT on their smartphones, for instance, to which useful apps can be downloaded (Lember, 2018). Instead, it could be more useful to explore how to enhance existing ICT with additional functionality rather than starting from scratch with a new system (Sørensen, 2016). In short, presupposing that the citizen volunteers have "nothing" before the specific ICT system is developed could lead to unnecessary detours.

This thesis demonstrates that mobile apps, i.e. mobile technologies with applications that package functionalities, are suitable for ICT-enabled coproduction in crisis and emergency response. The citizen volunteers in this thesis's case study of emergency response are infrequent users. There are few alerts in rural areas, the technology is not used on an everyday basis. This needs to be considered when developing the technology (Harnesk and Lindström, 2011). This has similarities with crisis response, because crises occur infrequently. In this thesis's first case study of crisis response, this was also important even though the end-users were professional responders. For citizen volunteers who respond in a crisis, having ICT that is suitable for infrequent users would not be of less importance than for professionals 
responding in a crisis. Thus, it is especially important that the technology is easy to use and intuitive. It is then a clear advantage to use a device that the end-users normally use in their everyday lives. The results of this thesis show the advantages of mobile apps from an end-user perspective, and are supported by recent literature on citizen volunteers (Berglund et al., 2018; Pilemalm, 2020). It is also argued in related research that the technology enables citizens to co-produce at any time, wherever they are. For instance, they do not have to be at home to be able to receive an alert (Lember, 2018).

Moreover, when using an existing device, the cost can also be kept low. App development is also relatively cost-efficient, and studies claim that mobile apps cost at least $80 \%$ less to develop than phone-based solutions (Clark et al., 2013). Previous and contemporary research point toward other costs, for instance hidden transaction costs, incremental costs, and costs and investment for the professionals and citizen volunteers involved (Agranoff, 2007; Loeffler and Bovaird, 2018). However, the increased transaction costs and investments, such as those for platforms, apps, and databases, are often only an initial cost (Loeffer and Bovaird, 2018; Linders, 2012).

There are also several previous and contemporary studies in which smartphone apps, sometimes combined with online platforms, have been used for ICT-enabled co-production, although these studies do not label it as co-production (e.g. Havlik et al., 2016; de Lanerolle et al., 2010; Meissen et al., 2017; Schmidt et al., 2018; Schönböck et al., 2016; Paletti, 2016). One example is the Mobile Life Saver (MLS) app in Stockholm, Sweden, where citizens are alerted to out-of-hospital cardiac arrests (OHCAs) by geographically locating the citizens using their mobile phone positioning system and linking information about where to find the closest automated external defibrillators (AEDs) to perform cardiopulmonary resuscitation (CPR) (Ringh et al., 2011; Berglund et al., 2018). Another example is online platforms used in crises, where citizens are alerted by SMS when their verified personal profiles include the skills and competencies needed (Schmidt et al., 2018; Meissen et al., 2017). In summary, several studies claim that mobile apps make it easier for citizens to participate and engage in crisis and emergency response. This thesis confirms these studies regarding mobile apps' strong advantages, even though the devices (mobile phones) for the response do not include the "latest" technology (e.g. AI) in the thesis's co-production case study. The thesis also shows that citizen volunteers need a device they know, that is simple to use, and that they always have with them. This is especially important when it comes to emergency response in remote areas with few alerts, and could also be transferable to crisis response where the end-users may have to learn how to use the technology quickly and occasionally. 


\subsubsection{Emphasis on the ICT development process and end-user-based functionalities}

Even though previous and contemporary literature about citizen volunteer engagement and co-production agrees on the advantages of mobile apps, these studies often take mobile apps for granted - they do not explore the technology further (e.g. Havlik et al., 2016; Meissen et al., 2017; Schmidt et al., 2018; Berglund et al., 2018). Thus, there is little research on studies exploring the interconnectedness of the ICT used. The ICT system's development process is seldom addressed, especially in relation to the needs of the end-users themselves and which functions are developed, as explored in this thesis. Instead, previous and contemporary studies seem to focus on the general role ICT plays in supporting co-production, and only describe the ICT system on a general level (e.g. Lember et al., 2019; Verschuere et al., 2012). Thus, the ICT system is studied at an overall level and the requirements and ICT functions are not included, at least not with an enduser involvement perspective. This thesis takes this assumption on the advantages of mobile apps further by adding an end-user perspective and suggesting functionality based on end-user needs.

In other words, this thesis addresses the ICT development process in ICT-enabled co-production and it is thus possible to go further than simply concluding that mobile apps are a suitable technology. This thesis shows that, with an end-user focus, basic functionality in mobile apps enables citizen volunteers to be first responders, i.e. to perform initial actions that might limit material damage, increase perceived safety, and even save lives.

If an even more effective response is desirable, more functionality can be added in a stepwise manner. This is also referred as "technology divisibility" (Linton, 2002). The added functionality concerns improving both the citizen volunteers' conditions and their safety (e.g. aborting an assignment), as well as providing even more support for the professional responders. More specifically, the added functionality concerns two-way communication between citizen volunteers and professionals during the response. Thus, the professionals can be better prepared when they arrive, i.e. they can take actions more quickly at the incident site and even before arriving (see chapter 4.3.4 for all identified functions). With more ICT functionality, citizen volunteers could make an even greater contribution to an improved response.

At the same time, this thesis also argues that more functions do not automatically lead to a more suitable ICT system - it probably depends on whether or not the functions are end-user-based (Gulliksen et al., 2003; van den Besselaar, 1998; Vines et al., 2012; Markus, 1983; Iivari, 2010). Thus, 
the thesis shows the advantage of end-user involvement. In fact, it is difficult to accomplish an adaptable ICT system without it.

\subsubsection{The need for end-user involvement in order for ICT to truly enhance co-production}

As addressed in the above section, there is a need for end-user-based functionalities in ICT-enabled co-production. End-users have to be involved in the ICT development process to achieve this, which this section elaborates on.

With an end-user perspective on ICT-enabled co-production, this thesis shows that citizen volunteers as end-users need various solutions in order to become involved - one solution does not fit all (e.g. online versus physical meetings). In other words, this thesis points to dilemmas related to the heterogeneity of the citizen group itself, which is commonly addressed in end-user participation literature (e.g. Holgersson and Karlsson, 2014). Some end-users do not have sufficient technology knowledge (Linton, 2002). They can use apps, but they need help from educators or other endusers with more technology knowledge to help them learn how to use the app, and how to download and search for new apps. Thus, end-users with only general technology knowledge may be excluded if they do not receive the necessary support. Previous and contemporary literature highlights the risk that end-users will be required to have the "right" knowledge and competence in order to be involved (Dodge, 2012; Steen et al., 2018). Thus, the needs of end-users - no matter what their level of technology knowledge - are important to identify using techniques aiming to achieve active user participation (Schuler and Namioka, 1993).

The thesis also shows that, with general technology knowledge, citizen volunteers can act as informal developers of the ICT system. This is connected to the influence of digitalization and the openness of the ICT system's infrastructure, i.e. mobile phone-based (Sørensen, 2016, Tilson et al., 2010). Citizen volunteers can add additional functions using other technologies, such as online maps, GPS, and search engines. This give endusers the opportunity to develop the technology in an ICT system on their own, without relying on the formal developer of the ICT response system. Hence, they can adapt an ICT system on their own. At the same time, this makes it difficult to foresee how the ICT response system and the information it contains will be used by citizen volunteers, which is further addressed in section 5.3.5.

Another challenge which this thesis demonstrates, no matter what the technology knowledge of the end-users, is that the actual practical end-user involvement becomes more complex, for instance, how and when to involve 
users, and the amount of time to be spent on their involvement. Previous research identifies similar challenges in user participation in general (Pilemalm, 2018a; Oostveen and van den Besselar, 2004). This thesis elaborates on these challenges and connects them specifically to ICTenabled co-production. In the thesis's second case study, the professionals had to meet citizen volunteers outside office hours. Also, because of the long geographical distances, they had to spend a significant amount of time traveling, which made it difficult to meet the volunteers as often as desired. This is connected to the level of technology knowledge to some degree, since online meetings did not work because only the end-users with high technology knowledge participated.

Despite the heterogeneity of citizen volunteers with different levels of technology knowledge, there is high engagement from all the citizen volunteers to be involved in the ICT development process, based on the thesis's case study of co-production. This stands in contrast to some previous and contemporary literature, which highlights a lack of motivation and a lack of time to participate on the part of citizen volunteers as end-users (Kotamraju and van der Geest, 2013; Jansen, 2006; Lember, 2018). Other studies argue that the willingness to participate is in fact often high (Holgersson and Karlsson, 2014). Hence, this thesis confirms the findings of Holgersson and Karlsson (2014), in that motivation and engagement among end-users was substantial and remained so as the co-production continued.

Another challenge regarding how to involve the end-users is connected to the formal organizational environment (Carlsson, 2000). While the structures and tasks in organizations can often be partly reproduced in the ICT development, the co-production generally lacks such structures which complicates end-user involvement and the integration of the technology. Similar findings have also been observed in previous and contemporary research regarding a lack of organizational affiliation - in addition to heterogeneity and difficulties achieving active involvement, as addressed above - but not specifically regarding co-production (Holgersson and Karlsson, 2014; Yousefi Mojir and Pilemalm, 2014; Jansen, 2006). Thus, this thesis enhances our understanding of end-user involvement in ICTenabled co-production.

The challenges and opportunities due to the citizen volunteers' lack of formal organizational environment is further addressed below in connection with the implications of the overall structure of co-production (i.e., how to integrate citizen volunteers into the ICT system). 


\subsubsection{Non-organizational affiliation of the citizen volunteers - both a challenge and an opportunity}

The citizen volunteers involved in the co-production engage without belonging to a formal organization, i.e. they have no formal organizational environment (Carlsson, 2000). Thus, they lack a formal organizational structure to connect with the professionals' organizational structure, such as regulations, formal responsibilities, obligations, and technology infrastructure (Pilemalm, 2018b; Jansen, 2006; Agranoff, 2007; Weber, 1998). When citizens engage in crisis and emergency response, they are usually formally organized in some way, for instance through formal voluntary organizations. When this way of engaging is not followed - as in this thesis's second case study, where co-production was developed - the complexity increases, as the municipalities organization's structure does not fit or support this type of collaboration. Based on the second case study, it is not desirable for the professionals to direct the citizen volunteers to belong to a formal voluntary organization. Instead, professionals can develop this type of collaboration to avoid formal structures and instead use more informal collaboration, while at the same time being able to shape the collaboration to fit the professionals' needs. Hence, this thesis shows that the challenge for local governments is to find new ways to support this type of collaboration with non-organized citizens.

One specific issue which emerges due to the lack of formal organizational affiliation, and where new innovative ways may have to be found, is how to integrate citizen volunteers into the ICT system used for the response alert. As Kling et al. (2003) underline, both the technological applications and the infrastructure have to be integrated in order for the whole ICT system to function. Thus, this thesis illustrates difficulties in the ICT integration of citizen volunteers as users of the professionals' ICT systems. There are, for instance, legal barriers and legitimacy issues involved in integrating citizens (with no obligations) into a government's ICT system. Another alternative is a separate ICT system for the citizen volunteers, but then the professionals will also need to access and use this ICT system in order to receive information if citizen volunteers respond, and to communicate with them. The professionals will then need to use two parallel ICT systems, which could lead to difficulties from an end-user perspective.

Previous and contemporary literature does not identify these complexities of ICT integration (e.g. Meijer, 2012; Lember, 2018). However, contemporary literature stresses the importance of understanding the technological impact of co-production for governments (Steen et al., 2018). 
Thus, this thesis enhances the contemporary literature by increasing our understanding of the implications of the technological impact for governments when they co-produce. One reason why these complexities are not addressed in contemporary and previous literature may be that they mostly emphasize other types of co-production and not full or heavy coproduction (Bovaird, 2007; Pestoff, 2012; Lember, 2018), as is the case in this thesis. Hence, the thesis also demonstrates the importance of studying such forms of co-production (i.e. where the citizen volunteers are involved in the actual delivery).

To summarize, the challenge identified in this thesis involves striking a balance whereby the co-production is still informal yet sufficiently structured and regulated. Thus, this thesis illustrates an empirical example of the paradox and ambidexterity of organizations - how the organizational structure is influenced by collaboration and ICT, for example, and how to achieve a balance between traditional methods and innovative ideas in order to be effective and adaptable in view of the challenges faced by the organization (Thompson, 1967; O’Reilly and Tushman, 2013).

\subsubsection{Ethical and privacy considerations when engaging citizen volunteers as responders - a lack of formal and social control}

The organizational environment aspect discussed above is closely connected to the aspect of formal and social control (Carlsson, 2000). Because the citizen volunteers have no formal organizational affiliation, there is also a lack of formal and social control. In more detailed terms, there is a lack of regulations, responsibilities, and safety protection for the citizen volunteers who act as responders. Citizen volunteers who co-produce become providers of crisis and emergency response, and act as representatives of the professional crisis and emergency response. Thus, confidentiality, privacy and ethical issues might arise between citizen responders and individual victims at the response site, and this thesis argues that having some regulations and structures is essential. These challenges are missing from related literature (e.g. Brandsen et al., 2018; Lember et al., 2019), which appears to relate to the above discussion that the thesis's co-production type has been overlooked in previous and contemporary literature, i.e. where citizen volunteers are involved in the delivery of the public service (Ostrom, 1996; Alford and O'Flynn, 2012).

Moreover, even if the ICT response system did not handle sensitive information, the citizen volunteers added information from open sources and could thus indirectly obtain sensitive information. This can be linked to the framework's aspect of formal and social control (Linton, 2002). Similar 
risks are addressed by Meijer (2012), albeit in relation to social media forums where the police share information and citizens can become involved in police actions. Meijer (2012) address this as a risk of citizen privacy when 'mixing information sources' with 'mixing functions' (Meijer, 2012:203204). It is important to note that, despite the personal integrity and privacy risks identified in the literature, this was not perceived as an important issue in the thesis's co-production case study. It was discussed by the citizen volunteers and the professionals, but was not considered to be an argument for not engaging citizens in order to improve the response. Although the risk involved with sensitive information was not observed in the case study of coproduction, the thesis's framework aspect of formal and social control (Linton, 2002) and additional previous literature (Meijer, 2012; Rubenfeld, 2008) imply that governments should at least be aware of this risk, and whether it is appropriate, violates any regulations, or raises ethical considerations. As Rubenfeld (2008) observes, there is a tendency to prioritize safety over privacy. Thus, the risk of citizen volunteers getting hold of sensitive information may be balanced by the possibility of saving lives or material assets. If a person suffers heart failure, their personal privacy is less important than their chances of survival. However, different people have different priorities when it comes to their personal privacy. If the incident involves limited material damage, for instance, then some individuals may prioritize their personal privacy. However, it can be difficult to predict the seriousness or size of an incident's consequences when receiving an alert.

In summary, this thesis enriches previous and contemporary literature (Meijer, 2012; Brandsen et al., 2018; Paletti, 2016; Lember et al., 2019) by identifying that there are challenges relating to safety, ethics, and privacy when engaging citizen volunteers as responders, and governments must consider these challenges.

\subsubsection{High engagement from citizen volunteers and high personal democratic values}

Despite the challenges addressed above, opportunities are also identified in ICT-enabled co-production. The citizen volunteers in this thesis willingly spent their spare time being responders. They placed high personal value on the co-production, and on playing a part in the safety of the community. The co-production was seen as a positive change, as a public service improvement, in contrast to the more common reductions in public services within the community. Recent studies (Lember, 2018; Pilemalm, 2020) also support the thesis's findings by arguing similarly that ICT-enabled coproduction can ease inclusion and empower citizens, in other words creating 
generalized beliefs and common ground (Carlsson, 2000). However, some studies also point out that although more research is necessary, aspects such as social capital, socio-economic context, and the extent to which one is well established in society influence citizens' possibilities to co-produce (Thijssen and van Dooren, 2015; Pilemalm, 2020; Dietrich et al., 2017; Guldåker and Hallin, 2014). Other studies argue that empowerment not only concerns resourceful citizens, as in the case study in this thesis, but can also cut across barriers and stimulate social capital, as well as trust (Clark et al., 2013; Loeffler and Bovaird, 2018; Ewert and Evers, 2012).

Previous and contemporary literature also argue that if the perceived potential effects of the co-production do not occur, this can lead to trust issues, not only for the specific co-production, but also for the opportunity to play a part in society and to be considered as a contributor within the community (van Eijk and Steen, 2014; van Eijk et al., 2017). This involves a risk of co-destruction rather than co-production (Steen et al., 2018), for instance in crisis and emergency response. Previous literature mentions the inequality of power relations and even a risk of reduced democracy (Agranoff, 2007; Weber, 1998). These risks were not seen in this thesis. In the co-production case study, the citizen volunteers perceived good opportunities to engage in the response. However, as the co-production evolved, more needs - both physical material needs (e.g. torches and fire extinguishers) and technology needs - were identified by the citizen volunteers. Some of these needs could be met by the municipalities, but not all of them. However, there were no indications in this thesis that the needs that were not met influenced the citizens' trust or their perceived opportunities to engage in the co-production. This may be explained by the existence of generalized belief and common ground (Carlsson, 2000) between the citizen volunteers and the professional responders.

To summarize, this thesis suggests that there is high level of engagement from the citizen volunteers and a perceived high value of the co-production for the community, which was seen by the citizens as a positive initiative from the local government. The citizen volunteers shared generalized beliefs and common ground (Carlsson, 2000), which facilitated their engagement. In addition, the citizens had high social capital and were well established in society (Brandsen et al., 2016), which also assisted their engagement in the co-production. 

Chapter 6

\section{Conclusions and future research}

This thesis provides an example of how information and communication technology (ICT) can enable new types of network collaborations - coproduction - between governments and citizen volunteers, for a more effective crisis and emergency response.

The chapter is structured as follows. In the first section, the conclusions of the thesis are summarized and connected to the thesis's objectives. Thereafter, the thesis's major theoretical and practical contributions are addressed. The transferability and limitations of the thesis's results are then reflected upon. The chapter ends with a discussion of future research.

\subsection{Summary of conclusions}

The thesis's conclusions are addressed with reference to the thesis's objectives in the two sections below.

\subsubsection{Transformation of the crisis and emergency response domain - toward ICT-enabled co-production}

The thesis's first objective was to describe the transformation from ICTenabled inter-municipality network collaboration toward ICT-enabled coproduction within crisis and emergency response.

In order to address this objective, the thesis describes how the municipalities' initiatives at the beginning of the 21st century were focused on ICT-enabled inter-municipal network collaboration to achieve a more effective response. Several crises occurred at the time which demonstrated a lack of an effective response, and there was increased demand for higher quality (Kaiser et al., 2004; Parker et al., 2009; SOU 2005:104; SEMA, $2005 \mathrm{~b}$ ). However, the resources available to each municipality for response delivery were insufficient, and hence one solution was to come together with other municipalities to obtain additional financial and staff resources through network collaboration (Carlsson, 2000; Agranoff, 2007; Wankhade and Murphy, 2012).

Even though ICT was expanded at this time to include more interactive processes and technologies to encourage citizens to participate (Sæbø et al., 
2008; Asgarkhani, 2005; Janowski et al., 2012), the municipalities were not interested in collaborating with informal (unaffiliated) citizen volunteers with non-specific competence - they found it hard to see how citizen volunteers could assist with the response. In fact, the municipalities were actually more interested in how they could manage spontaneous citizen volunteers who got in the way of the professional response. Thus, the municipalities tried to keep these volunteers' engagement to a minimum.

In view of heightened public service challenges, such as increased resource constraints, higher quality demands, and societal challenges, including increased vulnerabilities and threats (Bason, 2018; Haddow and Bullock, 2013), the thesis shows a changed perception of citizen volunteers in the response domain about ten years later. The collaboration between municipal professional responders is no longer deemed sufficient in order to achieve a more effective response. Thus, municipalities have to think in new innovative ways to complement the existing collaborations. One such way is to use citizen volunteers in co-production, viewing them as an unutilized resource rather than a hindrance to an effective response.

Around this time - at the beginning of the 21st century (2006-2007) and about ten years later (2014-2017) - there was also strong growth in ICT use within society in general, and within the response domain in particular (Bason, 2018; Bonsón et al., 2012; Haddow and Bullock, 2013). These new digitalization opportunities (Tilson et al., 2010; Sørensen, 2016) are used to facilitate ICT-enabled co-production. Co-production is an attempt to collaborate in a different way with volunteers compared to previous collaborations (such as part-time fire brigades, local home guards, and formal volunteer organizations) for response delivery. Co-production requires fewer resources from professional municipal responders than earlier volunteer collaboration. Citizen volunteers are alerted via basic SMS technology on their personal mobile phones, but with the ability to add functionality such as GPS themselves, thus making it an open sociotechnical system (Tilson et al., 2010). The volunteers sign up and receive basic training. However, the professional responders perceive it as an informal arrangement - the citizen volunteers participate voluntarily and there is no obligation to respond, not even to answer when receiving an alert. The citizen volunteers have no specific regulations to follow - they only respond in their role as a citizen. The thesis thus shows how ICT-enabled coproduction can be a resource-effective solution to complement the professional response, at a time when local governments face fiscal constraints in combination with increased societal vulnerability and threats.

The enhanced use of ICT in society and within crisis and emergency response - in other words, digitalization (Tilson, et al., 2010; Sørensen, 
2016) - thus leads to new possibilities to engage citizen volunteers within the response. When comparing two different time periods, within the response domain and in terms of general ICT developments, as in this thesis, it is possible to observe a changed understanding of ICT as a means of support for response. The two time periods influence how ICT was understood as an enabler of collaboration. During the first time period, the end-users had difficulties understanding ICT's potential to support them in their response. During the later time period, ICT had become easier to use and to understand as an enabler of new collaborations. Hence, with increased digitalization, end-users' technology knowledge (Linton, 2002) also grows, which in turn facilitates ICT use.

This thesis thus argues that the municipal professional responders' perception of citizen volunteers has changed in line with the development and use of ICT. Along with ICT-enabled inter-municipality network collaborations, municipalities also collaborate directly with informal (unaffiliated) groups of citizen volunteers. Thus, there has been a transformation in the response domain to include other types of citizen volunteer engagement - a development toward ICT-enabled co-production.

\subsubsection{Implications of ICT-enabled co-production}

The thesis's second objective, based on the description above, was to identify implications, i.e. challenges and opportunities to develop future ICTenabled co-production.

The thesis identifies several opportunities of ICT-enabled co-production, although there are also several challenges which need to be addressed - both for the municipalities and for the citizen volunteers who become responders. Co-production in crisis and emergency response brings new opportunities to improve and to achieve a more effective response. At the same time, the thesis concludes that co-production faces additional challenges other than inter-municipal network collaboration. In particular, these challenges concern the organizational environment (e.g. a lack of structure on which to build co-production and regarding the integration of citizen volunteers into the ICT response system) and formal and social control (e.g. regulations, safety concerns for the citizen volunteers as responders, and confidentiality, privacy, and moral issues).

The most prominent opportunities and challenges when developing ICTenabled co-production can be summarized as follows:

Opportunities:

- A high degree of engagement from citizen volunteers

- an effective complement to professional response 
- co-production does not demand significant resources from the municipalities

- only a basic ICT system is needed in order for citizen volunteers to be responders

- the ability for citizen volunteers to add ICT functionalities on their own

- perceived safety is increased and the community is empowered Challenges:

- a lack of formal organizational affiliation for citizen volunteers (no structure on which to build co-production)

- integrating citizen volunteers into the ICT response system and the difficulty of identifying a common ICT system for professional responders and citizen volunteers

- striking a balance between informal and necessary structure of co-production (e.g. protection of citizens with insurance)

- risk of privacy and ethical dilemmas

- complexity of involving citizen volunteers as end-users in the formal ICT development process

The thesis concludes that if the above challenges are addressed, ICTenabled co-production could make a long-lasting contribution to effective crisis and emergency response.

\subsection{The thesis's contributions}

The phenomenon of Swedish crisis and emergency response collaboration was virtually unexplored at the beginning of the thesis's first case study in 2006. It has since been developed into a concept in the response domain (e.g. Díaz et al., 2016; Alford, 2014; Imani and Schlappa, 2018; Pilemalm, 2020). Thus, the work of this thesis spans a long period of time, which can be seen as both a strength and problematic. Some may question the relevance of contributions from research at the beginning of the 21st century. At the same time - especially during a period of rapid ICT development and increased focus on co-production within IS and other research disciplines, as well as among governments and citizens in practice (e.g. Bonsón et al., 2012; Pestoff et al., 2012; Brandsen et al., 2018; Ostrom, 1996) - such research would appear to be essential for understanding the transformation toward ICT-enabled co-production and its implications. An understanding of the past and the present can facilitate comprehension of the transformation and direction of similar future ICT-enabled coproductions in crisis and emergency response. The scientific and practical contributions of this thesis are addressed below. 


\subsubsection{Scientific contributions}

The thesis contributes to an enhanced understanding of previous and contemporary research on ICT-enabled co-production, end-user involvement, and sociotechnical systems approaches within the application domain of crisis and emergency response.

This thesis has a holistic perspective on the response domain. It thus demonstrates both the possibility and the need for a more holistic perspective, and not studying crises and emergencies separately in silos, compared to much of the previous and contemporary literature (e.g. Ringh et al., 2011; Berglund et al., 2018; Auferbauer et al., 2015; Havlik et al., 2016). In this way, the true potential of emerging collaborations to engage citizen volunteers as responders can be better understood. One example is the advantage of using the same ICT systems when citizen volunteers respond, regardless of whether the situation is an emergency or a crisis (Paper V). The thesis points to similar ICT functionalities and common citizen volunteer end-user needs, irrespective of whether they respond to a crisis or an emergency.

Moreover, regarding combining perspectives, there is also a need to cross-fertilize different research disciplines when studying ICT-enabled coproduction (Pestoff et al., 2012; Brandsen et al., 2018; Gil-Garcia et al., 2018). The thesis contributes in this respect by combining the IS discipline with public administration. The IS discipline's focus is related to increased digitalization and how ICT changes and influences the opportunities to support co-production by using basic technologies in new ways (e.g. Linders, 2012; Paletti, 2016; Meijer, 2012). This is combined with the public administration discipline's rapidly-growing network collaboration coproduction, whereby citizens are engaged in governments' service delivery to overcome resource deficit and increased societal vulnerabilities and challenges (e.g. Carlsson, 2000; Linton, 2002; Ostrom, 1994). This focus makes the thesis's contribution distinctive and increases the possibility to capture the complex character of ICT-enabled co-production and its implications. The thesis's implications concern the impact on governments and citizen volunteers, the ICT development processes, and how to achieve an adaptable, end-user-based ICT system. These contributions will be discussed in greater detail below.

The thesis identifies implications for ICT-enabled co-production, in terms of both challenges and opportunities. An analytical framework has been gradually developed and used to support and connect the analysis to the thesis's theoretical foundation (consisting of a sociotechnical systems approach, co-production/network collaboration, and end-user involvement). The framework consists of certain aspects which previous 
theory and research have deemed important to consider when developing ICT-enabled network collaboration, including co-production (Carlsson, 2002; Linton, 2002). The thesis's implications thus concern scientific contributions regarding government implications (when citizens become closely involved in the delivery of the response) and consequences for the specific co-production (the challenges involved in getting it working and the opportunities that arise once it is working). In other words, the thesis contributes to describing the phenomenon whereby ICT enables citizen volunteers to become involved in the delivery of the response. Hence, the thesis enriches our understanding of an emerging type of citizen volunteerism, referred to as full or heavy co-production (Lember, 2018; Bovaird, 2007; Pestoff, 2012). This understanding is growing, but has not yet been studied in previous or contemporary literature to any great extent. The thesis's contribution may not be confined to the crisis and response domain; it may also contribute to a deeper understanding of a wider public government context, such as which challenges and opportunities exist for involving volunteers to provide ICT-enabled public service in connected research areas, for example e-government.

The thesis also enriches our understanding of the ICT system used in coproduction, including the social and technical components of an ICT system (Bostrom and Heinen, 1977a) and the influence of digitalization (Sørensen, 2016; Tilson et al., 2010). This type of ICT-enabled co-production seems to be absent from previous and contemporary co-production literature (Meijer, 2012; Lember, 2018) and the general engagement of citizens as volunteers in crisis and emergency response (Ringh et al., 2011; Pijls et al., 2016; Schmidt et al., 2018; Ferguson et al., 2016). The thesis thus helps to fill an urgent knowledge gap. It also takes previous and contemporary research one step further by not only confirming the advantages of mobile technologies (Schmidt et al., 2018; Meissen et al., 2017; Berglund et al., 2018) but also showing how the ICT development process of mobile apps can be addressed and what kinds of end-user-based functions this can result in more generally - not only confined to a specific mobile app technology.

Regarding contributions to the literature on achieving an adaptable ICT system, previous end-user involvement literature within the IS discipline is often focused on methodologically involving end-users, for example through PD techniques (e.g. Bjerknes et al., 1987; Tollmar, 2001; Iversen et al., 2010). Although this is important, there is a lack of emphasis on the actual implications of involving end-users with non-formal organizational affiliation in the ICT development process, and with the influence of digitalization (Sørensen, 2016), which this thesis addresses. Thus, this thesis adds to previous literature on understanding the involvement of end- 
users with non-organizational affiliation in the ICT development process. In addition, the thesis points out how digitalization influences users' involvement in the ICT development process by providing new prerequisites for them. The digitalization facilitates their involvement in developing the technology, sometimes at their own initiative without the awareness or involvement of formal developers (Tilson et al., 2010). Thus, the thesis also enriches the IS discipline on a general level by emphasizing users outside formal organizations who do not use the ICT system in their role as workers (Sørensen, 2016).

\subsubsection{Practical contributions}

The thesis's practical contributions include "hands-on" knowledge. This is especially important at a time when societal vulnerabilities are increasing and governments have scarce resources to deal with crises and emergencies. Since the thesis's empirical data collection was completed, several crises and emergencies have occurred, including major forest fires (Murphy, 2020) and pandemics (Huang, 2020), with financial instability as one consequence. Government reports and both previous and contemporary literature show that citizen volunteers are an important but still underutilized resource in these crises and emergencies (SOU 2019:7; Rogstadius et al., 2013; Johansson et al., 2018; Murphy, 2020), especially in terms of the possibility to use adaptable ICT systems. Moreover, when the thesis's case study of co-production within emergency response in Sweden's Medelpad Province began in 2014, it was one of the first initiatives of its kind and quickly spread to other municipalities, and to other contexts such as cities, socio-economically vulnerable areas, and internationally (Pilemalm, 2020; Berglund et al., 2018; Pijls et al., 2016). This suggests that the thesis's results contribute to extensive knowledge of co-production enabled by ICT, which other authorities and volunteers can use to deal with contemporary and future emergencies - both in Sweden and internationally.

This also implies that experiences from emergency responses to frequent and unexpected uncertainties can inspire new crisis response approaches (Weick and Sutcliffe, 2007). This thesis thus demonstrates the likely benefits of taking a holistic view of the whole response domain, no matter what the response type. It argues that there are common questions and potential similar solutions for both crisis and emergency response, for example how to improve response despite resource deficits, how to use citizen volunteers enabled by ICT in new ways, and how to handle infrequent end-users. Although there are differences between crises and emergencies (e.g. difference in response alerts and different societal levels), the results of the thesis imply that there are unutilized synergy effects between these two 
areas. Thus, the common denominator could in some situations be the "response", and which common resources can be utilized (both ICT and as citizen volunteers).

To be more specific, the lessons identified in the thesis can be used by contemporary and future local governments when developing ICT-enabled co-production in crisis and emergency response. These implications can also be used by national and regional agencies within the response domain when planning and adopting strategies for improving response by engaging citizen volunteers. This includes identified challenges and opportunities concerning ICT and its context that must be considered when developing ICT-enabled co-production in crisis and emergency response.

Another practical contribution is the identification of common ICT functionalities for the ICT system when alerting citizen volunteers. As addressed above, there is a need to develop adaptable ICT system with enduser-based functionalities. Digitalization makes these possibilities easier.

In addition, the thesis's analytical framework and theoretical foundation can also provide support when developing ICT-enabled coproduction. To make it easier for practitioners to apply the thesis's findings when developing ICT-enabled co-production, the analytical framework's development aspects (chapters 5.2.3 and 3.5) may instead be expressed in the form of questions:

- End-user involvement: How can the end-users of the ICT system (primarily citizen volunteers, but also professional responders) be involved in the development from the beginning and throughout the process? Is it possible to create forums at the beginning that are easy to manage and maintain?

- Problem definition: What problem will the co-production seek to solve? Do the citizen volunteers and the professionals have a common problem definition? Which tasks will the citizen volunteers perform? What support do they need?

- Generalized belief and common ground: Is there a mutual understanding of what is perceived as good, bad, effective, and desirable? (In order to facilitate engagement and to co-produce.) Are there existing social relationships and interactions? Do the professionals and the citizen volunteers trust each other? Do they already know each other, or are social-bonding activities necessary?

- Physical/organizational environment: What is the physical environment? (A small remote village? Or a town?) Is there a formal organizational structure on which to build co-production? 
Does such a structure need to be created? How much formal structure is desirable?

- Formal and social control: Are there legal issues to consider? Are there ethical, privacy, and/or confidentiality issues? How are the citizen volunteers protected when they act as first responders? What are the citizen volunteers' "obligations", and what support do they receive? (E.g. education/training, material resources.)

- Complexity of technology: What type of ICT is suitable? What needs do the citizen volunteers have? What types of devices and technologies do they already use? (E.g. mobile phones and applications.) Can these be re-used? Are new technologies required?

- Technology knowledge: What level of technology knowledge do the end-users (citizen volunteers) have? How does this influence the methods for involving them in the ICT development? (E.g. online versus physical meetings, degree of training and support needed in order to use the ICT.)

- Divisibility (i.e. incremental project management): Is it possible to start with basic ICT and then improve it as the co-production develops?

- Technology championing (key actors): Are there end-users who can act as technology champions or key actors to promote and be a driving force in the co-production, and especially in the technology development? How can these volunteers be supported? How can the results be shared with others within the co-production?

\subsection{Reflections on the thesis's limitations and transferability}

Reflections on the thesis's limitations and transferability are discussed below. For the thesis's general quality criteria and validity, see chapters 2.7 and 2.8 .

\subsubsection{The conceptual framework - theoretical quality and application area}

The analytical framework for ICT-enabled co-production, which was built and used in this thesis, presents a comprehensive and contemporary understanding of the phenomenon, and describes it based on "human nature and organizational practice" (Whetten, 1989:494). These are all 
factors related to theoretical quality, as argued by Whetten (1989). Moreover, the framework can be evaluated according to its utility and originality (Weber, 2012; Whetten, 1989). The framework was created because there was no existing framework that fully captured the thesis's focus. The framework has been applied in the thesis's two case studies to support the analysis. The simplicity of the framework made it easy to use in the analysis of the case studies. It was also created with the ambition of contributing further to the theoretical foundation of the thesis's analysis, and the analysis thus has a close theoretical connection which can strengthen its transferability. However, I am aware that if theories and approaches other than those included in this thesis (sociotechnical systems, network collaboration, and co-production) had been applied, other aspects of the results could have been highlighted and influenced the outcome.

On the other hand, the framework has only been empirically applied in this thesis, and is thus built to fit the thesis's case studies. The empirical applications of some aspects of the framework were thus emphasized more than others. In another co-production with different prerequisites, other aspects might have been highlighted. To increase the framework's quality and transferability, it needs to be applied further in similar studies. Nevertheless, the framework is flexible and the aspects are on a general level, which implies that it may be transferable to other co-productions in their specific contexts.

\subsubsection{The concept of co-production - connection with other concepts and network collaborations}

Several similar concepts are used to describe the phenomenon studied in this thesis, so there is no easy way to choose which concept should be used. Thus, the choice in this thesis to use the concept of ICT-enabled coproduction might limit the thesis's reach. Researchers and other target groups using other concepts such as e-government, we-government, digital co-production, and co-creation and co-design might perceive this thesis to be outside their area of interest (e.g. Linders, 2012; Brandsen et al., 2018; Sanders and Stappers, 2008). At the same time, the thesis may also fill important knowledge gaps for understanding similar concepts used to describe the phenomenon.

Likewise, the thesis's conclusion mainly concerns a specific network collaboration type: co-production (Ostrom, 1996). However, the thesis's conclusions may also be of interest to other types of network collaborations, such as collaborative networks (Agranoff, 2007), network governance (Loukis et al., 2016), and government information networks (Janowski et 
al., 2012). The similarities are shown in papers I and II, with inter-municipal network collaboration, as well as by the excluded case studies in papers IV and $\mathrm{V}$ regarding cross-collaboration such as co-using and co-location (Yousefi Mojir, 2018). The other types of network collaborations have similarities to the thesis's co-production in terms of context, challenges, and needs. This implies that the thesis's conclusions may be of broader interest for network collaboration types other than co-production.

\subsubsection{Sweden as the setting for the case studies}

The thesis's case studies have Sweden as their setting. The understanding and hence the conclusions may be limited to the context-specific setting studied, and international transferability may be questioned.

On the other hand, since the case studies were conducted co-production has rapidly spread and developed internationally. The case study of Swedish response thus reflects the ongoing public sector collaboration trends, including in other contexts. Moreover, previous and contemporary literature shows similarities between Sweden and international contexts, both in the response domain (e.g. Pijls et al., 2016; Schmidt et al., 2018) and in terms of public service challenges such as resource deficits (Wankhade and Murphy, 2012), increased digitalization (which influences both the use and development of ICT systems) (Bonsón et al., 2012; Linders, 2012; Lember, 2018), and last but not least the importance of end-user involvement in ICT development processes (Iversen et al., 2010).

Therefore, many of the thesis's contribution may also be transferable to settings other than Sweden, such as fundamental response tasks, the need for mobile application technologies, and routines. However, there are also differences, such as instance laws and regulations, governmental structure, and management of the response system - whether centralized at national governmental level or, as in Sweden, decentralized to governance-oriented network structures with strong local governmental autonomy (Sørensen and Torfing, 2007; Bram and Vestergren, 2012). The thesis's findings may thus be mostly relevant to other countries which also have a decentralized governmental response system.

\subsubsection{Using two case studies from different time periods}

The two case studies in this thesis are compared to each other. However, different municipalities have been used in the two case studies, which can of course be seen as a limitation. The emerging phenomenon of engaging informal citizen volunteers with non-specific competence did not occur in 
the case study, which I first conducted regarding inter-municipal network collaboration, but emerged about ten years later in another inter-municipal network collaboration. I therefore conducted the second case study within this collaboration. However, the municipalities in the co-production case (the second case study) had similar perceptions to the municipalities in the first case study at the time when the first case study was conducted. In other words, they also had not perceived citizen volunteers to be useful for response purposes a decade previously, and were focused on other types of collaboration such as inter-municipal network collaboration and formal citizen volunteerism with specific competence. This increases the probability that the two case studies in the thesis can be compared. However, the case studies are not cross-comparable in every aspect, only on an overall level in order to compare two emerging ICT-enabled collaboration phenomena. Thus, it is important to note the limitation that they are not fully comparable. This limitation may be addressed by future research, in which it would be beneficial to compare additional similar case studies, for example involving the same municipalities.

\subsection{Future research}

The knowledge gained from this thesis can be further developed and tested in future research and development for co-production, specifically in crisis and emergency response but also in other public service delivery contexts. There are several areas to consider for future research, some of which are addressed below.

There is rapid ICT development and an increased focus on co-production within both the IS discipline and other research disciplines (Linders, 2012; Brandsen et al., 2018; Díaz, et al., 2016). The thesis shows that there is now an understanding that this type of network collaboration can be one of many solutions to complement the professional response and contribute to a more effective response. However, the thesis only includes two case studies which are not completely cross-comparable. Thus, more similar case studies are needed in different contexts, cities, and countries. This thesis has only taken the initial step. A concrete example is the challenges identified when citizens are involved in the response delivery. There is a need for future research on co-production to further explore these challenges in other case studies, and to consider how to resolve them.

Regarding the thesis's framework, it can potentially be used for future research within crisis and emergency response and within other forms of public service, based on its broad and general theoretical foundation (Carlsson, 2000; Linton, 2002). However, to further develop the framework 
or eventually claim that it can be used as theory in itself, it is necessary to continue to apply it further in future research, both theoretically and in more empirical case studies.

Moreover, the thesis's co-production focus is on citizen volunteers who are alerted digitally and involved in the delivery onsite. However, this thesis and recent literature (e.g. Paletti, 2016; Schönböck et al., 2016; Tan et al., 2019) imply that similar ICT needs are shared with other types of coproduction and citizen engagement, which would be interesting to explore further.

Also, the concept of co-production and connected concepts such as cocreation and co-design would benefit from further clarification (Brandsen et al., 2018; Sanders and Stappers, 2008). This thesis argues that this is an important area to study for future research - to have coherency in the concepts used in order to know what we mean by them, for advancement in the exploration of the phenomenon. The concept of co-production includes various kinds of citizen engagement, and thus different opportunities and challenges. It would be beneficial to continue to use a multidisciplinary approach in order to further comprehend the concepts, as well as generally. Conceptual studies are thus needed in future research.

In addition, the thesis takes a holistic perspective on the response domain by including both crisis and emergency responses. This perspective highlights the benefits of using citizen volunteers regardless of the type of response. Thus, the perspective also would be useful to apply in future research. Civil defense and military operations (Grant, 2019) may also be an interesting domain for future research, to explore any similarities and the possible joint use of citizen volunteers.

Moreover, the thesis focuses on end-users who do not belong to a formal organization and who do not use ICT in connection with their work. The thesis claims that their involvement in the ICT development process increases the complexity. The thesis also argues that there are specific implications when involving this type of end-user, since they do not have regulations to adhere to (compared to end-users with formal organizational affiliation), and this is particularly apparent due to the influence of digitalization. An understanding of this type of end-user, how to involve them in the ICT development process, and how they might influence the ICT with additional technologies would be interesting aspects to study in a wider context in future research - not only in the light of digitalization.

Lastly, it is vital to continue studying the central role of ICT in coproduction and public service delivery in general. In this thesis, the concept of ICT-enabled co-production is used. Having previously been seen as a possible source of support for public service delivery, ICT is now a core 
element, a necessity, for all types of service delivery and collaboration (Lember et al., 2019; Paletti, 2016). Hence, with the increasing use of ICT and digitalization, the prefix 'ICT-enabled' may eventually be included in the concept of co-production on the same basis as the humans involved in the co-production. However, this thesis shows that this prefix is still necessary in future research when studying the ICT system used and when exploring how ICT enables and influences co-production - and hence also the impact on governments. Here, the IS discipline has much to offer in order to increase our understanding in future research. 


\section{References}

Agranoff, R. (2007) Managing within Networks: Adding Value to Public Organizations, Washington: Georgetown University Press.

Alford, J., \& O'Flynn, J (2012) Rethinking Public Service delivery: Managing with External Providers, Hampshire, UK: Palgrave Macmillan.

Alford, J. (2014) The Multiple Facets of Co-production: Building on the Work of Elinor Ostrom, Public Management Review, 16(3), 299-316.

Alter, C., \& Hage, J. (1993) Organizations Working Together, Newbury Park, CA: Sage Publications.

Alter, S. (2002a) Sidestepping the IT Artifact, Scrapping the IS Silo, and Laying Claim to "Systems in Organizations", Communications of the Association for Information Systems, 12, 494-526.

Alter, S. (2002b) The Work System Method for Understanding Information Systems and Information System Research, Communications of the Association for Information Systems, 9, 90-104.

Alter, S. (2003) 18 Reasons Why IT-reliant Work Systems Should Replace "the IT Artifact" as the Core Subject Matter of the IS Field, Communications of the Association for Information Systems, 12, 366395 .

Anthopoulos, L. G., Siozos, P., \& Tsoukalas, I. A. (2007) Applying Participatory Design and Collaboration in Digital Public Services for Discovering and Re-designing e-Government Services, Government Information Quarterly, 25(2), 353-376.

Archer, N. (2005) An Overview of the Change Management Process in eGovernment, International Journal of Electronic Business, 3(1), 68-87.

Asgarkhani, M. (2005) The Effectiveness of e-Service in Local Government: a Case Study, Electric Journal of e-Government, 3(4), 157-166.

Ashton, P., Weber, R., \& Zook, M. (2017) The Cloud, the Crowd, and the City: How New Data Practices Reconfigure Urban Governance, Big Data \& Society, 4(1).

Auferbauer, D., Ganhör, R., \& Tellioğlu, H. (2015) Moving Towards Crowdtasking for Disaster Mitigation, Proceedings of the 12th International Conference of Information Systems for Crisis Response and Management (ISCRAM), Kristiansand, Norway.

Axelsson, K., Melin, U., \& Lindgren, I. (2013) Public e-Services for Agency Efficiency and Citizen Benefit - Findings from a Stakeholder Centered Analysis, Government Information Quarterly, 30(1), 10-22.

Axelsson, K., \& Melin, U. (2014) Contextual Factors Influencing Health Information Systems Implementation in Public Sector - Investigating 
the Explanatory Power of Critical Success Factors, International Conference on Electronic Government EGOV 2014: Electronic Government, 59-71.

Babiak, K., \& Thibault, L. (2009) Challenges in Multiple Cross-sector Partnerships, Nonprofit and Voluntary Sector Quarterly, 38(1), 117-143. Bannister, F., \& Connolly, R. (2011) Trust and Transformational Government: a Proposed Framework for Research, Government Information Quarterly, 28(2), 137-147.

Bason, C. (2018) Leading Public-sector Innovation: Co-creating for a Better Society, Bristol, UK: The Policy Press.

Bekkers, V., \& Homburg, V. (2007) The Myths of e-Government: Looking Beyond the Assumptions of a New and Better Government, The Information Society Journal, 23(5), 373-382.

Bekkers, V., \& Thaens, M. (2005) Interconnected Networks and the Governance of Risk and Trust, Information Polity, 10(1,2), 37-48.

Berger, P. L., \& Luckmann, T. (1991) The Social Construction of Reality: A Treatise in the Sociology of Knowledge, London, England: Penguin Books.

Berglund, E., Claesson, A., Nordberga, P., Djärva, T., Lundgren, P., Folke, F., Forsberg, S., Rivaa, G., \& Ringh, M. (2018) A Smartphone Application for Dispatch of Lay Responders to Out-of-hospital Cardiac Arrests, Resuscitation, 126, 160-165.

Bharosa, N., Janssen, M., \& Tan, Y.-H. (2011) A Research Agenda for Information Quality Assurance in Public Safety Networks: Information Orchestration as the Middle Ground Between Hierarchical and Netcentric Approaches, Cognition, Technology \& Work, 13, 203-216.

Biggs, J., \& Tang, C. (2011) Teaching for Quality Learning at University, New York: University Press.

Bjerknes, G., Ehn, P., \& Kyng, M. (Eds.) (1987) Computers and Democracy - a Scandinavian Challenge, Aldershot/Brookfield Vermont: Gower Publishing.

Bjögvinsson, E., Ehn, P., \& Hillgren, P. (2012) Design Things and Design Thinking: Contemporary, Participatory Design Challenges, Design Issues, 28(3), 101-116.

Börzel, T. (1998) Organizing Babylon - on the Different Conceptions of Policy Networks, Public Administration, 76 (2), 253-273.

Bonsón, E., Torres, L., Royo, S., \& Flores, F. (2012) Local e-Government 2.0: Social Media and Corporate Transparency in Municipalities, Government Information Quarterly, 29(2), 123-132.

Bostrom, R. P., \& Heinen, J. S. (1977a) MIS Problems and Failures: A Sociotechnical Perspective PART I: The Causes, MIS Quarterly, 1(3), 17-32. 
Bostrom, R. P., \& Heinen, J. S. (1977b) MIS Problems and Failures: A Sociotechnical Perspective PART II: The Application of Socio-technical Theory, MIS Quarterly, 1(4), 11-28.

Bovaird, T. (2007) Beyond Engagement and Participation: User and Community Coproduction of Public Services, Public Administration Review, 67(5), 846-860.

Bovaird, T., \& Loeffler, E. (2012) From Engagement to Co-production: The Contribution of Users and Communities to Outcomes and Public Value, VOLUNTAS: International Journal of Voluntary and Nonprofit Organizations, 23, 1119-1138.

Bram, S., \& Vestergren, S. (2012) Emergency Response Systems: Concepts, Features, Evaluation and Design, CARER Rapport no. 5, Linköping University Electronic Press.

Brandsen, T., Evers, A., Cattacin, S., \& Zimmer, A. (2016) The Good, the Bad and the Ugly in Social Innovation, in Brandsen ,T., Cattacin, S., Evers, A., \& Zimmer, A. (Eds.) Social Innovations in the Urban Context, New York, Dordrecht, London: Springer Cham Heidelberg, 303-310.

Brandsen, T., \& Honingh, M. (2018) Definitions of Co-production and Cocreation, in Brandsen, T., Steen, T., \& Verschuere, T. (Eds.) Coproduction and Co-creation: Engaging Citizens in Public Services. New York, NY: Routledge, chapter 2.

Brandsen, T., Steen, T., \& Verschuere, T. (Eds.) (2018) Co-production and Co-creation: Engaging Citizens in Public Services, New York, NY: Routledge.

Bratteteig, T., \& Wagner, I. (2016) What is a Participatory Design Result?, Proceedings of the 14th Participatory Design Conference, ACM, New York, NY, 141-150.

Carlsson, L. (2000) Policy Network as Collective Action, Policy Studies Journal, 28(3), 502-520.

Cegarra-Navarroa, J-G., Garcia-Perezb, A., \& Moreno-Cegarraa, J. L. (2014) Technology Knowledge and Governance: Empowering Citizen Engagement and Participation, Government Information Quarterly, $31(4), 660-668$.

Chen, R., Sharman, R., Rao, H.R., \& Upadhyaya, S. J. (2007) Design Principles for Critical Incident Response Systems, Information Systems and e-Business Management, 5(3), 201-227.

Chen, R., Sharman, R., Rao, H.R., \& Upadhyaya, S. J. (2008) Coordination in Emergency Response Management, Communications of the ACM, 51(5), 66-73. 
Cheng, Y., Yu, Y., Shen, Y., \& Huang, B. (2020) Coproducing Responses to COVID-19 with Community-based Organizations: Lessons from Zhejiang Province China, Public Administration Review, 8o(5), 866-873.

Clark, B., Brudney, J., \& Jang, S.-G. (2013) Coproduction of Government Services and the New Information Technology: Investigating the Distributional Biases, Public Administration review, 73(5), 687-701.

Cordella, A., \& Tempini, N. (2015) e-Government and Organizational change: Reappraising the Role of ICT and Bureaucracy in Public Service Delivery, Government Information Quarterly, 32(3), 279-286.

Dawes, S. (2009) Governance in the Digital Age: a Research and Action Framework for an Uncertain Future, Government Information Quarterly, 26(2), 257-264.

de Lanerolle, T. R., Defabbia-Kane, S., Gochev, D., Anderson, W. V., FoxEpstein, E., \& Morelli, R. A. (2010) Development of a Virtual Dashboard for Event Coordination between Multiple Groups, Proceedings of the 7th International Conference of Information Systems for Crisis Response and Management (ISCRAM), Seattle, USA.

Díaz, P., Carroll, J. M., \& Aedo, I. (2016) Coproduction as an Approach to Technology-mediated Citizen Participation in Emergency Management, Future Internet, 8(3), 41.

Dietrich, T., Trischler, J., Schuster, L., \& Rundle-Thiele, S. (2017) Codesigning Services with Vulnerable Consumers, Journal of Service Theory and Practice, 27 (3), 663-688.

Dodge, J. (2012) Addressing Democratic and Citizenship Deficits: Lessons from Civil Society?, Public Administration Review, 73(1), 203-206.

Dunleavy, P., \& Margetts, H. Z. (2010) The Second Wave of Digital Era Governance, APSA 2010 Annual Meeting Papers.

Dynes, R. R. (1970) Organized Behavior in Disaster, Lexington, MA: Heath Lexington Books.

Ewert, B., \& Evers, A. (2012) Co-production: Contested Meanings and Challenges for User Organizations, in Pestoff, V., Brandsen, T., \& Verschuere, B. (Eds.) New Public Governance, the Third Sector, and Coproduction, New York, NY: Routledge, chapter 4.

Ferguson, H. T., Gesing, S., \& Nabrzyski, J. (2016) Measuring Usability in Decision Tools Supporting Collaborations for Environmental Disaster Response, Proceedings of the 49th Hawaii International Conference on System Sciences, Koloa, HI, USA, 2873-2881.

Fleishman, R. (2009) To Participate or Not to Participate? Incentives and Obstacles for Collaboration, in O'Leary, R. \& Bingham, L. (Eds.) The Collaborative Public Manager: New Ideas for the Twenty-first Century, Washington, DC: Georgetown University Press. 
Flyvbjerg, B. (2006) Five Misunderstandings About Case-study Research, Qualitative Inquiry, 12(2), 219-245.

Fö2009/1451/SSK, Strategy for Strengthening the Societal Resources in Coping with Emergency Situations, Mission from the Government of Sweden, 2009.

Gascó, M. (2017) Living Labs: Implementing Open Innovation in the Public Sector, Government Information Quarterly 34(1), 90-98.

Gazley, B. (2008) Inter-sectoral Collaboration and the Motivation to Collaborate: Toward an Integrated Theory, in Bingham, L.E. \& O'Leary, R. (Eds.) Big Ideas in Collaborative Public Management, New York: M.E. Sharpe, 36-54.

Gil-Garcia, J. R., Dawes, S. S., \& Pardo, T. A. (2018) Digital Government and Public Management Research: Finding the Crossroads, Public Management Review, 20(5), 633-646.

Goldsmith, S., \& Eggers, W. D. (2004) Governing by Network: The New Shape of the Public Sector, Washington, DC: Brookings Institution Press and the Innovations in American Government Program at the John F. Kennedy School of Government at Harvard University.

Grant, T. J. (2019) Tsunami of Smallsat Mega-constellations: C2 implications, in Alberts, D.S. (Ed.) Proceedings of the 24th International Command \& Control Research \& Technology Symposium (ICCRTS 2019), Laurel, MD, paper 45.

Gould, J. D., \& Lewis, C. (1985) Designing for Usability: Key Principles and What Designers Think, Communications of the ACM, 28(3), 300-311.

Government Bill 2007/o8:92, Stärkt krisberedskap - för säkerhets skull, the Swedish Ministry of Justice, 2008.

Government Bill 2019/20:176, En effektivare kommunal räddningstjänst, the Swedish Ministry of Justice, 2020.

Guldåker, N., \& Hallin, P-O. (2014) Spatio-temporal Patterns of Intentional Fires, Social Stress and Socio-economic Determinants: a Case study of Malmö, Sweden, Fire Safety Journal, 70, 71-80.

Gulliksen, J., \& Eriksson, E. (2006) Understanding and Developing User Involvement at a Public Authority, The Fourth Nordic Conference on Human-Computer Interaction, Oslo, Norway.

Gulliksen, J., Göransson, B., Boivie, I., Blomkvist, S., Persson. J., \& Cajander, Å. (2003) Key Principles for User-centred Systems Design, Behaviour \& Information Technology , 22(6), 397-409.

Haddow, G., Bullock, J., \& Coppola, D.P. (2013) Introduction to Emergency Management, Waltham, MA: Butterworth-Heinemann.

Harnesk, D., \& Lindström, J. (2011) Exploring Socio-technical Design of Crisis Management Information Systems, in Jennex, M. E. (Ed.) Crisis 
Response and Management and Emerging Information Systems: Critical Applications, Hershey PA, USA: IGI Global.

Havlik, D., Pielorz, J., \& Widera, A. (2016) Interaction with Citizens Experiments: From Context-aware Alerting to Crowdtasking, Proceedings of the International Conference of Information Systems for Crisis Response and Management (ISCRAM), Rio de Janeiro, Brazil.

Hillgren, P., Seravalli, A., \& Emilson, A. (2011) Prototyping and Infrastructuring in Design for Social Innovation, CoDesign, 7(3-4), 169183 .

Holgersson, J., \& Karlsson, F. (2014) Public e-Service Development: Understanding Citizens' Conditions for Participation, Government Information Quarterly, 31(3), 396-410.

Huang, I.Y-F. (2020) Fighting COVID-19 through Government Initiatives and Collaborative Governance: The Taiwan Experience, Public Administration Review, Viewpoints on COVID-19 Symposium, 80(4), 665-670.

Iivari, J. (2010) Twelve Theses on Design Science Research in Information Systems, Design Research in Information Systems, 22, 43-62.

Imani, Y., \& Schlappa, H. (2018) Case Study-Leading Co-production: The Case of Hertfordshire Fire and Rescue Service's Community Volunteer Scheme, in Brandsen, T., Steen, T., \& Verschuere, T. (Eds.) Coproduction and Co-creation: Engaging Citizens in Public Services. New York, NY: Routledge, chapter 9.1.

Iversen, O., Halskov, K., \& Leong, T. (2010) Rekindling Values in Participatory Design, Proceedings of the 11th Participatory Design Conference, ACM, New York, NY, 91-100.

Janowski, T., Pardo, T. A., \& Davies, J. (2012) Government Information Networks: Mapping Electronic Governance Cases through Public Administration, Government Information Quarterly, 29(1), 1-10.

Jansen, A. (2006) Strategies for User Involvement in e-Government Projects: What Can Be Learned from the Scandinavian IS tradition?, Proceedings of the NordiCHI'o6 Workshop on User Involvement and Representation in e-Government Projects, 11, Oslo, Norway.

Janssen, M., \& van den Hoven, J. (2015) Big and Open Linked Data (BOLD) in Government: A Challenge to Transparency and Privacy?, Government Information Quarterly, 32(4), 363-368.

JCCM, (2020), retrieved from: https://onlinelibrary.wiley.com/page/journal/14685973/homepage/pr oductinformation.html.

Johansson, R., Danielsson, E., Kvarnlöf, L., Eriksson, K., \& Karlsson, R. (2018) At the External Boundary of a Disaster Response Operation: The 
Dynamics of Volunteer Inclusion, Journal Contingencies and Crisis Management, 26(4), 519-529.

Jukić, T., Pevcin, P., Benčina, J., Dečman, M., \& Vrbek, S. (2019) Collaborative Innovation in Public Administration: Theoretical Background and Research Trends of Co-production and Co-creation, Administrative Sciences, 9(4), 90.

Kaiser, M., Larsson, P., \& Hörnsten Friberg, L. (2004) Krishantering med en vidgad syn på nätverksorganisering, FOI-R-1248-SE, Stockholm: FOI.

Karlsson, F., Holgersson, J., Söderström, E., \& Hedström, K. (2012) Exploring User Participation Approaches in Public e-Service Development, Government Information Quarterly, 29(2), 158-168.

Kawasaki, A., Berman, M. L., \& Guan, W. (2013) The Growing Role of Webbased Geospatial Technology in Disaster Response and Support, Disasters, 37(2), 201-221.

Kensing, F., \& Blomberg, J. (1998) Participatory Design: Issues and Concerns, Computer Supported Cooperative Work (CSCW), 7(3-4), 167185.

Kensing, F., \& Madsen, K. H. (1992) Generating Visions: Future Workshops and Metaphorical Design, in Greenbaum, J., \& Kyng, M. (Eds.) Design at Work: Cooperative Design of Computer Systems, Hillsdale, NJ: Lawrence Earlbaum, 155-168.

Kickert, W., Klijn, E.-H., \& Koppenjan, J.F.M. (Eds.) (1997) Managing Complex Networks: Strategies for the Public Sector, London: Sage Publications.

Kitchin, R. (2016) Reframing, Reimagining and Remaking Smart Cities, Programmable City, working paper 20.

Kling, R. (1991) Computerization and Social Transformations, Science, Technology, \& Human Values, 16(3), 342-367.

Kling, R., McKim, G., \& King, A. (2003) A Bit More to IT: Scholarly Communication Forums as Socio-technical Interaction Networks, Journal of the American Society for Information Science and Technology, 54(1), 47-67.

Kling, R., \& Scacchi, W. (1982) The Web of Computing: Computer Technology as Social Organization, Advances in Computing, 21, 1-90.

Kotamraju, N. P., \& van der Geest, T. M. (2013) The Tension Between Usercentred Design and e-Government Services, Behaviour \& Information Technology, 31(3), 261-273.

Land, F. (2000) Evaluation in a Socio-technical Context, Proceedings of IFIP W.G.8.2 Working Conference, IS2000: The Social and Organizational Perspective on Research and Practice in Information Systems, Aalberg, Denmark. 
Layne, K., \& Lee, J. (2001) Developing Fully Functional e-Government: a Four Stage Model, Government Information Quarterly, 18(2), 122-136. Lember, V. (2018) The Increasing Role of Digital Technologies in Coproduction and Co-creation, in Brandsen, T., Steen, T., \& Verschuere, T. (Eds.) Co-production and Co-creation: Engaging Citizens in Public Services. New York, NY: Routledge, chapter 10.

Lember, V., Brandsen, T., \& Tõnurist, P. (2019) The Potential Impacts of Digital Technologies on Co-production and Co-creation, Public Management Review, 21(11), 1665-1686.

Lin, A., \& Cornford, T. (2000) Sociotechnical Perspectives on Emergence Phenomena, in Coakes, E., Willis, D., \& Lloyd-Jones, R. (Eds.) The New Sociotech: Graffiti on the Longwall, London: Springer Verlag.

Linders, D. (2012) From e-Government to we-Government: Defining a Typology for Citizen Coproduction in the Age of Social Media, Government Information Quarterly, 29(4), 446-454.

Linton, J.D. (2002) Implementation Research: State of the Art and Future Directions, Technovation, 22, 65-79.

Loeffler, E., \& Bovaird, T. (2018) Assessing the Effect of Co-production on Outcomes, Service Quality and Efficiency, in Brandsen, T., Steen, T., \& Verschuere, T. (Eds.) Co-production and Co-creation: Engaging Citizens in Public Services, New York, NY: Routledge, chapter 20.

Loukis, E., Janssen, M., Dawes, S., \& Zheng, L. (2016) Evolving ICT and Governance in Organizational Networks: Conceptual and Theoretical Foundations, Electronic Markets, 26(1), 7-14.

Ludwig, T., Reuter, C., \& Pipek, V. (2015) Social Haystack: Dynamic Quality Assessment of Citizen-generated Content during Emergencies, ACM Transactions on Computer, Human Interaction, 22(4), 17-27.

Lu, Z., Zhang, N., \& Meng, Q. (2010) Understanding Cross-sector Collaboration in e-Government Development: Theoretical Considerations Based on Extended Bryson's Framework, Proceedings of the Pacific Asia Conference on Information Systems (PACIS), Taipei, Taiwan, AIS Electronic Library (AISeL), 1007-1019.

Margetts, H. (2005) Smartening up to Risk in Electronic Government, in Lips, M., Taylor, J. A., \& Bannister, F. (Eds.), Public Administration in the Information Society: Essays on Risk and Trust, Amsterdam: IOS Press, 81-94.

Markus, M. L. (1983) Power, Politics, and MIS Implementation, Communications of the ACM, 26(6), 430-444.

Markus, M. L., \& Robey, D. (1988) Information Technology and Organization Change: Causal Structure in Theory and Research, Management Science, 34(5). 
Marti, P., \& Bannon, L. J. (2009) Exploring User-centred Design in Practice: Some Caveats, Knowledge, Technology \& Policy, 22(1), 7-15.

Meijer (2012) Co-production in an Information Age, in Pestoff, V., Brandsen, T., \& Verschuere, B. (Eds.) New Public Governance, the Third Sector and Co-production, New York, NY: Routledge, chapter 10.

Meissen, U., Jendreck, M., Hardt, M., Fuchs-Kittowski, F., Pfenningschmidt, S., \& Voisard, A. (2017) A General System Architecture and Design for the Coordination of Volunteers for Agile Disaster Response, Proceedings of the 14th International Conference of Information Systems for Crisis Response and Management (ISCRAM), Albi, France.

Melin, U., \& Axelsson, K. (2014) Implementing Healthcare Information Systems - Mirroring a Wide Spectrum of Images of an IT Project, Health Policy and Technology, 3(1), 26-35.

Melin, U., \& Wihlborg, E. (2018) Balanced and Integrated e-Government Implementation: Exploring the Crossroad of Public Policy-making and Information Systems Project Management Processes, Transforming Government: People, Process and Policy, 12(2), 191-208.

Moynihan, D.P. (2009) From Intercrisis to Intracrisis Learning, Journal of Contingencies and Crisis Management, 17(3), 189-198.

MSB (2009) En strategi för förstärkningsresurser, diarienr 2009-10825.

MSB (2020a) homepage, FRG, retrieved from https://www.msb.se/sv/amnesomraden/krisberedskap-civiltforsvar/frivilliga/frivilliga-resursgruppen-frg/.

MSB (2020b) homepage, retrieved from https://www.msb.se/sv/amnesomraden/krisber Edskap-civiltforsvar/frivilliga/ffo/.

Mumford, E. (1981) Participative System Design: Structure and Method, Systems, Objectives, Solutions, 1(1), 5-19.

Mumford, E. (1995) Effective Systems Design and Requirements Analysis: The Ethics Method, London: Palgrave Macmillan.

Mumford, E. (2000) Socio-technical Design: An Unfulfilled Promise or a Future Opportunity?, in Baskerville R., Stage J., DeGross J. I. (Eds.) Organizational and Social Perspectives on Information Technology, The International Federation for Information Processing (IFIP), 41.

Murphy, M. (2020) Crisis Response Volunteer Processes and Digitalisation: a Case Study in the Aftermath of Swedish Forest Fires Year 2018, Proceedings of the 53th Hawaii International Conference on System Sciences (HICSS), Maui, Hawaii, USA.

Myers, M. (2009) Qualitative Research in Business and Management, Thousand Oaks, CA: Sage Publications. 
Nabatchi, T., Sancino, A., \& Sicilia, M. (2017) Varieties of Participation in Public Services: The Who, When, and What of Coproduction, Public Administration Review, 77(5), 766-776.

Nævestad, T.-O. (2009) Mapping Research in Culture and Safety in Highrisk Organizations: Arguments for a Sociotechnical Understanding of Safety Culture, Journal of Contingencies and Crisis Management, 7(2), $126-136$.

Nograšek, J., \& Vintar, M. (2014) e-Government and Organisational Transformation of Government: Black Box Revisited?, Government Information Quarterly, 31(1), 108-118.

Norman, D. A., \& Draper, S. W. (Eds.) (1986) User Centered System Design: New Perspectives on Human-Computer Interaction, Hillsdale, NJ: Lawrence Erlbaum Associates.

Ödlund, A. (2008) Interorganisatorisk samverkan som nationell resurs i krishanteringen, Stockholm: FOI.

O'Leary, R., \& Bingham, L. (Eds.) (2009) The Collaborative Public Manager: New Ideas for the Twenty-first Century, Washington, DC: Georgetown University Press.

Oostveen, A. M., \& Peter van den Besselaar, P. (2004) From Small Scale to Large Scale User Participation: a Case Study of Participatory Design in eGovernment Systems, Proceedings of the Eighth Conference on Participatory Design: Artful Integration: Interweaving Media, Materials and Practices, 1, 173-182.

O'Reilly, C. A., \& Tushman, M. L. (2013) Organizational Ambidexterity: Past, Present, and Future, Academy of Management Perspectives, 27, (4).

Orlikowski, W. J., \& Baroudi, J. J. (1991) Studying Information Technology in Organizations: Research Approaches and Assumptions, Information System Research, 2(1), 1-28.

Ostrom, E. (1994) Institutional Analysis, Design Principles and Threats to Sustainable Community Governance and Management of Commons, in Pomeroy, R. S. (Ed.) Community Management and Common Property of Coastal Fisheries in Asia and Pacific: Concepts, Methods and Experiences, ICLARM Conference Proceedings, 45(189), 34-50.

Ostrom, E. (1996) Crossing the Great Divide: Coproduction, Synergy and Development, World Development, 24(6), 1073-87.

Palen, L., Anderson, K. M., Mark, G., Martin, J., Sicker, D., Palmer, M., \& Grunwald, D. (2010) A Vision for Technology-mediated Support for Public Participation and Assistance in Mass Emergencies and Disasters, Proceedings of the 2010 ACM-BCS Visions of Computer Science Conference (ACM-BCS '10), British Computer Society, Swinton, UK. 
Paletti, A. (2016) Co-production Through ICT in the Public Sector: When Citizens Reframe the Production of Public Services, in Caporarello, L., Cesaroni, F., Giesecke, R., \& Missikoff, M. (Eds.) Digitally Supported Innovation, Lecture Notes in Information Systems and Organisation, Cham: Springer, 18, 141-152.

Parker, C. F., Stern, E. K., Paglia, E., \& Brown, C. (2009) Preventable Catastrophe? The Hurricane Katrina Disaster Revisited, Journal of Contingencies and Crisis Management, 17(4), 206-220.

Payne, G., \& Payne, J. (2004) Key Concepts in Social Research, London: Sage.

Pekkola, S., Kaarilahti, N., \& Pohjola, P. (2006) Towards Formalised Enduser Participation in Information Systems Development Process: Bridging the Gap between Participatory Design and ISD Methodologies, Proceedings of the Ninth Conference on Participatory Design: Expanding Boundaries in Design, New York, NY, ACM, 1, 21-30.

Pestoff, V., Brandsen, T., \& Verschuere, B. (Eds.) (2012) New Public Governance, the Third Sector, and Co-production, New York, NY: Routledge.

Pestoff, V. (2012) New Public Governance, Co-production and Third Sector Social Services in Europe: Crowding, In and Crowding Out, in Pestoff, V., Brandsen, T., \& Verschuere, B. (Eds.) New Public Governance, the Third Sector, and Co-production, New York, NY: Routledge, chapter 19.

Pijls, R. W. M., Nelemansb, P. J., Rahelc, B. M., \& Gorgelsa, A. P. M. (2016) A Text Message Alert System for Trained Volunteers Improves Out-ofhospital Cardiac Arrest Survival, Resuscitation 105, 182-187.

Pilemalm, S., Lindell, P., Hallberg, N., \& Eriksson, H. (2007) Integrating the Rational Unified Process and Participatory Design for Development of Socio-technical Systems: A User Participative approach, Design Studies, 28(3), 263-288.

Pilemalm, S., Stenberg, R., \& Andersson Granberg, T. (2013) Emergency Response in Rural Areas, International Journal for Information Systems for Crisis Response and Management, 5(2), 19-31.

Pilemalm, S. (2018a) Participatory Design in Emerging Civic Engagement Initiatives in the New Public Sector: Applying PD Concepts in Resourcescarce Organizations, ACM Transactions on Human-ComputerInteraction, 5(1), article no. 5 .

Pilemalm, S. (2018b) Emerging Forms of Network Governance in the Public Sector: the Case of Cross-sector Collaboration in Swedish Emergency Response, Proceedings of the 7th LAEMOS Colloquium on Organizing for Resilience: Scholarship in Unsettled Times, Buenos Aires, Argentina. 
Pilemalm, S. (2020) Volunteer Co-production in Emergency Management in Excluded Areas Using Civil Citizens and Semi-professionals as First Responders, JEDEM, 12(1), 61-86.

Poole, M. S., \& DeSanctis, G. (1990) Understanding the use of group decision support systems: The theory of adaptive structuration, in Fulk, J., \& Steinfeld, C. (Eds.) Organizations and Communication Technology, Newbury Park: Sage.

Ragin, C.C. (1999) The Distinctiveness of Case-oriented Research, Health Service Research, 34(5 Pt 2), 1137-1151.

Rhodes, R. A. W., \& Marsh, D. (1992) New Directions in the Study of Policy Networks, European Journal of Political Research, 21, 181-205.

Rhodes, R. A. W. (1997) Understanding Governance, Buckingham: Open University Press.

Ringh, M., Fredman, D., Nordberg, P., Stark, T., \& Hollenberg, J. (2011) Mobile Phone Technology Identifies and Recruits Trained Citizens to Perform CPR on Out-of-hospital Cardiac Arrest Victims Prior to Ambulance Arrival, Resuscitation, 82, 1514-1518.

Ringh, M., Rosenqvist, M., Hollenberg, J., Jonsson, M., Fredman, D., Nordberg, P., Järnbert-Pettersson, H., Hasselqvist-Ax, I., Riva, G., \& Svensson, L. (2015) Mobile-phone Dispatch of Laypersons for CPR in Out-of-hospital Cardiac Arrest, The New England Journal of Medicine, 372(11), 2316-2325.

Roberts, A., Nimegeer, A., Farmer, J., \& Heaney, D. J. (2014) The Experience of Community First Responders in Co-producing Rural Health Care: In the Liminal Gap between Citizen and Professional, BMC Health Services Research, 14, article no. 460.

Rogstadius, J., Teixeira, C., Karapanos, E., \& Kostakos, V. (2013) An Introduction for System Developers to Volunteer Roles in Crisis Response and Recovery, Proceedings of the 1oth International Conference of Information Systems for Crisis Response and Management (ISCRAM), Baden-Baden, Germany.

Rubenfeld, J. (2008) The End of Privacy, Stanford Law Review, 61(1), 101162.

Saarikko, T., Nuldén, U., Meiling, P., \& Pessi, K. (2020) Framing Crisis Information Systems: The Case of WIS, Proceedings of the 53rd Hawaii International Conference on System Sciences.

Sæbø, Ø., Jeremy Roseb, J., \& Skiftenes Flakc, L. (2008) The Shape of eParticipation: Characterizing an Emerging Research Area, Government Information Quarterly, 25(3), 400-428. 
Salasznyk, P. P., \& Lee, E. E. (2006) A Systems View of Data Integration for Emergency Response, International Journal of Emergency Management, 3(4), 313-331.

Sanders, E. B.-N., \& Stappers, P. J. (2008) Co-creation and the New Landscapes of Design, CoDesign, 4(1), 5-18.

Schmidt, A., Wolbers J., Ferguson, J., \& Boersma, K. (2018) Are you Ready2Help? Conceptualizing the Management of Online and Onsite Volunteer Convergence, Journal of Contingencies and Crisis Management, 26, 338-349.

Schuler, D., \& Namioka, A. (Eds.) (1993) Participatory Design: Principles and Practices, Hillsdale, NJ: Lawrence Erlbaum Associates Inc.

Schönböck, J., Raab, M., Altmann, J., Kapsammer, E., Kusel, A., Pröll, B., Retschitzegger, W., \& Schwinger, W. (2016) A Survey on Volunteer Management Systems, Proceedings of the 49th Hawaii International Conference on System Sciences (HICSS), Koloa, HI, USA, 767-776.

SEMA - Swedish Emergency Management Agency (2005a) Krishantering i stormens spår, dnr: 0257/2005.

SEMA - Swedish Emergency Management Agency (2005b) Så vill vi utveckla krisberedskapen, dnr: 0418/2005.

SEMA - Swedish Emergency Management Agency (2006) FRG, Frivilliga resursgrupper, faktablad.

SFS 1991:900, Kommunallag.

SFS 1994:524, Förordning om frivillig försvarsverksamhet.

SFS 2006:544, Lag om kommuners och landstings åtgärder inför och vid extraordinära händelser i fredstid och höjd beredskap.

SFS 2015:1052, Förordning om krisberedskap och bevakningsansvariga myndigheters åtgärder vid höjd beredskap.

SFS 2017:870, Förordning om länsstyrelsernas krisberedskap och uppgifter vid höjd beredskap.

SFS 2003:778, Lag om skydd mot olyckor.

SFS 2020:882, Lag om ändring i lagen (2003:778) om skydd mot olyckor.

Sørensen, C. (2016) The Curse of the Smart Machine? Digitalisation and the Children of the Mainframe, Scandinavian Journal of Information Systems, 28(2), 57-68.

Sørensen, E., \& Torfing, J. (Eds.) (2007) Theories of Democratic Network Governance, Basingstoke, UK: Palgrave/Macmillan.

SOU - Official Report from the Swedish Government - 2005:6, Efter flodvågen - det första halvåret.

SOU - Official Report from the Swedish Government - 2005:104, Sverige och tsunamin - granskning och förslag. 
SOU - Official Report from the Swedish Government - 2018:54, En effektivare kommunal räddningstjänst räddningstjänst.

SOU - Official Report from the Swedish Government - 2019:7, Skogsbränderna sommaren 2018.

St. Denis, L., \& Hughes, A. L. (2018) Crisis Cleanup: Creating a Virtual Command Post to Support Relief Organizations on the Ground, Proceedings of the 15th International Conference of Information Systems for Crisis Response and Management (ISCRAM), Rochester, NY, USA.

Steen, T., Brandsen, T., \& Verschuere, B. (2018) The Dark Side of Cocreation and Co-production, Seven Evils, in Brandsen, T., Steen, T., \& Verschuere, T. (Eds.) Co-production and Co-creation: Engaging Citizens in Public Services, New York, NY: Routledge, chapter 21.

Svejvig, P., \& Blegind Jensen, T. (2013) Making Sense of Enterprise Systems in Institutions: A Case Study of the Re-implementation of an Accounting System, Scandinavian Journal of Information Systems, 25(1), article 1.

Tan, M. T., Prasanna, R., Stock, K., Hudson-Doyle, E., Leonard, G., \& Johnston, D. (2019) Enhancing the Usability of a Disaster App: Exploring the Perspective of the Public as Users, Proceedings of the 16th International Conference of Information Systems for Crisis Response and Management (ISCRAM), València, Spain.

The Swedish Association of Local Authorities and Regions (2005) Storm krishantering i kommuner och landsting som drabbats av stormen Gudrun, Stockholm.

The Swedish Ministry of Justice (2015) Rapport från Skogsbrandsutredningen, Skogsbrandutredningen, Stockholm: Government Offices of Sweden.

Thijssen, P., \& van Dooren, W. (2015) Who You Are/Where You Live: Do Neighborhood Characteristics Explain Co-production?, International Review of Administrative Sciences, 82(1), 88-109.

Thompson, J.D. (1967) Organizations in Action: Social Science Bases of

Administrative Theory, Transaction Publishers: New Brunswick/London.

Thomson, A. M., \& Perry, J. L. (2006) Collaboration Processes: Inside the Black Box, Public Administration Review, 66, 20-32.

Tilson, D., Lyytinen, K., \& Sørensen, C. (2010) Research Commentary-

Digital Infrastructures: The Missing IS Research Agenda, Information Systems Research, 21(4), 748-759.

Tollmar, K. (2001) Towards CSCW Design in the Scandinavian Tradition, $\mathrm{PhD}$ Dissertation, NADA - KTH/SU, Stockholm University.

Toots, M., McBride, K., Kalvet, T., \& Krimmer, R. (2017) Open Data as Enabler of Public Service Co-creation: Exploring the Drivers and 
Barriers, Proceedings of the 2017 International Conference for EDemocracy and Open Government (CeDEM 2017), Krems, Austria, IEEE Computer Society.

Townsend, A. M. (2013) Smart Cities: Big Data, Civic Hackers, and the Quest for a New Utopia, New York: W.W. Norton \& Company.

Trist, E. (1980) The Evolution of Socio-technical Systems: a Conceptual Framework and an Action Research Program, Conference on Organizational Design and Performance, Wharton School, University of Pennsylvania, subsequently published in Van de Ven and W. Joyce, Perspectives on Organizational Design and Behavior, Wiley Interscience, 1981.

van den Besselaar, P. (1998) Democracy \& Technological Change: Limits to Steering, Proceedings of the Participatory Design Conference, Seattle, USA.

van Eijk, C., \& Steen, T. (2014) Why People Co-produce: Analyzing Citizens

Perceptions on Co-planning Engagement in Health Care Services, Public Management Review, (16), 358-382.

van Eijk, C., Steen, T., \& Verschuere, B. (2017) Co-producing Safety in the

Local Community: A Q-methodology Study on the Incentives of Belgian and Dutch Members of Neighbourhood Watch Schemes, in Local Government Studies, 43(3), 323-343.

van Eijk, C., \& Gasco, M. (2018) Unravelling the Co-producers: Who are They and What Motivations do They Have?, in Brandsen, T., Steen, T., \& Verschuere, T. (Eds.) Co-production and Co-creation: Engaging Citizens in Public Services, New York, NY: Routledge, chapter 7.

van Velsena, L., van der Geesta, T., Heddeb, M., \& Derksc, W. (2009)

Requirements Engineering for e-Government Services: A Citizen-centric Approach and Case Study, Government Information Quarterly, 26(3), 477-486.

van Wynsberghe, R., \& Khan, S. (2007) Redefining Case Study, International Journal of Qualitative Methods, 6(2).

Verdegem, P., \& Verleye, G. (2009) User-centered e-Government in Practice: A Comprehensive Model for Measuring User Satisfaction Government Information Quarterly, 263), 487-497.

Verschuere, V., Brandsen, T., \& Pestoff, V. (2012) Co-production: the State of the Art in Research and the Future Agenda, VOLUNTAS, International Journal of Voluntary and Non-profit Organisations, 23(4), 1083-1101.

Vines, J., Clarke, R., Leong, T., McCarthy, J., Iversen, O. S., Wright, P., \& Olivier, P. (2012) Invited SIG - Participation and HCI: Why Involve People in Design?, in CHI '12 Extended Abstracts on Human Factors in Computing Systems, New York, NY: ACM, 1217-1220. 
von Hippel, E. (1986) Lead Users: A Source of Novel Product Concepts, Management Science, 32(7), 791-805.

Voorberg, W. H., Bekkers, V., \& Tummers, L. G. (2015) A Systematic Review of Co-creation and Co-production: Embarking on the Social Innovation, Journey, Public Management Review, 17(9), 1333-1357.

Wankhade, P., \& Murphy, P. (2012) Bridging the Theory and Practice Gap in Emergency Services Research: A Case for a New Journal, International Journal of Emergency Services, 1(1), 4-9.

Weber, E. P. (1998) Pluralism by the Rules: Conflict and Cooperation in Environmental Regulation, Washington, DC: Georgetown University Press.

Weber, R. (2012) Evaluating and Developing Theories in the Information Systems Discipline, Journal of the Association for Information Systems, 13(1),1-30.

Weick, K. E., \& Sutcliffe, K. M. (2007) Managing the Unexpected: Resilient Performance in an Age of Uncertainty, San Francisco, CA: Jossey-Bass.

Whetten, D. A. (1989) What Constitutes a Theoretical Contribution?, Academy of Management Review, 14(4), 490-495.

Whicher, A., \& Crick, T. (2019) Co-design, evaluation and the Northern Ireland Innovation Lab, Public Money \& Management, 39(4), 290-299. Whitaker, G. P. (1980) Co-production: Citizen Participation in Service Delivery, Public Administration Review, 40, 240-246.

Whittaker, J., McLennan, B., \& Handmer, J. (2015) A Review of Informal Volunteerism in Emergencies and Disasters: Definition, Opportunities and Challenges, International Journal of Disaster Risk Reduction, 13, 358-368.

Wilson, S., Bekker, M., Johnson, P., \& Johnson, H. (1997) Helping and Hindering User Involvement: A Tale of Everyday Design, Proceedings of the ACM SIGCHI Conference on Human Factors in Computing Systems, New York, NY: ACM, 178-185.

Yousefi Mojir, K., \& Pilemalm, S. (2014) Emerging Communities of Collaboration: Co-location in Emergency Response Systems in Sweden, Proceedings of the 11th International Conference of Information Systems for Crisis Response and Management (ISCRAM), Pennsylvania State University, USA, 548-555.

Yousefi Mojir, K. (2018) Information Systems Development for Emerging Public Sector Cross-sector Collaborations: the Case of Swedish Emergency Response, Linköping University, Department of Management and Engineering, Linköping Studies in Arts and Sciences; 750 . 


\section{Papers}

The papers associated with this thesis have been removed for copyright reasons. For more details about these see:

http://urn.kb.se/resolve?urn=urn:nbn:se:liu:diva-172250 

This thesis provides an understanding of how information and communication technology (ICT) can enable new types of network collaboration co-production - between government and citizens, for a more effective crisis and emergency response. This is explored in the light of digitalization and taking an end-user perspective.

The thesis describes the transformation toward ICT-enabled co-production in crisis and emergency response where citizen volunteers become involved in the actual delivery of the response, despite non-specific competence and non-organizational affiliation. The thesis also identifies related opportunities and challenges of ICT-enabled co-production.

\section{FACULTY OF ARTS AND SCIENCES}

Linköping Studies in Arts and Sciences No. 799, 2021

Department of Management and Engineering, Information Systems and Digitalization

Linköping University

SE-581 83 Linköping, Sweden

\section{www.liu.se}

